\title{
Simulation in health care: lessons learned
}

Citation for published version (APA):

Groothuis, S. (2002). Simulation in health care: lessons learned. [Doctoral Thesis, Maastricht University]. Universiteit Maastricht. https://doi.org/10.26481/dis.20021115sg

Document status and date:

Published: 01/01/2002

DOI:

$10.26481 /$ dis.20021115sg

Document Version:

Publisher's PDF, also known as Version of record

\section{Please check the document version of this publication:}

- A submitted manuscript is the version of the article upon submission and before peer-review. There can be important differences between the submitted version and the official published version of record.

People interested in the research are advised to contact the author for the final version of the publication, or visit the DOI to the publisher's website.

- The final author version and the galley proof are versions of the publication after peer review.

- The final published version features the final layout of the paper including the volume, issue and page numbers.

Link to publication

\footnotetext{
General rights rights.

- You may freely distribute the URL identifying the publication in the public portal. please follow below link for the End User Agreement:

www.umlib.nl/taverne-license

Take down policy

If you believe that this document breaches copyright please contact us at:

repository@maastrichtuniversity.nl

providing details and we will investigate your claim.
}

Copyright and moral rights for the publications made accessible in the public portal are retained by the authors and/or other copyright owners and it is a condition of accessing publications that users recognise and abide by the legal requirements associated with these

- Users may download and print one copy of any publication from the public portal for the purpose of private study or research.

- You may not further distribute the material or use it for any profit-making activity or commercial gain

If the publication is distributed under the terms of Article $25 \mathrm{fa}$ of the Dutch Copyright Act, indicated by the "Taverne" license above, 


\section{Simulation in Health Care:}

\section{Lessons Learned}

Siebren Groothuis 


\title{
Simulation in Health Care:
}

\section{Lessons Learned}

\author{
PROEFSCHRIFT \\ ter verkrijging van de graad van doctor aan \\ de Universiteit Maastricht, \\ op gezag van de Rector Magnificus, \\ Prof. Dr. A.C. Nieuwenhuijzen Kruseman \\ volgens het besluit van het College van Decanen, \\ in het openbaar te verdedigen \\ op vrijdag 15 november 2002 om 12:00 uur
}

door

Siebren Groothuis

Geboren op 30 mei 1957 te Meppel 


\section{Promotores:}

Prof.dr.ir. A. Hasman

Prof.dr. G.G. van Merode

Beoordelingscommissie:

Prof.dr. W.N.J. Groot (voorzitter)

Prof.dr. M.P. van Dieijen - Visser

Prof.dr. J. van der Lei (Erasmus Universiteit Rotterdam)

Prof.dr. G. Ramsay

\section{HEA.IH}

The studies presented in this dissertation were conducted under the auspices of The Maastricht Research Institute for Prevention and Care (HEALTH) at Maastricht University. The Netherlands. HEALTH is part of the Netherlands School of Primary Care Research (CaRe), which has been acknowledged since 1995 by The Royal Netherlands Academy of Art en Sciences (KNAW).

Financial support for the printing of this thesis was provided by the BAZIS foundation and was gratefully acknowledged.

Productie drukwerk: Datawyse, Maastricht

Ontwerp omslag: Siebren Groothuis

ㄱ 2002, Siebren Groothuis, Maastricht, The Netherlands 


\section{Table of contents}

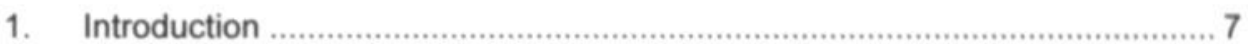

2. Workflow management: changing your organization through simulation...... 17

3. Simulation as decision tool for capacity planning …..................................2 27

4. Turn-around times for chemical and endocrinology analyzers studied using simulation

5. Application of computer simulation analysis to assess the effects of

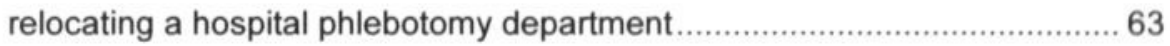

6. Predicting capacities required in cardiology units for heart failure

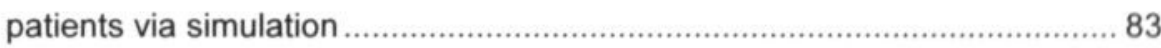

7. Discrete event simulation in the health policy and management program

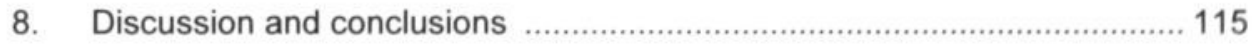

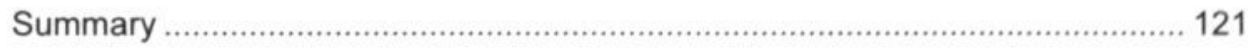

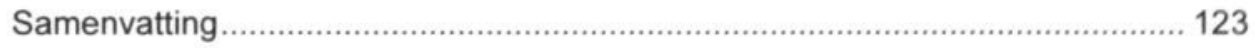

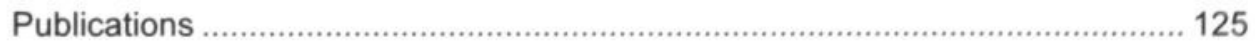

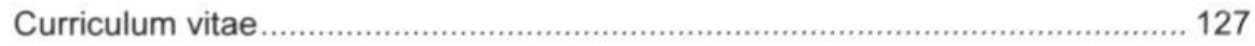

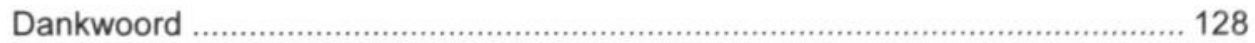


1 . Introduction 


\subsection{Introduction}

Systems thinking [1] is an approach that, to order our thoughts, makes conscious use of the particular concept of the word system, indicating the wholeness of a structure which is more than the addition of the constituting parts. Thinking about the functioning of organizations and decision-making is often governed by mental models. A mental model is an assumption and generalization of (a part of) the world. Managers may possess different mental models that may or may not correctly describe a system. In other words: their mental models may be incomplete and imprecise. If they base their decisions on the consequences of an incorrect model their decisions will be incorrect too. Making these assumptions and generalizations about the world more explicit is therefore of the greatest importance; this will enable managers to learn about the reliability of their internal pictures. Eventually this will result in more effective decision-making.

The recognition of feedback loops is one of the key points in systems thinking; in general people only think in linear structures and therefore they often misinterpret delayed feedback. Systems thinking, based on the system dynamics approach, is especially useful to understand dynamic complexity. Dynamic complexity is characterized by the fact that cause and effect are separated in time and also in place. In the functioning of organizations we often have to deal with dynamic complexity: an organization is usually part of a larger system that can influence it in several ways; cause and effect are separated in place and time. Senge distinguishes a second kind of complexity: complexity of detail. This form of complexity applies to cases where a lot of variables are used to describe a system.

Senge [1] introduces a notation to explicate mental models. It consists of arrows between factors, indicating an influence. Feedback loops often contain a delay. These delays explain why there is a separation in time of cause and effect. Some feedback loops may have a balancing effect; others may have a reinforcing effect. Senge stresses that it is important to identify these feedback loops and assess their character ${ }^{1}$. Combinations of feedback loops can be used to build a mental model of an organization.

In health care organizations capacities like e.g. operation rooms and clinical laboratories are used for the treatment of different types of patients. The flow of patients through a hospital is determined by the test results of each individual patient and their interpretation by medical specialists. Each patient requires specific tests and these tests have to be performed by technicians and medical specialists. These different interactions between patients and capacities (e.g. medical specialists, $\mathbf{x}$-ray camera, $\mathrm{x}$-ray technician) make a hospital an organization in which we almost can say that each patient influences the flow of each other patient. Systems thinking is a way to analyze these complex systems. It aims to investigate the most important factors and it can be used e.g. to detect feedback loops that

\footnotetext{
${ }^{1}$ Senge identifies some basic building blocks (archetypes). The functioning of these building blocks is known and therefore they can be used to explain the functioning of the system (Senge [1], p. 398 ff.).
} 
explain the behavior of the system. Using the systems thinking methodology managers in a hospital will improve their mental models of the hospital and therefore improve their decision-making.

Approaches based on systems thinking, like system dynamics, proved to be a successful tool to analyze policy options in health care [2, 3]. We will apply this approach when presenting the capacity problems that we will study in greater detail in the next chapters. For the purpose of our study we focus on a subpart of the systems described here in the introduction. This subpart is described here qualitatively and studied in more detail, using simulation techniques in the next chapters. We first model the problem situation qualitatively using Senge's notation.

The qualitative model also includes exogenous factors that in our study are not taken into account. The qualitative model reminds us of the fact that the system is larger than the subpart we are studying. By setting up a qualitative model and by experimenting with a quantitative model we not only make explicit and possibly correct the mental models of the persons involved but we also provide a more quantitative insight in the processes that are studied.

\subsection{Cardiology}

Let us examine the use of a catheterization room. A catheterization room is a capacity that is used for diagnostic and therapeutic procedures. About $50 \%$ of the patients treated in the catheterization room are emergency patients; the others are

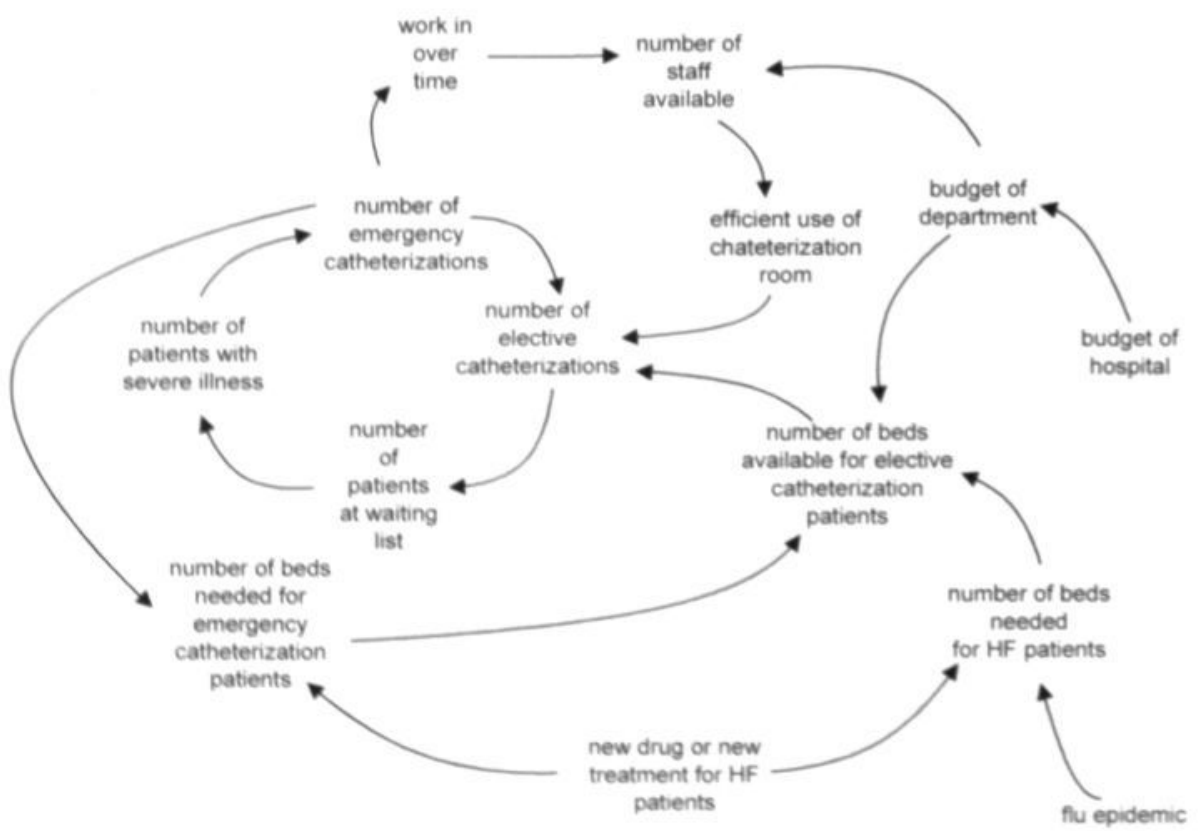

Figure 1-1: Mental model of capacity utilization by catheterization patients and heart failure (HF) patients at the department of cardiology. 
elective patients. If the catheterization room is not efficiently used less patients can be treated and the waiting list will grow. What factors determine whether the catheterization room is used efficiently? In Figure 1-1 the mental model of the use of the catheterization room is depicted. If the number of severely ill patients increases the number of emergency catheterizations will increase too. These emergency catheterizations will partly be performed in overtime. They will reduce the number of elective catheterizations. Work in overtime has to be compensated by extra hours off duty. This will result in the fact that less staff is available to perform catheterizations. This will result in a decrease of the efficient use of the catheterization room, which will decrease the number of elective catheterizations. This in turn will increase the number of people on the waiting list to be catheterized. For each patient on which an emergency catheterization is performed, a bed should be available. This influences the number of beds available for elective catheterization patients. Also the number of beds needed for heart failure (HF) patients (an admission of a HF patient is always an emergency admission) influences the number of beds available for elective catheterization patients.

The question is how we can use the catheterization room in an efficient way? In this specific case an efficient way means that the number of catheterizations per day should be as high as possible and the number of working hours in overtime should be as low as possible. How many patients can be scheduled each day? The mental model does not provide quantitative answers. Is discrete event simulation a technique to study this problem and does it allow us to learn how to use this capacity in the most efficient way? It is not clear what the impact of several actions will be, especially temporal aspects are difficult to assess. In the study of the use of the catheterization room, changes in the environment of the catheterization room are not taken into account. Exogenous factors like additional finances from the government may be important, however.

As described above the needed capacity for HF patients influences the number of beds available for elective catheterization patients. An increasing number of people in our ageing population are suffering from heart failure $[4,5]$. $\mathrm{HF}$ patients that have severe complaints have to be admitted immediately. The management needs an estimate of how many patients they can expect the coming days. On the one hand if the predicted number is too high, some beds remain empty. These beds could be used for elective catheterization patients. On the other hand if the actual number of admissions is higher compared with the number of reserved beds, the staff has to search for empty beds in other departments in the hospital and has to cancel elective catheterization patients for the next day(s). Several questions need to be answered. Crucial is the correct prediction of the number of HF patients that will be admitted during the coming days. If that number is correctly estimated the capacity (beds at the cardiology floor) is used as efficiently as possible. The question therefore is whether we can predict the number of HF patients at the floor correctly. We have to predict when they arrive and when they leave the floor. Based on adequate mental models we can build a simulation model that can provide the detailed answers. In order to be able to run a model additional data have to be 
collected. How accurately can such a model predict the arrival and length of stay of HF patients using discrete event simulation? In this study we will not include factors that influence the number of $\mathrm{HF}$ admissions like a flu epidemic or the introduction of a new kind of drug. Again, the environment will be regarded as constant but the mental model reminds us of these exogenous factors.

\subsection{Clinical laboratory}

In a hospital blood tests are often requested. Sometimes it is necessary to know the test results as soon as possible, such a test request is called a stat. In the other cases the physician wants to know the test results within two or three hours. The manager of the clinical laboratory wants to run the laboratory as efficiently as possible. Stat requests (urgent requests) are labor intensive and disrupt the processing of the other samples. In Figure 1-2 a mental model is shown of the processing of test requests at the clinical laboratory. Crucial in this mental model is the fact that batching will increase the turn-around time (TAT). An increase of the TAT will increase the number of unsatisfied customers (medical specialists). Because they are not satisfied about the service level of the laboratory they will order more stat requests. This fact will decrease the efficiency of the laboratory, which in turn does increase the TAT.

Are there any other factors that influence the TAT? If this is the case, in which way do they influence the TAT? Can we influence those factors? Can discrete event

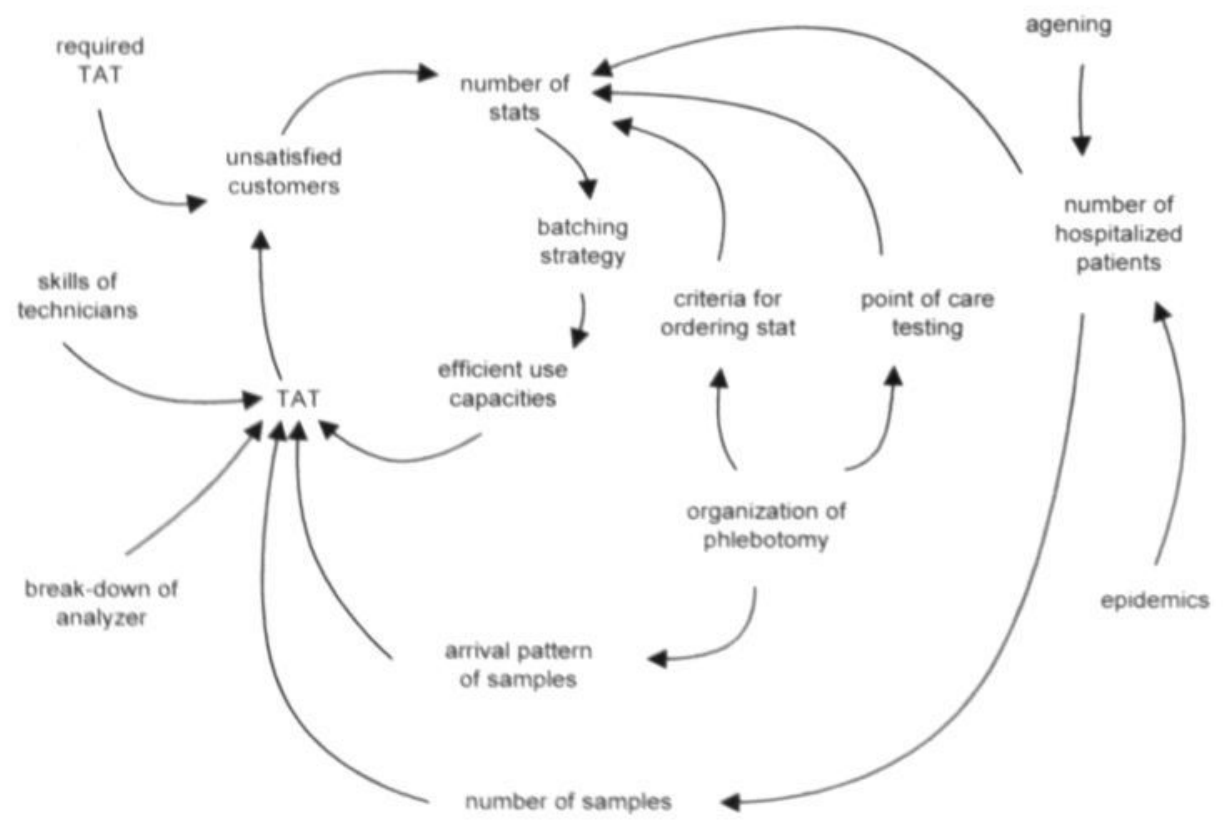

Figure 1-2: Mental model of the performance of analyzers. TAT: turn-around time. In this case capacities are analyzers and technicians. 
simulation increase our knowledge about the extent to which factors influence the TAT of an analyzer?

\subsection{Phlebotomy service}

Before a blood test can be done one has to take a blood sample of the patient. Often this is done at the phlebotomy service of the hospital. At the phlebotomy service one wants to serve the patient in an efficient way and in addition one tries to minimize the waiting time of the patient. The management wants to operate the service in a cost efficient way. In Figure 1-3 the mental model of a phlebotomy service is depicted. Given the fixed number of nurses working at the phlebotomy service, the number of patients will influence the service level (often this will be the turn-around time of the patients, but it can also be a combination of different performance measures like error rate, quality of the blood samples, etcetera). If the number of patients increases, more work has to be done by the same number of nurses so the service level decreases. If the service level decreases the reputation of the hospital decreases too. This may negatively influence the number of patients visiting the service if there are other facilities in the neighborhood. If the number of patients decreases the cost effectiveness will decrease too but the service level will increase. Less work has to be done by the same number of nurses. For the management of the service it is important to know which factors influence the service level of the laboratory and what the effect of changes in these factors on the service level will be. If one has the possibility to redesign the layout of the service

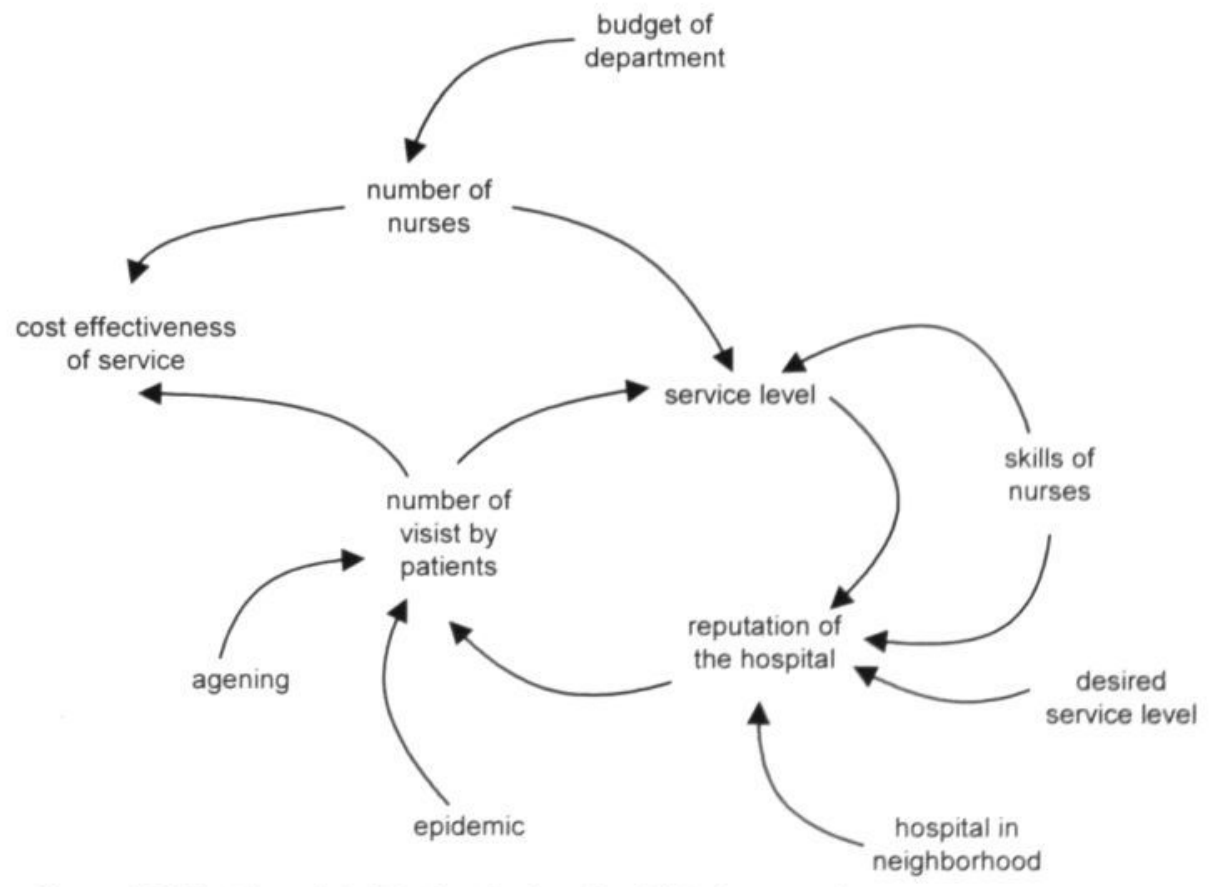

Figure 1-3: Mental model of the functioning of a phlebotomy service. 
one wants to know what the effects of different redesigns on the service level will be.

\subsection{Education}

Senge [1] and Simon [6] both indicate that we can learn about the functioning of a system through simulation. Via simulation managers can learn how the part of the organization that is studied will react on changes. This will influence their mental models. We may ask ourselves whether simulation is also a good teaching tool for students. Their background knowledge is less extensive and therefore cannot be compared with that of managers. How should we use simulation so the students' knowledge about the functioning of an organization will increase?

\subsection{Research questions}

The main question to be answered in this thesis is how simulation of the functioning of a department or service in a health care organization can increase the manager's knowledge of the system so that he is able to make better decisions.

This main question will be answered by addressing five related questions, each related to one of the problem areas described above. The following questions are addressed:

1. Is simulation an appropriate method to study the relation between patient scheduling strategies and resource utilization?

2. How accurately can one predict the arrival of new patients and their stay at a department?

3. Can simulation be used to assess the effect of organizational and layout changes of a department in a hospital?

4. Do simulation experiments provide insight in the factors determining the flow of entities (patients or samples)?

5. Is simulation an appropriate method to teach students how to analyze the functioning of a health care organization and if so, how should it be used?

Systems thinking helped us to determine factors that influence the behavior of the system. It shows us which subsystems play a crucial role in the behavior of the system to analyze the behavior of these subsystems. However, a qualitative model alone is not enough. A detailed numerical comparison of the functioning of these subsystems in different circumstances is needed also.

\subsection{Overview of the thesis}

In chapter 2 the use of simulation is discussed regarding the analysis and design of a workflow management system for a clinical laboratory. In this chapter the process of designing and validating a simulation model is described. This way of building. running and validating models is used in all studies reported here. In this chapter also the definition and use of performance indicators to evaluate different alternatives to the present situation are discussed. 
As stated earlier, resources are scarce in health care. Health care organizations try to use their resources in the most efficient way. The catheterization room is an example of a resource one wants to use efficiently. In chapter 3 we explore how simulation can be used to compare two patient scheduling strategies for the catheterization room. Furthermore the impact of a number of alternatives on the number of treatments per day is investigated.

Simulation can be a means for the laboratory management to investigate the effects of proposed changes in service levels. Knowledge about which factors influence the turnaround times can support the negotiating process. In chapter 4 the impact of different arrival patterns and batching methods on the turnaround time is presented.

A redesign (either forced by the management of the hospital or voluntary) of a department in a hospital provides an opportunity to look at the performance indicators of the department. None of the values of the performance indicators should decrease due to the redesign. However the effects of the redesign on the performance indicators of a department are not always clear. In chapter 5 we investigate the use of simulation to assess the consequences of a redesign and relocation of a phlebotomy department on turn-around time and resource utilization.

The efficient use of capacities in health care is important. The management of a ward wants to know how many beds are available for elective patients. To answer this question they need to know how many beds will be occupied by non-elective patients. In chapter 6 we investigate whether it is possible to predict the capacity needed for heart failure patients.

Since health care organizations are complex organizations, students in the Health Care Policy and Management program at the faculty of Health Sciences of Maastricht University need to get insight in the impact of changes of the organization on the patient logistics and the utilization of resources. In chapter 7 we investigate whether simulation can be used as a tool to provide students insight in the function of health care organizations.

In chapter 8 we discuss the results reported in the previous chapters and make some concluding remarks.

\subsection{References}

[1] Senge PM. The Fifth Discipline; the art \& practice of the learning organization. London: Random House, 1990.

[2] Vennix JAM, Gubbels JW. Knowledge elicitation in conceptual model building: a case study in modeling a regional Dutch health care system. In: Morecroft JDW, Sterman JD, eds. Modeling for Learning Organisations. Portland OR: Productivity Press, 1994; 29-49. (Asay D, ed. System Dynamics Series).

[3] Post D, Vennix JAM, eds. De gezondheidszorg in model, ons complex zorgsysteem gemeten en gewogen (The health care system modeled, our complex care system measured and 
analyzed). Houten: Bohn Stafleu Van Loghum, 1992.

[4] Reitsma JB, Mosterd A, de Craen AJ, Koster RW, van Capelle FJ, Grobbee DE, Tijssen JG. Increase in hospital admission rates for heart failure in The Netherlands, 1980-1993. Heart 1996;76:388-92

[5] Mosterd A. Epidemiology of heart failure [PhD. Thesis]. Rotterdam: Erasmus University, 1997. $145 \mathrm{pp}$.

[6] Simon HA. The sciences of the artificial. (3rd ed.) Cambridge, MA: The MIT Press, 1996. 


\section{Workflow management: changing your organization through simulation}

\section{Abstract}

This paper discusses first performance measures for clinical laboratories. In order to realize a required performance, workflow management is essential. The use of discrete event simulation is discussed with regard to analyzing and designing a workflow management system. This is illustrated by a simple example.

Published as: van Merode GG, Groothuis S, Goldschmidt HMJ. Workflow management: changing your organization through simulation. Accred Qual Assur 1999:4:438-42 


\subsection{Introduction}

How are your goals defined and how do you achieve them? The methods used in practice and discussed in literature are most often either top-down or bottom-up. Top-down methods use the vision or strategy as the starting point for the analysis. The actual analysis and improvement of operational processes are often the last phase in this method, resulting in strategies that may be far from reality. Bottom-up methods start with the operational processes to evaluate and improve them. In this approach, an integrated organizational strategy often does not exist. Workflow management methods are often a combination of top-down and bottom-up approaches. The operational processes are the focus of workflow management. Much attention is paid toward adjusting these processes to each other in time, place and capacity regarding the realization of value. In doing the latter, the strategy of the organisation as a whole is also taken into account.

In this article we discuss a workflow management method to analyse the workflow in the clinical laboratory with the purpose of improving the overall quality. We first discuss the way performance measures can be defined with regard to the processes. Next we discuss the method of analysing and designing new processes. Computer simulation is an important tool both in the analysis and design of the workflow management system.

\subsection{Defining performance measures: quality indicators}

When evaluating processes, managers often use a very limited set of performance measures and indicators. This set typically includes financial measures as, e.g., profit or the percentage of cost reductions. Non-financial measures are often underrepresented in such a set. In the clinical laboratory, the turnaround time is often used as a performance indicator. Before processes are evaluated, management should have a clear idea in which areas the clinical laboratory should perform and what the important measures are. The set of performance measures should relate to all aspects which management considers to be important. When this set is used for making management plans, the way performance measures relate to each other should be taken into account explicitly. For example, if both cost reductions and growth of the clinical laboratory are considered to be important, management should realise that growth requires education of staff, as well as research and development and other new investments. This may contradict the requirement of cost cutting. Kaplan \& Norton [1] developed a method (The Balanced Scorecard method) to define performance measures and balance them against each other in a dynamic way.

The balanced scorecard method distinguishes four areas of performance measures. Examples of each of these performance measures are given in Table 2-1.

When analysing and designing the workflow management system the various performance measures should be known. 


\subsubsection{Designing the workflow management system}

Figure 2-1 depicts the complete process from determining performance measures up to selecting the preferred design of the workflow management system.

\section{Determine your performance measures}

Using, for example, the balanced scorecard method, all performance measures of the clinical laboratory should be stipulated.

\section{Analyse the existing workflow}

Identify and describe the processes. Observation and historical data analyses are the core methods here.

\section{Determine the existing performance}

The existing performance should be measured: define the starting point. Observation and historical data analysis are important here, but client surveys, staff interviews and financial record analysis are even more important.

\section{Brainstorm about improvements}

Given the description of the processes and performance, better performance may be necessary. Sometimes it will be easy to detect possibilities for improvement, but often no obvious possibilities are at hand and a lot of time should be spent brainstorming. A major difficulty is that many processes relate in some way to each other, and an improvement in one process may weaken the performance of some other process.

\section{Define alternatives}

Alternatives should be obtained to achieve maximum insight into the effects of changes.

\section{Experiment with alternatives}

Experimentation is the only way to know the effect of alternatives.

Table 2-1: Types of performance measures and subsequent indicators

\begin{tabular}{lll}
\hline Type of performance measure & Example & Indicator \\
\hline Financial performance & Cost reduction & Money \\
& Profit realisation & Money \\
Internal processes & Quality control & Score \\
& Throughput times & Time \\
Learning and growth & Research \& development & N/A \\
& Staff development & Number of Fte \\
Client perspective & Investments & Money \\
& Turnaround times & Time \\
& Test diversity & Number of tests \\
\hline
\end{tabular}




\section{Select the best alternative}

Using the set of performance measures, the various alternatives are scored. It is important to realize that often no optimal alternative exists, as one alternative can score best on one performance measure and another alternative on another performance measure. Experimenting with the alternatives is crucial in this approach.

\subsection{Virtual experimenting: computer simulation}

Virtual experimenting by means of computer simulation is an alternative to conducting experiments. A discrete event simulation package could be used for this. Discrete event simulation concerns "the modeling of a system as it evolves over time by a representation in which the state variables change instantaneously at separate points in time" ([2], p.7). At points in time events occur. An event is "an instantaneous occurrence that may change the state of the system" ([2], p.7).

A computer is needed to apply discrete event simulation. Several discrete event simulation packages are available on the market. Nowadays several of these packages are equipped with a graphical user interface, allowing the definition of a great part of the situation to be simulated by drawing icons on the screens. Animation facilities are also available. These show, for example, how the workflow is processed and how staff is moving around in the situation which is being studied.

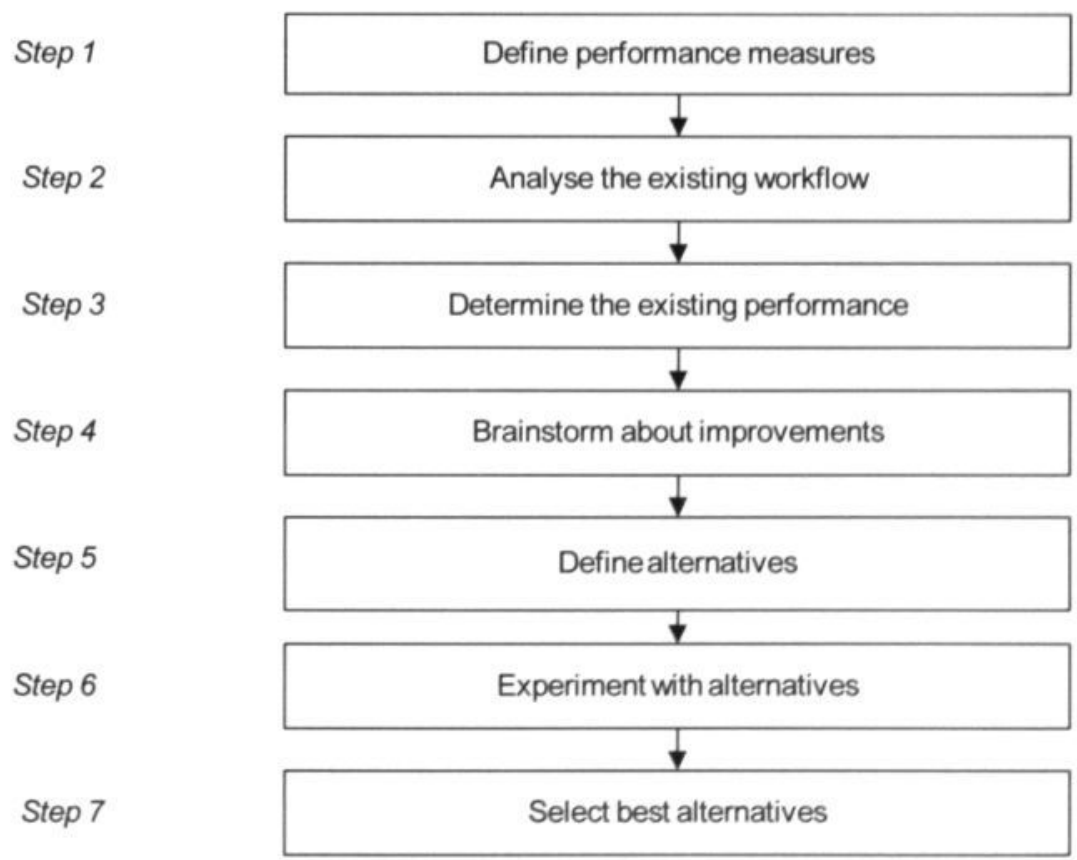

Figure 2-1: Process of analyzing workflow 


\subsubsection{Building simulation models}

Figure 2-2 describes the process of defining and validating the simulation model. Defining the model is the first step here. In fact, this means that the processes are described. In the next step, data are collected. Process definitions result from this step, and the process occurrences are produced. The process definitions and occurrences should be validated by several means. Several statistical tests are available for this. In the next step, the model is coded by some simulation programming language. This coding process can be done by text input, but some simulation packages also allow (to a certain extent) coding by a graphical device. The verification process is difficult, as it must test whether the simulation model of the process is correct. The simple question to be answered here is: does the program do what the programmer wanted it to? An often-used procedure is to run the program with input for which the output is known. Often no distinction is being made between validation and verification. The difference between these two is that

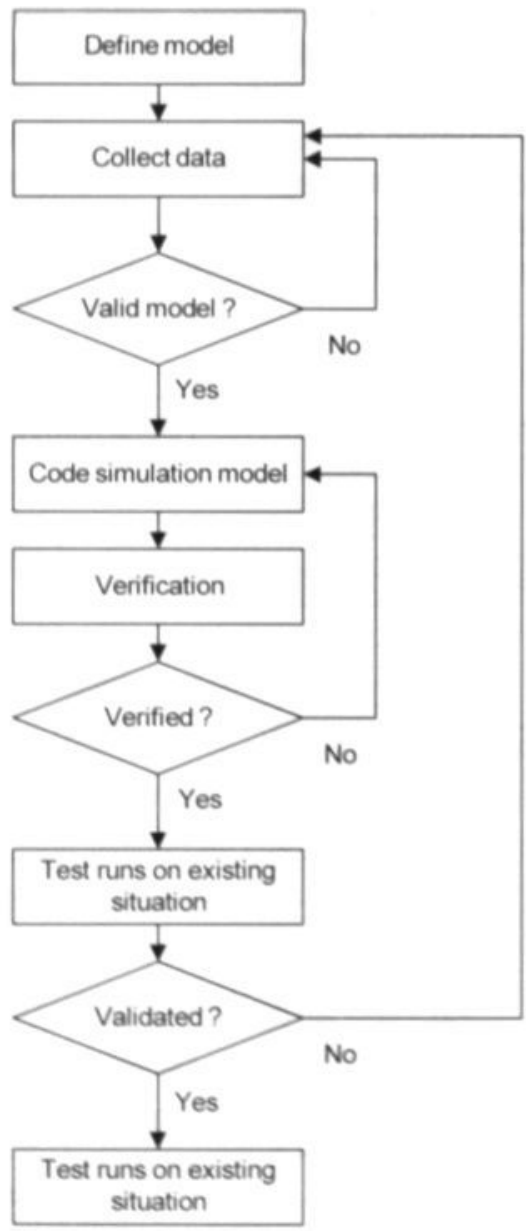

Figure 2-2 : Verification and validation of a simulation model. 
validation concerns the comparison between the model and the existing situation, whereas verification concerns the question of whether the model (in fact the computer program) does what it should do. After verification, the model is run with data from the existing situation and at this time the model is validated. Only after these validation and verification processes should experimentation with alternatives take place.

Figure 2-3 presents an example of a layout that can be simulated. This example is a simple but quite realistic representation of a (simple) laboratory. The simulation model is implemented in MedModel. MedModel is a discrete event simulation program with a graphical user interface.

Important elements in this layout are a reception, a centrifuge, a haematology analyser (Advia 120, Bayer diagnostics) and a clinical chemistry analyser (Axon, Bayer diagnostics).

This layout and the workflow management principles can be simulated by the simulation program mentioned. Figure 2-4 depicts the use of such a simulation model as a decision support tool.

The following results can be obtained:

- utilization degrees of capacity units and locations;

- throughput times of entities.

An example of the throughput times is given in Figure 2-5.

In addition, more information can be obtained if required by the user, e.g. the time staff spends on various activities. This is useful in gaining insights into the way staff capacity is used. It is used for direct, process related activities, on indirect work (like

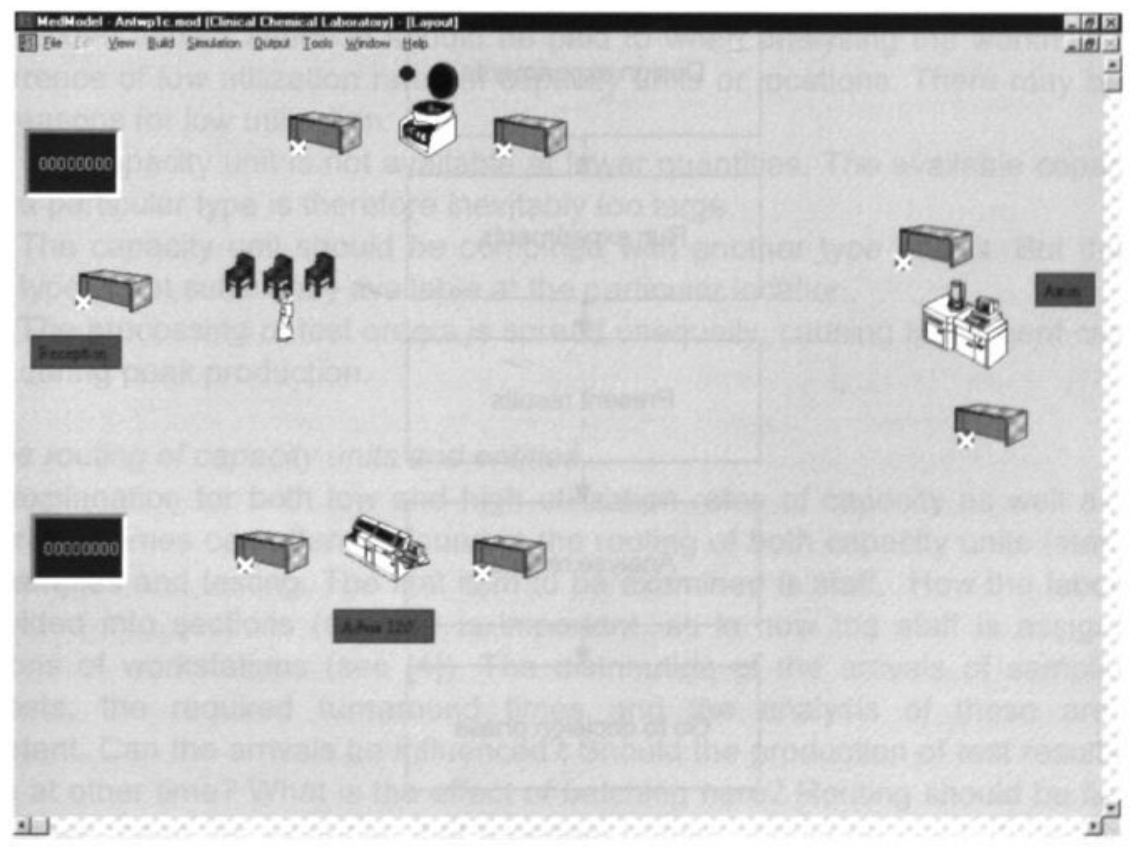

Figure 2-3: A layout of a simulation model of a clinical laboratory. 


\subsection{Conclusion}

We have discussed how workflow can be evaluated and improved. Top performance requires a professional approach to organizing the laboratory. Management should set standards in all critical areas of performance. A professional approach to the whole process of quality improvement and redesign is crucial.

Virtual experimenting with simulation tools is a very powerful way to gain insights into the existing situation, as well as possibilities for redesign. Due to modern simulation tools' graphical features, they also serve as communication tools between the laboratory staff and analyser/redesigner. The process from analysing the existing situation until the actual redesign of the layout of the laboratory is an iterative procedure. In most cases no optimal layout is immediately evident.

Therefore we strongly recommend the use of simulation tools to improve the quality of the clinical laboratory.

\subsection{References}

[1] Kaplan RS, Norton DP. The Balanced Scorecard. Boston: Harvard Business School Press, 1996

[2] Law AM, Kelton WD. Simulation Modeling and Analysis. (Second ed.) New York, USA: McGraw-Hill, 1991. (Riggs JL, ed. McGraw-Hill Series in Industrial Engineering and Management Science).

[3] van Merode GG, Hasman A, Derks J, Goldschmidt HMJ, Schoenmaker B, Oosten M. Decision support for clinical laboratory capacity planning. International Joumal of Biomedical Computing 1995;38:75-87

[4] van Merode GG, Hasman A, Derks J, Schoenmaker B, Goldschmidt HMJ. Advanced management facilities for clinical laboratories. Comput Methods Programs Biomed 1996;50:195-205 


\section{Simulation as decision tool for capacity planning}

\section{Abstract}

In this paper we demonstrate how discrete event simulation technique can be used to optimise the use of catheterization capacity. The patient flow at the catheterization room is described. A simulation model of the current situation was built in MedModel, a discrete event simulation package, and the model was validated. A short presentation of MedModel is given. To investigate alternative ways to optimise the use of the catheterization room three experiments were formulated, modelled and simulated. Two different scheduling strategies were applied to the current situation and the three experimental situations. The number of patients that can be treated and the duration of a working day were determined as measures of performance. The results of the simulation experiments are discussed. The results of these experiments give the management of the catheterization room valuable information how to optimise the use of the catheterization room.

Published as: Groothuis S, van Merode GG, Hasman A. Simulation as decision tool for capacity planning. Comput Methods Programs Biomed 2001:66:139-51. 


\subsection{Introduction}

Discrete event simulation is used in several health care domains. In this paper we will concentrate on the use of simulation for the capacity planning of catheterization rooms.

Catheterization provides valuable information about the cardiac condition of a patient. Using injections with contrast fluid one can make the coronary arteries visible with $\mathrm{X}$-rays. A sizeable number of patients suffering from cardiac problems are catheterized. About half of these patients are emergency cases on which an urgent catheterization is performed. The other half of the patients are from a waiting list. If a patient has significant narrowing(s) or an occlusion in the coronary arteries the patient can be treated by balloonangioplasty during the catheterization in case of a life-threatening situation or for practical reasons can be treated later if the decision what to do now cannot yet be made.

The catheterization room is a capacity that has to be utilised as efficiently and effectively as possible. In this article we describe how discrete event simulation can be of use in the planning of the catheterization rooms. We will discuss how to model patient scheduling procedures. As an example we will compare two different scheduling strategies. The goal of this article is not to provide solutions but to show how simulation can be used.

"A simulation is the imitation of the operation of a real-world process or system over time"[1]. This can be done by hand or on a computer. It creates a history of an artificial system based on which one draws inferences about the functioning of the real system. A system is a collection of entities (e.g. people, machines) that interact with each other and try to complete a certain task. 'Discrete event simulation concerns the modelling of a system as it evolves over time by a representation in which state variables change instantaneously at separate points in time' [2]. Variables describe the states of different objects in the system. Processes describe the interactions between the different objects in the system. Probability functions are used to describe the duration of processes and the occurrence of events [2]. Discrete event simulation has been applied for more than 30 years.

In this study first we describe the patient flow and the current procedure at the catheterization room at the cardiology department of the Maastricht Academic Hospital. Then a simulation model of the patient flow will be presented. Finally we will report some results of simulation experiments that aim to increase the patient flow at the catheterization room by applying different scheduling procedures.

\subsection{Patient flow at the department of cardiology}

Patients with cardiac problems can be referred to the department of cardiology in different ways (see Figure 3-1). The GP can refer a patient with complaints suggesting cardiac problems to a cardiologist at the outpatient clinic. After examination, the cardiologist may decide to hospitalise the patient. Normally the patient will then be admitted to the ward, but if the cardiac problems of the patient are severe the patient will be admitted to the first cardiac aid (FCA) or the coronary 
care unit (CCU). If a patient has severe cardiac problems a GP may decide to send the patient immediately to the hospital and the patient will be admitted to the FCA. At the FCA a cardiologist decides whether the patient will be transferred to the ward or to the CCU or whether the patient needs immediate catheterization. Also some patients staying in the ward have to be catheterized. Patients are referred from other hospitals for PTCA or coronary angiography. In Maastricht these patients are usually admitted to the FCA. In general patients return to the referring hospital after a few hours.

The CCU has only a few beds and if a patient doesn't have to stay longer in the $\mathrm{CCU}$ for medical reasons, the patient is transferred to the ward if there is a bed available. Vice versa if a patient at the ward develops severe complaints the patient will be transferred to the CCU if there is a bed available. A patient without

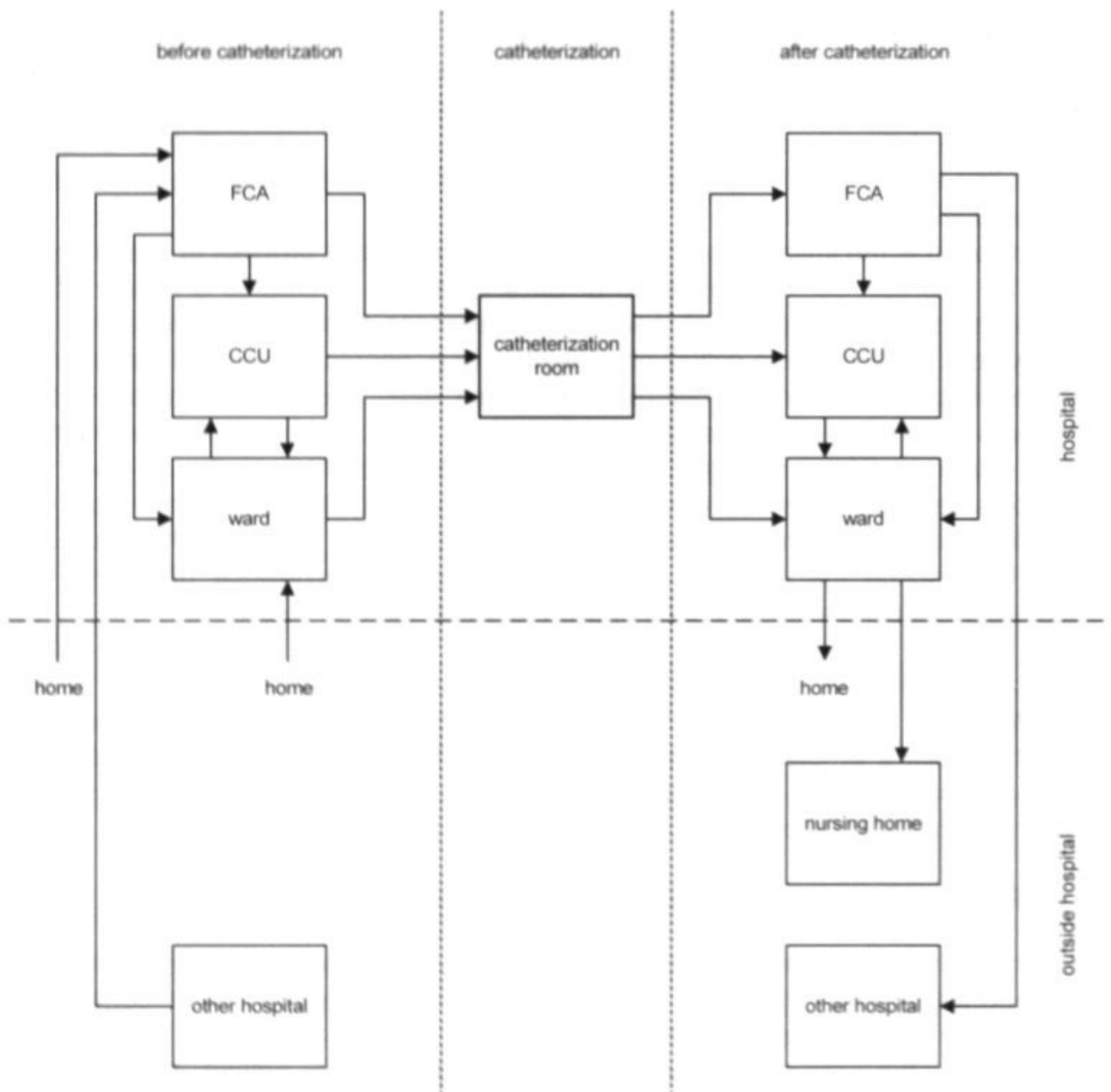

Figure 3-1: Flow of patients with cardiac complaints which are admitted to the cardiology department. 
complaints and with no examinations pending will be discharged. Normally the patient will go home but in some cases the patient is referred to a nursing home. In the latter case if there is no bed available in the nursing home, the patient will stay at the hospital.

\subsection{Catheterization}

One can distinguish two different catheterization procedures: a diagnostic catheterization and a therapeutic catheterization.

\subsubsection{Diagnostic procedure}

The aim of catheterization is to investigate the status of the cardiac system. During catheterization a catheter is introduced into a vein or artery and advanced towards the heart. The blood pressure and oxygen saturation in different compartments can be measured. By injecting a contrast fluid into the coronary arteries the site of these arteries can be visualised using X-ray equipment. The contraction of the heart chambers can be shown by making images during injection of a dye in these compartments.

\subsubsection{Therapeutic procedure}

By inflating a balloon catheter at a narrow or occluded part of one of the arteries of the heart, the vessel can be dilated to its normal size. This procedure is called PTCA (percutaneous transluminal coronary angioplasty). In $\sim 45 \%$ of the cases, a stent (a kind of small metal spring) is placed in the artery at the place where the PTCA was performed to improve results.

\subsection{Description of the catheterization rooms and procedures}

The Maastricht Academic Hospital has two catheterization rooms. Most of the time both rooms are used for catheterization but for several reasons (e.g. maintenance, lack of personnel) one of the rooms may not always be available. Each catheterization room has an X-ray camera. An X-ray technician serves the X-ray equipment. During the catheterization procedure a cardiologist is working with two technicians. One of the technicians assists the cardiologist in the catheterization room. The other one is concerned with the registrations of the ECGs and is working outside the catheterization room. At the Maastricht Academic Hospital often a resident cardiologist under direct supervision of a cardiologist performs the intervention.

At 09:00 h. the treatment of the first scheduled patient starts. Except for emergency cases, the treatment of the last patient has to start before $16: 00 \mathrm{~h}$. By doing so normally the technicians can leave the hospital at 17:00 h. For emergency cases a 24-hour 7 days-a-week service is available for catheterizations. One of the technicians schedules the patients for catheterization. Part of the patients scheduled for a particular day is taken from the waiting list and are pre-scheduled one week before. When a patient has to be investigated within a few hours or when an acute case occurs, cardiologists phone this technician and ask to schedule the patient. Non emergency patients may in such a case be rescheduled for the next day. The 
number of patients that is accepted for a certain day depends on the length of the procedure that has to be performed and on the fact whether a patient is included in a clinical study. The duration of a procedure also depends on complications arising during a procedure or other unexpected problems. In case of resident cardiologists the clinical experience of the resident and the attitude of the senior cardiologist as a teacher towards the resident will influence the duration of the procedure. In addition, also experienced cardiologists differ with respect to the duration of a certain treatment. Incomplete patient data will also lengthen the duration of the procedure.

\subsection{Process description at the catheterization room}

Based on observations the following process model of the patient flow at the catheterization room was obtained (see Figure 3-2).

A detailed description of the different parts of the schedule depicted in Figure 3-2 can be found in Table 3-1.

The 'preparation of the patient' and the 'preparation of patient to return to ward' are, for sanitary reasons, done in the room where the catheterization takes place.

\section{Model description}

The function based modelling approach was used. Following the classification of Fishwick [3] our model can be characterized as a queuing model. Phone calls were modelled to initiate the transportation of a new patient to the catherization room. Here the patient sometimes has to wait. MedModel was used to implement the model. MedModel is a Windows based simulation program.

To build a simulation model in MedModel one has to define: locations, entities, path networks, resources, the processing and arrivals. Locations (e.g. a waiting room), entities (e.g. patient, tube) and resources (e.g. doctor, nurse) are depicted with icons. Entities move from move from one location to another along a path network. A path network is an implementation of a queuing network. They may be accompanied by a resource. The interactions with resources (e.g. a consult or a catherization) and the routing of the entities are described in the processing part (see Figure 3-3). The duration of these interactions is described using probability functions like Beta, Pearson-5, Pearson-6 or Weibull distribution. Distribution functions like Pearson-5. Pearson- 6 and Weibull are often used to model the time to complete a task (see Law and Kelton Ch. 6.2 [2] for a further introduction and description of the various distributions). Furthermore one defines at which location and at which time an entity enters the system. The items described are needed to build a simple model. A more advanced model can be made using items like for example arrival patterns, assigning shifts to resources, assigning downtimes to locations. During simulation one can observe the movement of the entities and resources.

Based on the process description given above we defined the different locations involved and their capacities. We used two entities: patient and a phone call. Three path networks were used. One path network was used for the movement of the patients, the second path network was used for the resources and the third was 


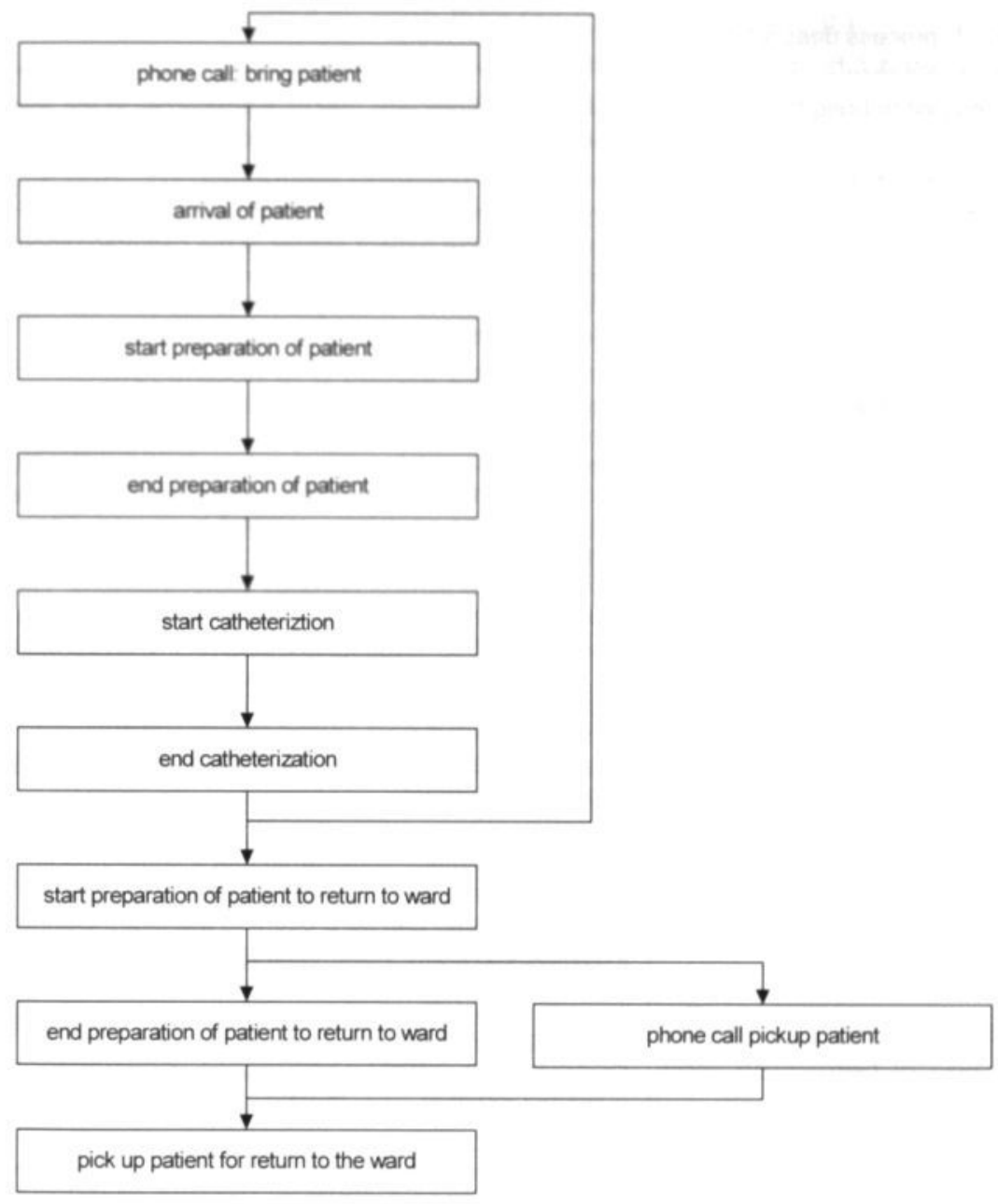

Figure 3-2: Process description at the catherization room.

used for the phone calls. Three different types of resources were used: cardiologist, nurse and technician. In the processing the interactions between the resources and the entity were described. Distribution functions were used to model the duration of the interactions. In addition the parameters of various probability functions describing the duration of processes and the occurrence of events were derived from observations. A number of decisions were made with respect to the simulation model:

- No distinction was made between different cardiologists or teams of cardiologists '. If this distinction would have been made, the number of catheterizations that must be observed to obtain data about the distributions 
Table 3-1: process description at the catheterization room.

\begin{tabular}{|c|c|}
\hline Phone call request to bring the patient & $\begin{array}{l}\text { One of the technicians makes a phone call to the ward } \\
\text { to ask to bring the patient to the catheterization room. }\end{array}$ \\
\hline Arrival of the patient & $\begin{array}{l}\text { After a while the patient arrives at the catheterization } \\
\text { room. The time between the phone call to bring the pa- } \\
\text { tient and the arrival of the patient varies between the } \\
\text { different wards. }\end{array}$ \\
\hline $\begin{array}{l}\text { Preparation of the patient for catheteri- } \\
\text { zation }\end{array}$ & $\begin{array}{l}\text { The technicians start with the preparation of the patient } \\
\text { to be catheterized. The patient is laid on the OR table. } \\
\text { The groins (sometimes the arms) are iodized. The ECG } \\
\text { electrodes are connected. The apparatus to measure } \\
\text { the blood pressure using a catheter is gauged. The } \\
\text { (resident) cardiologist examines the data in the medical } \\
\text { record and the films of previous catheterizations. The } \\
\text { absence of important data in the medical record can } \\
\text { cause a lengthening of the duration of the preparation of } \\
\text { the patient. Sometimes the cardiologist wants to discuss } \\
\text { by phone some aspects of the procedure with the at- } \\
\text { tending cardiologist. } \\
\text { The (resident) cardiologist and the technician cover the } \\
\text { patient with a sheet. }\end{array}$ \\
\hline Catheterization procedure & $\begin{array}{l}\text { A small cut is made in the groin and a small tube is } \\
\text { brought into the vein. By means of this tube, called } \\
\text { sheet, a catheter can be brought to the heart. During the } \\
\text { procedure, the type of catheter is often changed. The } \\
\text { number of different types of catheters often changes. } \\
\text { The same holds for the types of balloons for PTCA and } \\
\text { the number of stents. } \\
\text { During the procedure often a colleague is asked to give } \\
\text { a second opinion. }\end{array}$ \\
\hline $\begin{array}{l}\text { Preparation of the patient to return to } \\
\text { the ward }\end{array}$ & $\begin{array}{l}\text { When preparing of the patient to return to the ward the } \\
\text { decision is made to remove the tube in the groin. If the } \\
\text { sheet doesn't have to be removed only a plaster has to } \\
\text { be applied to the groin. If the sheet has to be removed } \\
\text { the wound has to be pressed for } 10 \text { minutes. The } \\
\text { electrodes used for the ECG. registration are removed. } \\
\text { During these activities the result of the procedure is of- } \\
\text { ten discussed with the patient. } \\
\text { After finishing this, the patient is put back into the bed. }\end{array}$ \\
\hline $\begin{array}{l}\text { Phone call request to pick up the pa- } \\
\text { tient }\end{array}$ & $\begin{array}{l}\text { One of the technicians makes a phone call to the ward } \\
\text { and asks the nursing staff to pick up the patient from the } \\
\text { catheterization room and bring the patient back to the } \\
\text { ward. This call is made several minutes after the prepa- } \\
\text { ration of the patient to return to the ward has started. }\end{array}$ \\
\hline Pick up of the patient & $\begin{array}{l}\text { The actual moment that the patient was picked up by } \\
\text { nurses from the ward. After the ward has received the } \\
\text { phone call to pick up a patient it takes several minutes } \\
\text { before they arrive at the catheterization room to pickup } \\
\text { the patient. }\end{array}$ \\
\hline
\end{tabular}


should be multiplied by more than ten to get sufficient data.

- Besides the FCA and the CCU only two wards were included in the model. Only a few patients came from other wards.

- Two different types of treatments were distinguished: catheterization and PTCA. To distinguish between all different types of catheterizations and types of PTCA procedures, the number of catheterizations that must be observed should be multiplied by more than ten to get sufficient data.

- No distinction was made between patients included in a clinical trial and patients who were not.

- The preparation of a patient before the catheterization starts and the removal of the catheters before return to the ward is carried out by only one cardiologist.

- The time needed to prepare a patient for treatment and the time needed to prepare a patient to return to the ward is assumed to be independent of the type of treatment and the ward the patient was staying in. During this time the cardiologist writes his report.

- The time between the start of preparation of the patient to return to the ward and the phone call to the ward to pick up the patient is assumed to be distributed in the same way for the wards, the CCU and the FCA.

- The beds and personnel at the wards are not included in this model. So we assume that sufficient beds and personnel are available for catheterised patients at the wards.

The model building took $\sim 120$ hours (time needed for observation not included).

\subsection{Data acquisition and model fitting}

During 14 days 69 catheterizations were observed and the duration of the processes were measured. These observations were performed in one of the two catheterization rooms. In Table 3-2 the observed average length of a working day and the number of patients treated during that day is shown. Five times the working day ended at 16:00 $\mathrm{h}$ or later.

To obtain the various distributions and their parameters, the data were fitted using Stat::Fit, a tool incorporated in MedModel. Stat::Fit ranked the adequacy of the different types of distribution and their parameters. The ranking of the distributions is based on the chi-square test. Preparation before treatment, treatment and preparation after treatment could be modelled best by Beta, Weibull and Pearson- 6 distributions respectively. An extensive description of these distribution functions and the meaning of the various parameters can be found in Law and Kelton Ch. 6.2 [2]. According to the literature [1,2] these distributions are suitable to model the time needed to perform a task. The exponential, inverse Gaussian and Pearson-5 distributions were used for modelling processes like the time the cardiologist and technicians have to wait for a new patient to arrive.

In $35 \%$ of the cases the treatment is a PTCA. All other procedures are diagnostic catheterizations. The duration of these diagnostic catheterizations could be best

\footnotetext{
A team of cardiologists consists of a resident and a senior cardiologist.
} 


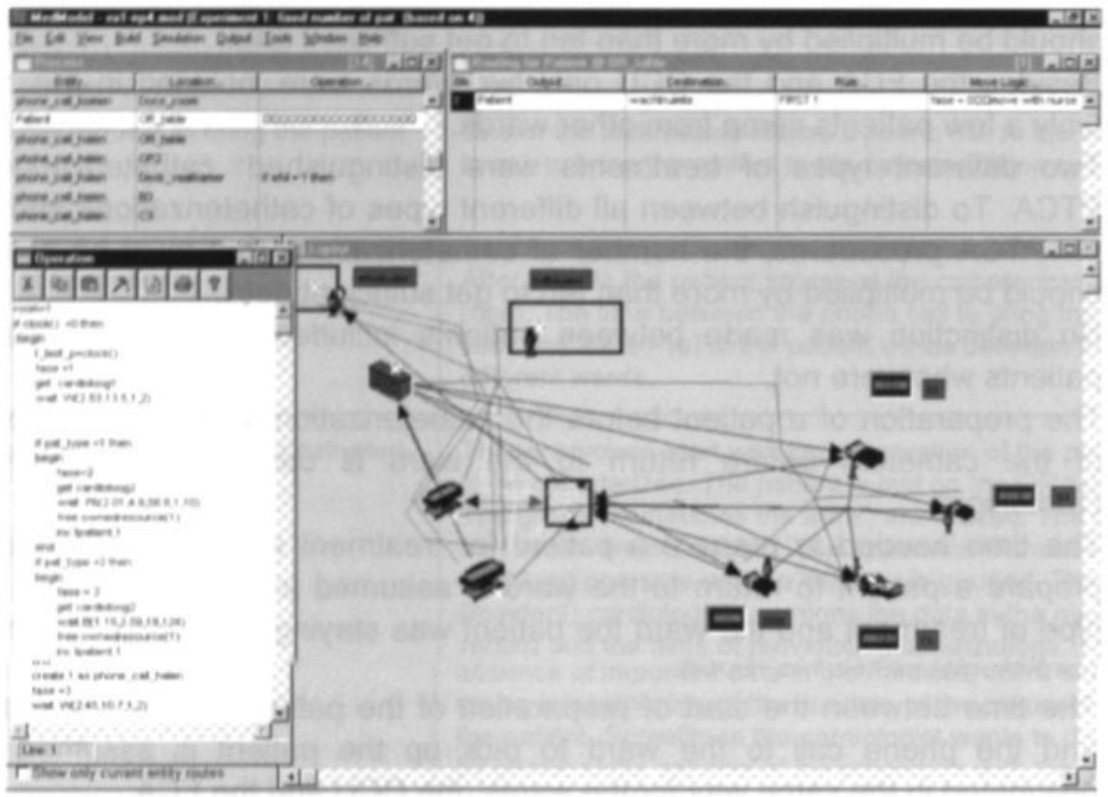

Figure 3-3: The user interface of MedModel while entering the process descriptions. In the rectangle, right below of the screen the layout of the modeled organization is shown.

fitted to a Pearson-6 distribution with shape parameters: $2.01,4.9$; scale parameter 58.8 and minimum value 10 (see Figure $3-4$ ). The duration of a PTCA could be best fitted to a beta distribution. The parameters of the fitted beta distribution are: lower shape parameter: 1.18 ; upper shape parameter: 2.59 ; minimum: 19 ; maximum 124 (see Figure 3-5).

\subsection{Model validation}

Validation of a simulation model is an important step in the simulation process. By performing a validation one tests if one has built the right model [1]. Sargent [5] describes 15 different validation techniques. The most well known are animation, face validity, historical data validation, sensitivity analysis and predictive validation. Sargent stresses that the results of the validation should be presented to the users to convince the users of the 'correctness' of the model.

In our study the simulation model was validated by animation and by historical data. The animation of the model was presented to a cardiologist and a technician. They considered it a correct representation of process at the catheterisation room. We were only interested in modelling fully booked catherization rooms. To validate the model we therefore only considered days that were fully booked (cases in which the treatment of the last patient ended after 16:00 h). These 8 days had an average observed length of $7.72 \mathrm{~h}$ (S.D. 0.53) and the average number of patients treated was 5.50 (S.D. 0.93). Based on 999 runs of the simulation model, the average length of a working day was 7.88 (S.D. 0.54) and on average 5.90 (S.D. 0.94) patients were treated. Also the percentage of fully booked working days exceeding 8 
$\mathrm{h}$ in duration is similar ( $30 \%$ compared to $25 \%$ observed).

Based on these data and the animation we consider the model to be valid.

\subsection{Simulation experiments}

As described above the catheterization room is an important capacity in the cardiology department. By performing a number of simulation experiments we want to show what quantitative insight one can obtain with respect to capacity planning. Since the cardiologists foresaw that the capacity of the catheterization room would not be enough in the future we suggested them to investigate this problem by simulation. We simulated a number of changes in the current use of the catheterization rooms. The results of the simulations can help the cardiologists and management to make decisions about building new catheterization rooms or changing the scheduling system.

We investigated two different scheduling procedures. The first one is the procedure currently used in the Academic Hospital Maastricht. In this case no new patient will be scheduled after 16:00 $\mathrm{h}$. The second procedure studied is to schedule a fixed number of patients each day. In this case it is determined how many patients can be scheduled with only a limited probability that the working day will exceed $8 \mathrm{~h}$. Both scheduling procedures were applied in a number of different situations.

Both cardiologists and technicians indicated that they often have to wait for the patient. After the treatment the technicians also have to wait before the nurses from the ward arrive to bring the patient back to the ward. Therefore the first experiment addressed the question:

1. What is the effect on the number of treatments per day of setting the waiting times to zero? That means that in the new situation the patient already waits outside the catheterization room to be picked up for treatment or to be brought back to the ward.

For the preparation of the patient before treatment and the preparation of the patient to return to the ward (see Figure 3-2 and Table 3-1) only one cardiologist or resident assisted by two technicians is sufficient. With two rooms available for the team one cardiologist could prepare in room A the first patient to return to the ward while the other cardiologist simultaneously in room B could prepare the second patient for catheterization. Each of them has to be assisted by two technicians for reasons mentioned earlier. The second question that we wanted to answer was:

2. What is the impact of the availability of an additional catheterization room with technicians on the patient throughput when the rooms are used in the way described above? It is again assumed that there are no waiting times.

Because catheterization rooms are expensive the second room described above is normally used by another team of cardiologists. The preparation of the patient before and after the intervention are parts of the procedure for which equipment in 
Table 3-2: Observed number of patients served per working day at the catheterization room.

\begin{tabular}{llll}
\hline $\begin{array}{l}\text { Number of patients } \\
\text { per working day }\end{array}$ & $\begin{array}{l}\text { Average length of work- } \\
\text { ing day } \\
\text { (h) }\end{array}$ & $\begin{array}{l}\text { Range of length of } \\
\text { working day } \\
\text { (h) }\end{array}$ & $\begin{array}{l}\text { Number of observed } \\
\text { working days }\end{array}$ \\
\hline 4 & 5.73 & $4.40-7.10$ & 6 \\
5 & 7.24 & $6.50-7.86$ & 4 \\
6 & 8.15 & $7.75-8.70$ & 3 \\
7 & 7.75 & - & 1 \\
\hline
\end{tabular}

the catheterization room is not needed. Presently these parts of the procedure are performed in the catheterization room for sanitary reasons. Although always some time is needed in the catheterization room, some time of the cardiologist is saved, because part of the preparation of the patient is done somewhere else. The time to bring a patient into the catheterization room and to get him out is assumed to be normally distributed with an average of $3 \pm 0.5$ minutes and an average of $5 \pm 1$ minutes, respectively.

The third question we wanted to answer was:

3. What is the effect on the throughput if a part of the preparation of the patient before and after the intervention is carried out outside the catheterization room? Preparation could be done by the cardiologist who is in charge at the ward together with the nurses. This approach is regarded as an 'aggressive' scenario.

The questions raised above were answered in experiments 1,2 and 3 .

In all experiments the two earlier mentioned appointment strategies were studied.

\section{Fitted Distribution}

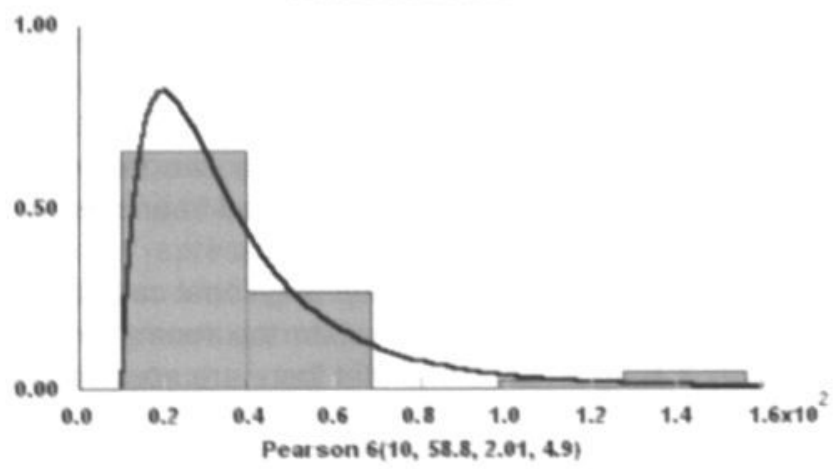

Figure 3-4: Fit of the duration of a diagnostic catheterization with a Pearson-6 distribution. $x^{2}=2.5, d f=4, P=0.64$, accuracy of the estimation is equal to 0.0003 


\section{Fitted Distribution}

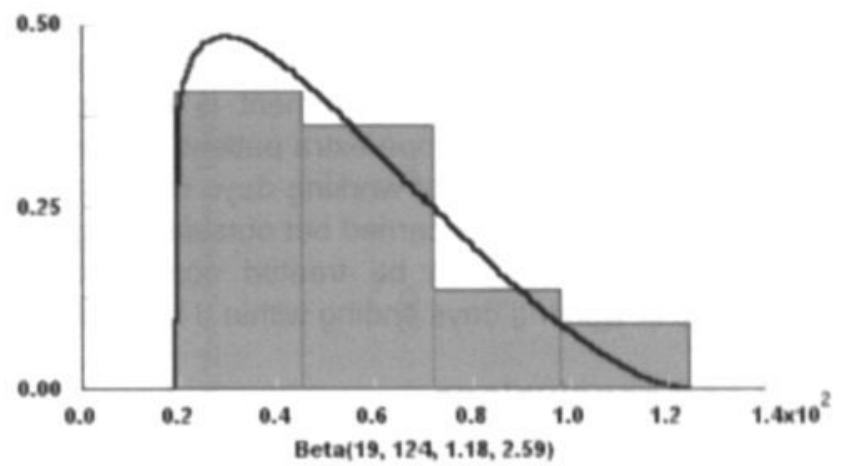

Figure 3-5: Fit of the duration of a PTCA with a beta distribution. $x^{2}=2.0, \mathrm{df}=3, P=0.57$, accuracy of the estimation is equal to 0.0003 .

The first strategy is that no new procedure starts after 16:00 h. It was determined how many patients on average can be treated per day in the different experiments using this strategy.

Using the second strategy it was determined how many patients could be scheduled each day while the length of a working day on average only exceeds $8 \mathrm{~h}$ in a for the management acceptable percentage of the cases. At the moment in $25 \%$ of the fully booked days the duration of a working day is longer than $8 \mathrm{~h}$.

Both appointment strategies were used to answer the questions raised above.

\subsection{Results of the simulation experiments}

For each experiment 999 days (the maximum number of days allowed by the program) were simulated and the results were averaged.

\subsubsection{First strategy}

In these simulation experiments no new procedures started after 16:00 $\mathrm{h}$. The number of patients that can be treated during one day and the duration of the working day as obtained by the experiments is given in Table 3-3.

In Figure 3-6 we plotted the percentage of working days finished as a function of the length of the working day. If the last patient appears to be a very complicated one the duration of a working day can last up to almost $15 \mathrm{~h}$. Figure 3-6 shows that in experiment 1 and experiment $2 \sim 70 \%$ of the simulated days have a duration of less than $8 \mathrm{~h}$. It should be stressed that each curve presents a situation in which a different number of patients may be treated (see Table 3-3). In Experiment $3 \sim 80 \%$ of the working days ended before or at 17:00 h. (within $8 \mathrm{~h}$ ) (see also Table 3-3).

\subsubsection{Second strategy}

During each simulation run the number of patients to be treated was kept constant. The results of the different experiments are summarised in Table 3-4. In this case the number of patients treated per day was varied from four to eight.

Table 3-4 shows that if the waiting times are reduced to zero (experiment 1 ) one 
extra patient can be treated compared to the current situation (five patients instead of four). However in this setting $93.0 \%$ of the working days will end within $8 \mathrm{~h}$ instead of $98.7 \%$ in the current situation. If one additional catheterization room is available and the preparation before the treatment is carried out in the other catheterization room (experiment 2) also one extra patient can be treated compared to the current situation. The percentage of working days that will end within $8 \mathrm{~h}$ will be 96.4 . If the preparation of a patient is carried out outside the catheterization room (experiment 3), two extra patients can be treated compared with the current situation. The percentage of working days ending within $8 \mathrm{~h}$ will be 96.1 .

\subsection{Discussion and conclusions}

Our aim was to present the possibilities of simulation. In particular we show how one can get insight in the impact of changes in procedures on the number of patients that can be catheterized during a day. We used a validated simulation model to investigate the effects of different procedures. We only wanted to show what results could be obtained by simulation experiments. We did not present a trade-off between costs and benefits. The numbers presented here can be used for such an analysis, however we did not carry out these calculations.

In the literature several authors report on successful simulation projects concerning the use of capacities in health care. Examples are of application areas are outpatient clinic (see e.g. Lacroix et al. [6]), emergency room (see e.g. Koppelman et al. [7]) and the clinical laboratory (see e.g. van Merode et al. [8]).

\subsubsection{Simulation model}

The simulation model presented here is a description of the general procedures carried out at the catheterization room. This means that we did not model each individual cardiologist and technician. Also only the general aspects of catheterizations and PTCA were modeled. The model parameters were based on the observation of 69 procedures during 14 days. The eight days that were fully booked were used to validate the model. We could show that the model adequately

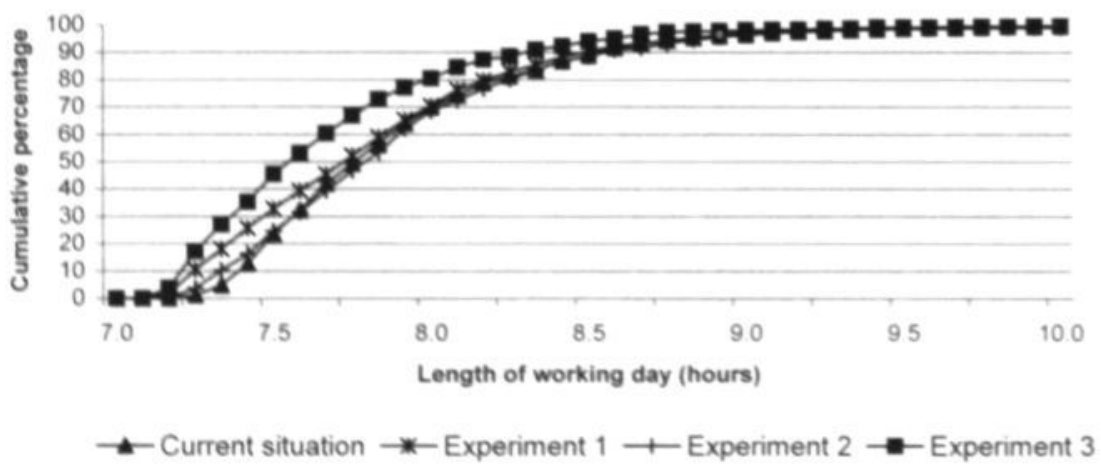

Figure 3-6: Cumulative percentage of working days finished as function of the length of the working day 
Table 3-3: Duration of a working day and number of patients treated in case no new patients are treated after $16: 00 \mathrm{~h}$ (first strategy) based on 999 simulation runs.

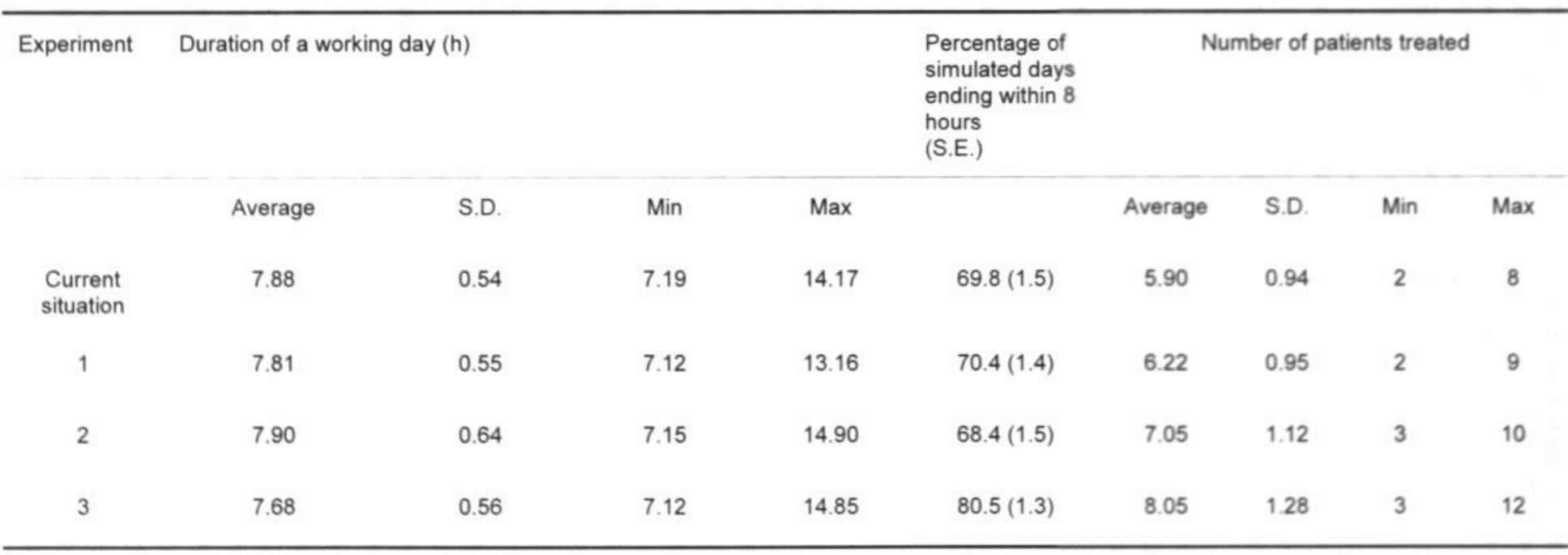


Table 3-4: The number of patients treated per working day using the second scheduling strategy, with a working day close to $8 \mathrm{~h}$ based on 999 simulation runs.

\begin{tabular}{|c|c|c|c|}
\hline Experiment & $\begin{array}{l}\text { Number of } \\
\text { patients } \\
\text { treated per } \\
\text { day }\end{array}$ & $\begin{array}{l}\text { Duration of a working day } \\
\text { mean (S.D.) in hours }\end{array}$ & $\begin{array}{l}\text { Percentage of simulated } \\
\text { days ending within } 8 \mathrm{~h} \\
\text { (S.E.) }\end{array}$ \\
\hline Current situation & 4 & $5.44(1.00)$ & $98.7(0.4)$ \\
\hline Current situation & 5 & $6.75(1.13)$ & $88.7(0.1)$ \\
\hline Current situation & 6 & $7.95(1.17)$ & $56.8(1.6)$ \\
\hline 1 & 4 & $5.09(1.01)$ & $98.0(0.4)$ \\
\hline 1 & 5 & $6.30(1.12)$ & $93.0(0.8)$ \\
\hline 1 & 6 & $7.53(1.20)$ & $70.7(1.4)$ \\
\hline 2 & 4 & $4.63(1.00)$ & $98.9(0.3)$ \\
\hline 2 & 5 & $5.70(1.10)$ & $96.4(0.6)$ \\
\hline 2 & 6 & $6.78(1.19)$ & $86.9(1.1)$ \\
\hline 2 & 7 & $7.87(1.34)$ & $60.8(1.5)$ \\
\hline 3 & 5 & $4.87(1.05)$ & $98.6(0.4)$ \\
\hline 3 & 6 & $5.80(1.16)$ & $96.1(0.6)$ \\
\hline 3 & 7 & $6.75(1.26)$ & $85.2(1.1)$ \\
\hline 3 & 8 & $7.71(1.30)$ & $64.5(1.5)$ \\
\hline
\end{tabular}

described the situation of the catheterization room.

We did not model individual cardiologists so the model is generally applicable. However if one wants to use the model in another hospital one has to determine the probability distributions describing the different activities and waiting times for these are specific for the Maastricht Academic Hospital.

The length of a simulated working day in our experiments is not normally distributed (see Figure 3-6). The results of both scheduling strategies (see Table 3-3 and Table 3-4) show high values for the maximum length of a working day. This can be explained by the fact that random numbers generated from some of the used distribution functions are not limited by a maximum value. In real life a cardiologist probably does have an 'upper boundary' if it concerns the duration of a procedure. The confidence intervals can be calculated using the fixed-sample-size procedure as described by Law and Kelton [2], p. 533. The simulation model can be characterised as a termination simulation model. Since the number of replications is 
very large (999 replications) the confidence intervals reported are very small and all differences are statistically significant.

\subsubsection{Experiments}

Since an additional catheterisation room (experiment 2) usually is too expensive we first compared the results of experiment 1 and 3 with the current situation. Experiment 1 only provided a marginal increase in the average number of patients that can be treated as compared to the current situation. The percentage of working days ending before $17: 00 \mathrm{~h}$ is the same. The results of experiment 3 were promising. Using this set-up on average two additional patients could be treated with fewer working days being longer than $8 \mathrm{~h}$.

The set-up described in situation 2 was not totally useless. In cases that there are no attending cardiologists for the second catheterization room (in case of illness of a cardiologist for example) this strategy can be used. In that case on average one additional patient can be treated while the length of the working days on average are the same.

\subsubsection{Comparison of strategies}

One can only compare the different scheduling strategies in the same setting. In the current situation the number of patients treated was nearly the same in both scheduling strategies. Using the first scheduling strategy the percentage of simulated working days ending within $8 \mathrm{~h}(69.8 \%$, see Table $3-3)$ was significantly higher than using the second scheduling strategy $(56.7 \%)$. In both cases 6 patients are treated.

In the first experiment (no waiting times), the number of patients treated using the first scheduling strategy (6.22) was somewhat higher than using the second strategy (6). The percentage of working days finishing within $8 \mathrm{~h}$ was nearly the same ( $70 \%)$.

In the two rooms experiment (experiment 2), the number of patients treated using the first strategy compared with the second strategy was about the same $(7.05$ and 7). The percentage of working days ending within $8 \mathrm{~h}$ differs however significantly: $68.7 \%$ versus $60.8 \%$.

In experiment 3 (preparation outside the catheterization room) we found also a difference in the results of the scheduling strategies. Using the first strategy 8.05 patients could be treated and the percentage of working days finished within $8 \mathrm{~h}$ is 80.5. Using the second strategy if 8 patients were treated only in $64.5 \%$ of the cases the working day ended within $8 \mathrm{~h}$.

We conclude that the old strategy is better than the newly suggested one.

Probably due to a change in the referral policy of other hospitals to the Maastricht Academic Hospital the number of patients that had to be catheterised dropped so there was no need to implement one of the strategies discussed above. Therefore we could not validate the conclusions in practice.

As stated in the beginning of the discussion the costs and benefits of the various suggested changes should be taken into account. If the management of the department of cardiology wants to implement one of the offered solutions they have 
now the information they need. MedModel is a user-friendly simulation program that is also used in an educational stetting [9]. After some training, the management of the department should be able to use MedModel to do some small experiments themselves to answer new questions. Simulation therefore can provide valuable material for discussions about how to optimise the use of capacities like a catheterization room.

\section{Acknowledgement}

The authors wish to thank Professor F.W.H.M. Bar, MD, Ph.D and the staff of the catheterization room of the Maastricht University Hospital for their co-operation during this research project.

\subsection{References}

[1] Banks J, Carson II JS, Nelson BL. Discrete-Event System Simulation. (Second ed.) Upper Saddle River, NJ: Prentice-Hall, 1996. (Fabrycky WJ, Mize JH, eds. Prentice-Hall International Series in Industrial and Systems Engineering)

[2] Law AM, Kelton WD. Simulation Modeling and Analysis. (Second ed.) New York, USA: McGraw-Hill, 1991. (Riggs JL, ed. McGraw-Hill Series in Industrial Engineering and Management Science).

[3] Fishwick PA. Simulation model design and execution : building digital worlds. Englewood Cliffs, New Jersey: Prentice Hall, 1995. Prentice Hall International Series in Industrial and Systems Engineering.

[4] MedModel homepage. ProModel Inc. http://www.promodel.com/products/medmodel

[5] Sargent RG. Verification and validation of simulation models. In: Tew JD, Manivannan S, Sadowski DA, Seila AF, eds. Winter Simulation Conference. Orlando FL: New York, NY: Institute of Electrical and Electronics Engineers, 1994:77-87

[6] Lacroix M, Ricard J, Perry MJ. Simulation of a Pulmonary Clinic. In: Anderson JG, Katzper M, eds. 1997 Western MultiConference: Simulation in the Medical Sciences. Phoenix, Arizona: SCS - Society for Computer Simulation International, San Diego CA, 1997:25-9

[7] Koppelman Y, van Merode F, Groothuis S. Simulation as Decision Support at the Emergency Department. In: Anderson JG, Katzper M, eds. 1999 Western MultiConference - 1999 Health Science Simulation Conference. San Francisco, CA: SCS - Society for Computer Simulation International, San Diego CA, 1999:28-32

[8] van Merode GG, Hasman A, Derks J, Schoenmaker B, Goldschmidt HMJ. Advanced management facilities for clinical laboratories. Comput Methods Programs Biomed 1996;50:195-205

[9] Groothuis S, van Merode GG. Discrete Event Simulation in the Health Policy and Management Program. Methods Inf Med 2000;39:339-42 


\section{Turn-around time for chemical and endocrinology analyzers studied using simulation}

\section{Abstract}

Simulation can be a means for the laboratory management to investigate the effects of proposed changes in the laboratory. Also, when specifications of analyzers are available one can investigate which analyzer should be purchased to fulfill existing needs. The potential of simulation is shown here by simulating the turn-around time of batched samples under several conditions. Three routine analyzers (DAX, AXON and IMMUNO-1) were modeled. The temporal pattern of the arrival of the samples at the different analyzers was determined. The impact of these patterns and the two batching methods on the turn-around time was investigated. Simulation proved to be a useful method to study the effects of batching and arrival patterns on the turn-around time. 


\subsection{Introduction}

In the hospital the management of a laboratory has to run the laboratory in an efficient way and keep the costs within agreed levels. Medical specialists, however, may demand that the results of their ordered tests should be available so quickly that the efficiency level of the laboratory would be reduced. Therefore the management of the laboratory should make service level agreements with the medical specialists and provide test results within the agreed times. Otherwise, a department might increase the volume of stat requests (urgent requests) if the results of routine requests are not reported in time. Such a change will not only influence the turn- around time (TAT) of routine and stat requests, but also the costs of the laboratory.

When negotiating service levels, the management of the laboratory has to know which factors influence the TAT and to what extent, e.g. the number of samples that arrive during the day and their arrival times. Also, characteristics of the analyzer influence the TAT.

The way an analyzer is operated depends on the laboratory, the number of technicians available and their individual skills. If batching is applied, the size of a batch will also influence the TAT. A technician can wait until a certain number of samples has arrived at the desk of the analyzer before putting the samples on the analyzer. Another way of operation is that at certain "fixed" times all samples that have arrived at the desk are put on the analyzer. In addition, the TAT is influenced by the temporal pattern of samples arrival at the analyzer. For example, the TAT will be smaller when there is a constant flow of samples during working hours compared to the situation that the samples arrive in two big batches.

For a medical laboratory it is important to know what the actual TAT is and how its value can be influenced. The management of the laboratory can manipulate the factors that influence the TAT to meet agreed service levels. They can, for example, suggest a ward to collect the routine samples four times a day instead of two times a day. This will result in a more steady flow of samples to the laboratory. In the negotiation process the management has an advantage when they know the outcomes of various proposals. One of the ways to obtain such knowledge is to use computer simulation. Also when the purchase of a new analyzer is being considered its impact can be simulated to select the most appropriate system. In this contribution we show an example how the management can determine the relative merits of two batching methods, taking different sample arrival patterns into account. Simulation has been applied before to study the operation of analyzers in medical laboratories. In the mid-seventies Slutsky and Cunningham [1] used a simulation model to determine the most economical rate of analysis (cost per specimen given a desired level of accuracy) for the auto analyzer. In their calculations the cost of staff and reagents was included. Their only purpose was to show that simulation could be used to make these calculations. Dankbar et al. [2] constructed simulation models of analyzers from different vendors to determine which was the best buy for their laboratory. The vendors provided the specifications of the analyzers. Vogt and coworkers [3, 4] studied the TAT using a simulation model in a normal and an extreme situation. The first arrival pattern was smooth during office hours and in the second 
all samples arrived between 8.00 and $9.00 \mathrm{a} . \mathrm{m}$. In this study they focused on staff utilization rates. The program of Hoffmann's Simlab $[5,6]$ is based on the model described by Vogt and co-workers [3, 4]. Clark and Crawford [7] used simulation models as a capacity-planning tool. Van Merode et al. [8, 9] used a simulation model as part of a decision support for capacity planning. Their tool provides advice concerning the clustering of job-shops using planning rules. None of the authors cited above studied the relative merits of batching strategies.

Two routine chemical analyzers (DAX: Bayer, Tarrytown, USA and AXON: Bayer, Dublin, Ireland) and one routine endocrinology analyzer (IMMUNO-1: Bayer Inc, Tarrytown, USA) in the Centralized Department of Clinical Chemistry and Hematology Laboratory ( $\mathrm{CKCHL}$ ) of the St. Elisabeth Hospital in Tilburg. The Netherlands, were modeled. These three analyzers process about $70 \%$ of all serum samples within the laboratory. We used the technical specifications of each analyzer, based on available manuals, to build a simulation model to determine the TAT under different conditions. The design, construction and evaluation of the simulation models will be described.

Different experiments were performed. First the actual situation was modeled for validation purposes. Then, in experiment 1 , the fixed batch size operation was modeled. The batch size was varied including a batch size of one (random access). In a second experiment the fixed interval operation during office hours ( $8.00 \mathrm{a}$ a.m.6.00 p.m.) was simulated. In this case the term "fixed" means that although on average the interval length was fixed small variations were incorporated in the model. Different sample arrival patterns were applied in both experiments.

\subsection{Materials and Methods}

\subsubsection{Methods}

The technique used is the discrete event simulation. "A simulation is the imitation of the operation of a real-world process or system over time" [10]. A simulation can be performed by hand or on a computer. A history of an artificial system is created. Based on this history inferences about the functioning of the real system are drawn. A system is a collection of entities (e.g. people, machines) that interact with each other and try to complete a certain task. "Discrete event simulation concerns the modeling of a system as it evolves over time by a representation in which the state variables change instantaneously at separate points in time" [11]. Variables describe the states of different objects in the system. The interactions between the different objects in the system are described by processes. The duration of processes and the occurrences of events are described by probability functions.

Discrete event simulation has been used for many years to model simple and complex systems. A list of the advantages and disadvantages of the use of simulation can be found in Banks [10]. The necessary steps that have to be carried out in a simulation study have been described by several authors [11, 12]. All those steps were carried out in this study. Validation is an essential step in a simulation study [13]. One has to show that a model is able to predict the current situation. In this study validation was done using historical data. The tool used was MedModel 
[14]. MedModel is a graphical discrete event simulation environment that has been extensively used for applications throughout the health care system.

\section{Data collection}

To build a simulation model, specific data have to be collected. In this case the data collection can be divided into two categories. The first category concerns the technical description of the analyzers. Capacities of the different parts of each analyzer have to be known. Also the routing of a sample within the analyzer and the processing time at each of the different locations has to be determined. These data were obtained by (a) studying written specifications and (b) through interviews with technicians (users).

The second category concerns the requested tests. On a request form several tests

Table 4-1: Test request patterns of the Immuno - 1 per sample. a, b, c and d represent groups of tests with the same processing time (group a: thyroxine, processing time: 2 minutes; group b: ferritin. triodothyronine, free thyroxine, luteinizing hormone, follicle stimulating hormone, human chorionic gonadotropin, cortisol, Estrogens, prolactin and progesterone, processing time: 38 minutes; group c: thyroid stimulating hormone, processing time: 36 minutes; and group d: e.g. vitamin B12 and folate, processing time: 90 minutes).

\begin{tabular}{|l|c|r|}
\hline Combination & Number & Percentage \\
\hline Abb & 1 & $0.3 \%$ \\
\hline Abbc & 2 & $0.6 \%$ \\
\hline Abc & 1 & $0.3 \%$ \\
\hline Ac & 5 & $1.7 \%$ \\
\hline B & 36 & $12.5 \%$ \\
\hline Bb & 7 & $2.4 \%$ \\
\hline Bbb & 4 & $1.4 \%$ \\
\hline bbbb & 1 & $0.3 \%$ \\
\hline bbbbbc & 2 & $0.6 \%$ \\
\hline Bbbc & 1 & $0.3 \%$ \\
\hline Bbc & 11 & $3.8 \%$ \\
\hline Bc & 44 & $15.2 \%$ \\
\hline Bcd & 1 & $0.3 \%$ \\
\hline Bcdd & 1 & $0.3 \%$ \\
\hline Bd & 3 & $1.0 \%$ \\
\hline Bdd & 1 & $0.3 \%$ \\
\hline C & 141 & $48.8 \%$ \\
\hline Cd & 3 & $1.0 \%$ \\
\hline Cdd & 5 & $1.7 \%$ \\
\hline D & $2.8 \%$ \\
\hline Dd & $3.8 \%$ \\
\hline & 11 & $100.0 \%$ \\
\hline
\end{tabular}


can be ordered to be executed on an analyzer. We call this combination of test requests a test request pattern. Different request forms may contain different test request patterns. In Table 4-1 we provide an overview of the different test request patterns and their relative frequencies for the Immuno-1 analyzer.

The arrival time of each sample at the analyzer and the time the last result of a test done on that sample is reported (first line validation) have to be determined. Different tests performed on the same analyzer may have different processing times. The time at which the last test result is known is important because all the test results are together used to assess the health status of the patient.

The arrival time of each sample at the analyzer was registered. This was done via barcode scanning. Based on these data the arrival pattern of the samples was determined for each analyzer. The reporting times of the corresponding test results were obtained from the laboratory information management system (LIMS). Using these data, the TAT value for each sample was calculated.

\subsubsection{Experiments}

It is important for the management to know how different factors like batching methods and arrival patterns influence the TAT. It is obvious that the lowest value of the TAT can be achieved if a sample is put immediately on the analyzer. However, this requires constant presence of a technician at the analyzer.

In this study we compared two batching methods: working with a fixed batch size and working with a fixed interval time between two batches.

When one is working with a fixed batch size the technician waits until the number of samples is equal to the batch size. When this is the case the tray with the samples is put on the analyzer. When a technician operates an analyzer using the fixed time interval method the technician waits until a fixed interval has elapsed and then puts all the available samples on the analyzer. This allows a technician to operate more than one analyzer at a time. To compare the dependency of the different analyzers on the arrival pattern, the arrival pattern of the samples for the different analyzers was applied to all analyzers.

When the arrival pattern is "flat" (has a steady flow), each batch is completed on average in the same time. This situation resembles the fixed interval method. If the arrival pattern is not "flat" and the fixed number batch size strategy is applied, samples may sometimes have to wait a long time before the batch is completed. This will cause an increase of the TAT.

In the first experiment a fixed batch size strategy during office hours was used for the analyzers. Other than the standard sizes were also investigated that were determined, through discussions with technicians and management of the CKCHL. For the standard laboratory batch size or a batch size of one sample the arrival pattern was varied and its influence studied. The duration of the interval times in the fixed interval batching method was again determined through extensive discussions with the personnel of the laboratory.

In the second experiment the fixed interval batching method was studied. Various arrival patterns were forced upon the analyzers and the influence of different interval times was studied. 


\subsection{Results}

\subsubsection{Data collection}

The specifications of the analyzers were obtained using available manuals. With the AXON, 26 different tests can be performed; 14 tests can be carried out with the DAX 22 and with the Immuno-1 analyzer. On the basis of information on a request form the test request patterns were determined for all analyzers. The test request pattern for the Immuno-1 analyzer is shown in Table 4-1.

The measured arrival times of the samples were used to calculate the arrival patterns. The arrival pattern describes the distribution of the arriving samples throughout the day expressed as the percentage of the total number of arrivals within each time slot. The width of each time slot was 10 minutes. The width of 10 minutes was chosen to obtain an arrival pattern that is neither too smooth nor too ragged (see Law and Kelton, example 6.23 [11]). Within the time slot the arrivals were considered to be uniformly distributed. The arrival patterns for the different analyzers are shown in Figure 4-1 - Figure 4-3. The number of samples processed by the analyzers in this hospital on a daily basis are for the AXON: 115 samples; for the Immuno-1: 260 samples and for the DAX: 400 samples (production level at the start of 1999).

\subsubsection{Model building}

With the data described above a model for each analyzer was built. To model the Immuno-1 four different groups of tests were distinguished because the tests within each group have the same processing time. With the Immuno-1 no new samples were processed after 15.00 hours. The AXON was used 24 hours a day. During office hours ( 8.00 a.m. -6.00 p.m.) the $A X O N$ was used as a batch analyzer and between 6.00 p.m.- 8.00 a.m. it was used as a random access analyzer. Re-runs were included in the model.

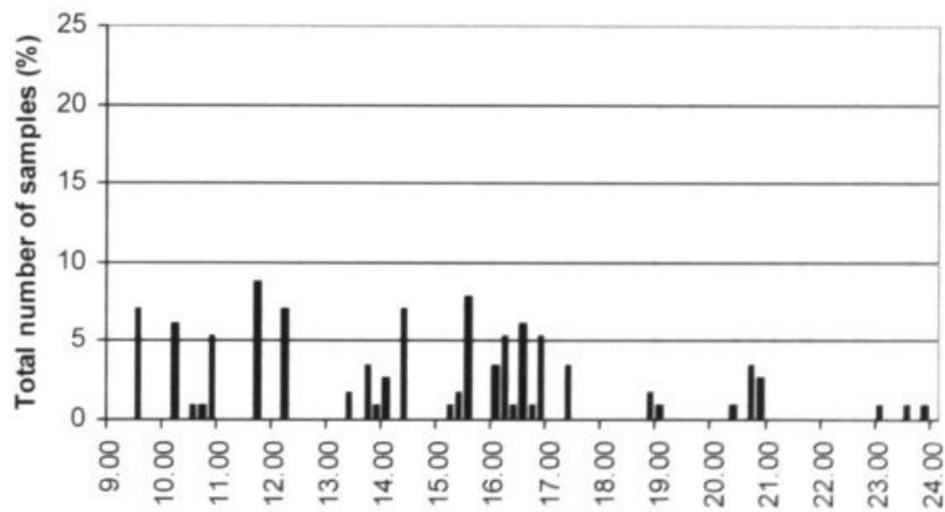

Sample arrival at AXON analyzer (hours)

Figure 4-1: Arrival pattern of samples at the AXON analyzer. The vertical axis represents the percentage of the total number of samples that arrived during an interval of 10 minutes at this analyzer (average total number of samples per day 115). 


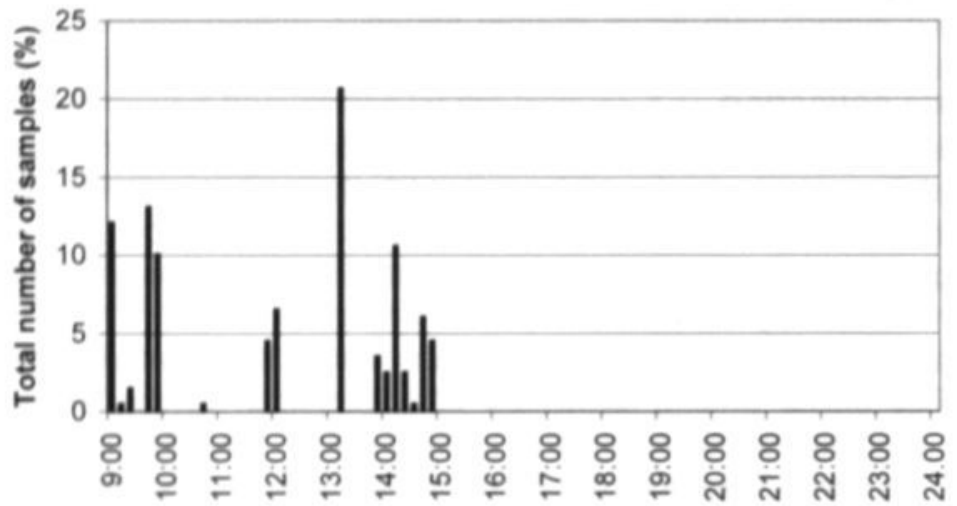

Sample arrival at Immuno-1 analyzer (hours)

Figure 4-2: Arrival pattern of samples at the Immuno-1 analyzer. The vertical axis represents the percentage of the total number of samples that arrived during an interval of 10 minutes at this analyzer (average total number of samples per day 260).

\subsubsection{Validation}

The observed TAT values are shown in Table 4-2 together with the simulation results. The difference between the observed values of the TAT and the simulated TAT was less than $10 \%$.

\subsubsection{Experiments}

Table 4-3 indicates in which Tables or Figures the results of the different experiments can be found.

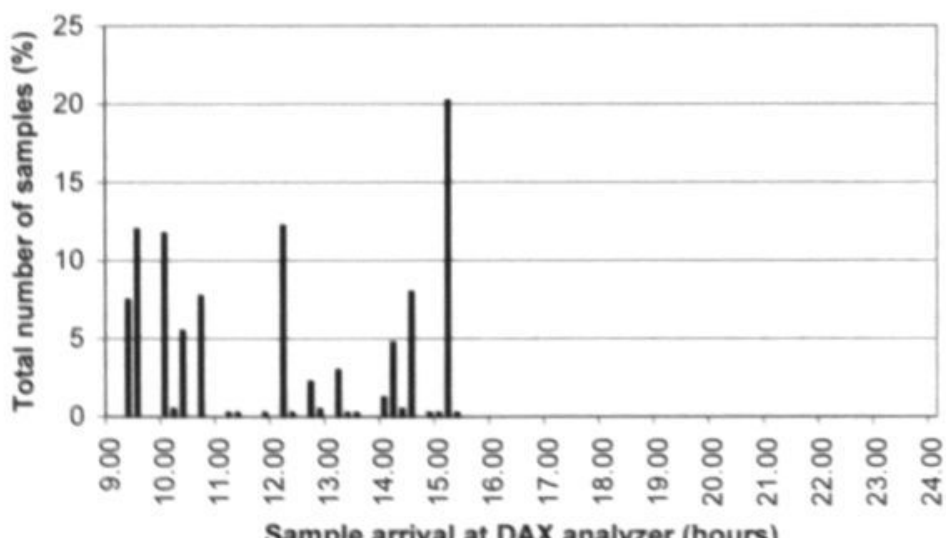

Figure 4-3: Arrival pattern of samples at the DAX analyzer. The vertical axis represents the percentage of the total number of samples arriving during an interval of 10 minutes at the analyzer (average number of samples per day 400 ). 
Table 4-2 The average TAT's (in minutes) and standard deviation (SD) of the three analyzers. The simulated data are based on 20 runs. Batch sizes used in simulation: AXON: 5 ; Immuno1: 45 and DAX: 50 . Malfunctioning of the DAX analyzer was observed during data collection. In the last two columns the results of a t-test (t-value degrees of freedom (df)) of the observed and simulated TAT values are shown.

\begin{tabular}{|c|c|c|c|c|c|c|c|}
\hline \multirow[t]{2}{*}{ Analyzer } & \multicolumn{2}{|c|}{ Measured TAT } & \multicolumn{2}{|c|}{ Simulated TAT } & \multirow{2}{*}{$\begin{array}{l}\text { Simulated } \\
\text { TAT - } \\
\text { observed. } \\
\text { TAT }(\%)\end{array}$} & \multirow[t]{2}{*}{$t$ - value } & \multirow[t]{2}{*}{ df } \\
\hline & Average & SD & Average & SD & & & \\
\hline$A X O N$ & 20.05 & 15.32 & 19.49 & 15.58 & -2.79 & -0.38 & 2413 \\
\hline Immuno1 & 114.83 & 60.50 & 115.82 & 47.02 & 0.86 & 0.33 & 5458 \\
\hline DAX & 50.33 & 27.50 & 54.74 & 24.45 & 8.76 & 3.50 & 8398 \\
\hline
\end{tabular}

\section{Experiment 1}

The batch size was varied for all analyzers. The resulting average TAT values for each analyzer are shown in Figure 4-4 and in Table 4-4 - Table 4-6. As can be expected, in all cases the TAT increased with the batch size. In Table 4-7 the TAT is shown for some fixed batch sizes for each of the three different arrival patterns.

\section{Experiment 2}

In this experiment the analyzers were operated using the fixed interval method. The interval was varied from 0 (random access) to 30 minutes. The results are shown in Figure 4-5 - Figure 4-7.

\subsection{Discussion}

For the management of a laboratory it is important to know the value of the TAT under various conditions. When service level agreements are made the management must be sure that they can provide the agreed level of service, otherwise departments will change their policies and for example will request more stat tests. This will negatively influence the TAT of routine requests and induce other departments to increase their volume of stat requests too. Therefore it is important to know how different factors influence the TAT. Here we demonstrated how the influence of different factors can be studied by simulation. Two routine chemical

Table 4-3 Results according to the experimental design.

\begin{tabular}{|l|c|c|c|}
\hline & \multicolumn{3}{|c|}{ Arrival Pattern } \\
\hline & AXON & Immuno-1 & DAX \\
\hline Batch size & Table 4-4 & Table 4-5 & Table 4-6 \\
& Table 4-7 & Table 4-7 & Table 4-7 \\
& Figure 4-4 & Figure 4-4 & Figure 4-4 \\
\hline Batch interval & $\begin{array}{c}\text { AXON: Figure 4-5 } \\
\text { Immuno-1: Figure 4-6 } \\
\end{array}$ & & \\
& DAX: Figure 4-7 & & \\
\hline
\end{tabular}




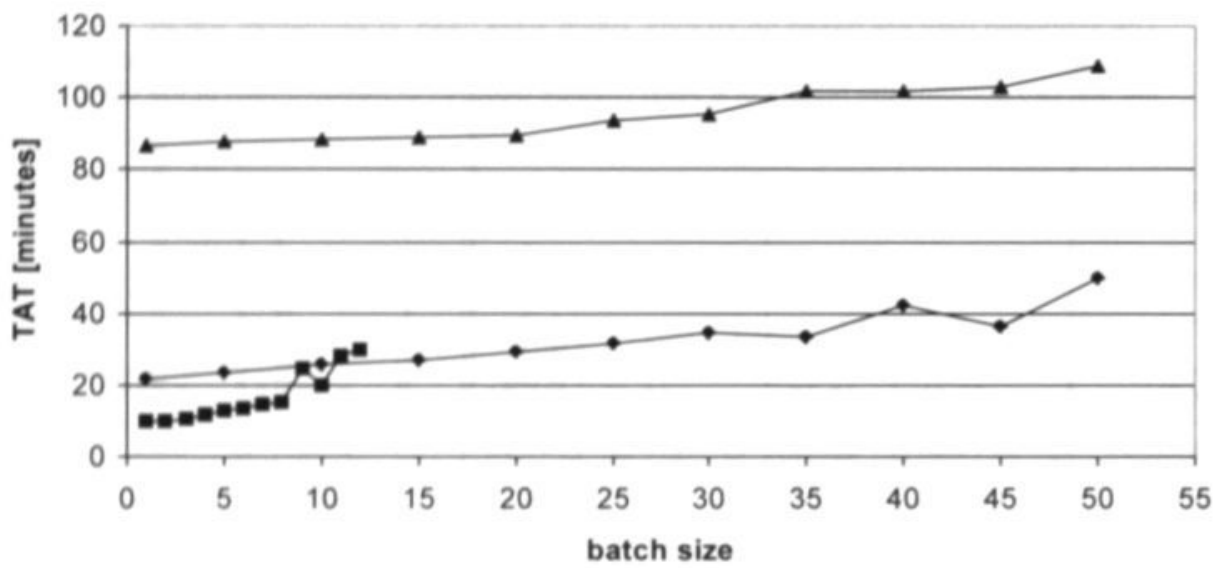

Figure 4-4: Median value of the TAT for the different analyzers for different batch sizes.

-AXON, AImmuno-1, • DAX.

analyzers and one routine endocrinology analyzer were modeled. Data used to build these models was gathered from the specifications of the analyzers and by time stamping the samples during working day.

\subsubsection{Validation}

The models were validated on the basis of historical data (see Table 4-2). The results were in good agreement with the observed data.

The simulated data for the DAX shows the largest deviation from the observed data. This can be explained by the fact that at the time of the observations some human intervention was necessary because of the malfunction of the analyzer. There were

Table 4-4: TAT (in minutes) for the AXON analyzer for different batch sizes. Each result is based on 20 simulation runs (equivalent of 20 working days)

\begin{tabular}{|c|c|c|c|c|}
\hline Batch size & Average & SD & Median & Maximum \\
\hline 1 & 10.41 & 1.77 & 10.09 & 20.28 \\
\hline 2 & 12.37 & 7.16 & 10.22 & 84.89 \\
\hline 3 & 14.79 & 10.68 & 10.64 & 107.80 \\
\hline 4 & 16.37 & 12.40 & 11.54 & 99.42 \\
\hline 5 & 19.49 & 15.28 & 12.73 & 111.78 \\
\hline 6 & 21.46 & 17.81 & 13.49 & 129.28 \\
\hline 7 & 25.01 & 22.57 & 14.45 & 134.03 \\
\hline 8 & 26.20 & 24.72 & 15.50 & 148.03 \\
\hline 9 & 33.33 & 26.21 & 24.44 & 149.25 \\
\hline 10 & 31.88 & 30.35 & 19.90 & 237.34 \\
\hline 11 & 37.31 & 35.11 & 27.82 & 254.27 \\
\hline 12 & 45.51 & 46.05 & 29.86 & 256.88 \\
\hline
\end{tabular}


Table 4-5 TAT (minutes) for the Immuno-1 analyzer for different batch sizes. Each result is based on 20 simulation runs (equivalent of 20 working days).

\begin{tabular}{|c|c|c|c|c|}
\hline Batch size & Average & SD & Median & Maximum \\
\hline 1 & 90.98 & 42.84 & 86.80 & 237.53 \\
\hline 5 & 91.42 & 41.82 & 87.71 & 244.03 \\
\hline 10 & 94.75 & 42.34 & 88.43 & 248.79 \\
\hline 15 & 97.51 & 41.87 & 88.83 & 250.77 \\
\hline 20 & 100.82 & 42.84 & 89.36 & 310.06 \\
\hline 25 & 104.04 & 42.75 & 93.63 & 325.84 \\
\hline 30 & 107.24 & 43.45 & 95.69 & 264.79 \\
\hline 35 & 113.06 & 44.49 & 101.87 & 320.86 \\
\hline 40 & 117.18 & 47.89 & 102.10 & 321.04 \\
\hline 45 & 115.82 & 47.02 & 103.23 & 328.45 \\
\hline 50 & 125.55 & 49.61 & 109.07 & 334.22 \\
\hline
\end{tabular}

minor interruptions and small batch sizes were then used instead of the standard batch size of 50 . This study was a part of a larger time study and therefore we were not able to carry out the data collection from the DAX on another day. We consider the model to be valid and accept it as a tool that can be used in the experiments.

\subsubsection{Experiment 1}

In this experiment the fixed batch procedure was investigated. In Table 4-4 the values of the response (TAT) are shown for the Axon analyzer. As expected, a batch size of one provides the lowest value of the TAT and when the batch size increases the TAT increases too. As is shown in Table 4-5 and Table 4-6, the same holds for the Immuno-1 and the DAX. As can be seen from Figure 4-1 - Figure 4-3, the flow of samples to the analyzers was not continuous. There were several $10-$

Table 4-6 TAT (minutes) for the DAX for different batch sizes. Each result is based on 20 simulation runs (equivalent of 20 working days)

\begin{tabular}{|c|c|c|c|c|}
\hline Batch size & Average & SD & Median & Maximum \\
\hline 1 & 23.70 & 5.94 & 21.42 & 59.34 \\
\hline 5 & 25.91 & 7.48 & 23.25 & 120.65 \\
\hline 10 & 28.71 & 10.22 & 25.53 & 135.20 \\
\hline 15 & 30.75 & 11.17 & 26.77 & 136.74 \\
\hline 20 & 33.01 & 10.97 & 29.29 & 136.18 \\
\hline 25 & 37.51 & 15.83 & 31.73 & 166.10 \\
\hline 30 & 40.55 & 16.68 & 34.45 & 144.38 \\
\hline 35 & 40.19 & 17.60 & 33.27 & 150.55 \\
\hline 40 & 48.39 & 21.49 & 42.31 & 155.70 \\
\hline 45 & 45.84 & 23.23 & 36.45 & 150.60 \\
\hline 50 & 54.74 & 24.45 & 47.58 & 184.34 \\
\hline
\end{tabular}


Table 4-7: TAT (minutes) for the different batch sizes and different sample arrival patterns. Each result is based on 20 simulation runs.

\begin{tabular}{|c|c|c|c|c|c|c|c|c|c|c|c|c|c|}
\hline & \multirow{3}{*}{$\begin{array}{l}\text { Batch } \\
\text { size }\end{array}$} & \multicolumn{12}{|c|}{ Forced arrival pattern } \\
\hline & & \multicolumn{4}{|c|}{$A X O N$} & \multicolumn{4}{|c|}{ Immuno-1 } & \multicolumn{4}{|c|}{ DAX } \\
\hline & & Average & SD & Median & Max. & Average & SD & Median & Max. & Average & SD & Median & Max. \\
\hline$A X O N$ & 5 & 19.49 & 15.28 & 12.73 & 111.78 & 16.71 & 16.25 & 11.74 & 157.88 & 17.82 & 15.23 & 11.81 & 127.70 \\
\hline AXON & 1 & 10.41 & 1.77 & 10.09 & 20.28 & 10.45 & 1.81 & 10.09 & 20.28 & 10.40 & 1.71 & 10.09 & 22.85 \\
\hline Immuno-1 & 45 & 123.25 & 58.18 & 105.90 & 423.14 & 115.82 & 47.02 & 103.23 & 328.45 & 111.60 & 46.95 & 90.64 & 304.69 \\
\hline DAX & 50 & 56.53 & 27.75 & 49.59 & 210.46 & 51.12 & 20.79 & 44.53 & 185.75 & 54.74 & 24.45 & 47.58 & 184.34 \\
\hline DAX & 1 & 19.47 & 2.37 & 18.82 & 40.67 & 26.31 & 8.30 & 23.53 & 80.58 & 23.70 & 5.94 & 21.42 & 59.34 \\
\hline
\end{tabular}




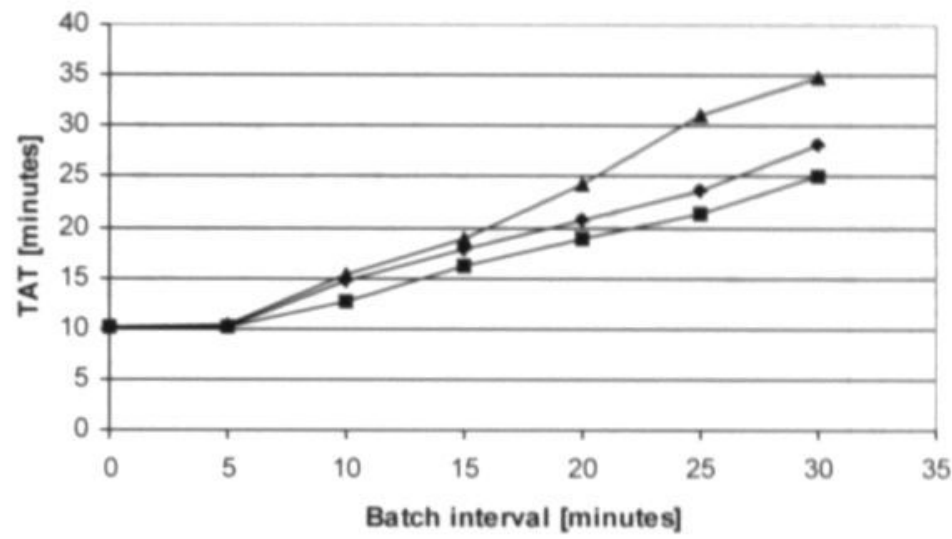

Figure 4-5: The median of TAT for the AXON analyzer for different batch intervals and different forced sample arrival patterns. - arrival pattern at AXON, $\triangle$ arrival pattern at Immuno-1,

- arrival pattern at DAX.

minute intervals in the arrival patterns of the Immuno-1 and the DAX (see Figure 4-2 and Figure 4-3, respectively) in which more than $10 \%$ of the samples arrived. These arrival patterns can be categorized as "peak". The increasing values of the standard deviation of the TAT with increasing batch size are caused by the fact that samples had to wait until the next group of samples arrives before being put on the analyzer. Sometimes a sample was directly placed in the analyzer because it completed a batch. The influence of the arrival patterns on the TAT is shown in Table 4-7. For a batch size of 1 the TATs for both the Immuno-1 and the DAX differed considerably for the different arrival patterns (Immuno-1: from 58.13 minutes to 90.98 minutes; DAX: from 19.47 minutes to 26.31 minutes; see Table 4-7). Applying different arrival

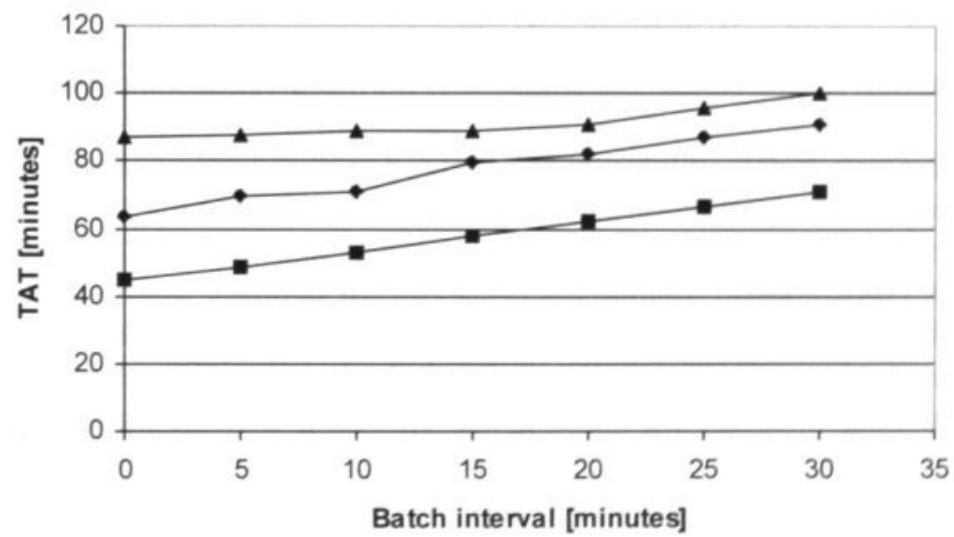

Figure 4-6: The median of the TAT for the Immuno-1 analyzer for different batch intervals and different forced sample arrival patterns. a arrival pattern at AXON, $\Delta$ arrival pattern at Immuno-1, • arrival pattern at DAX. 


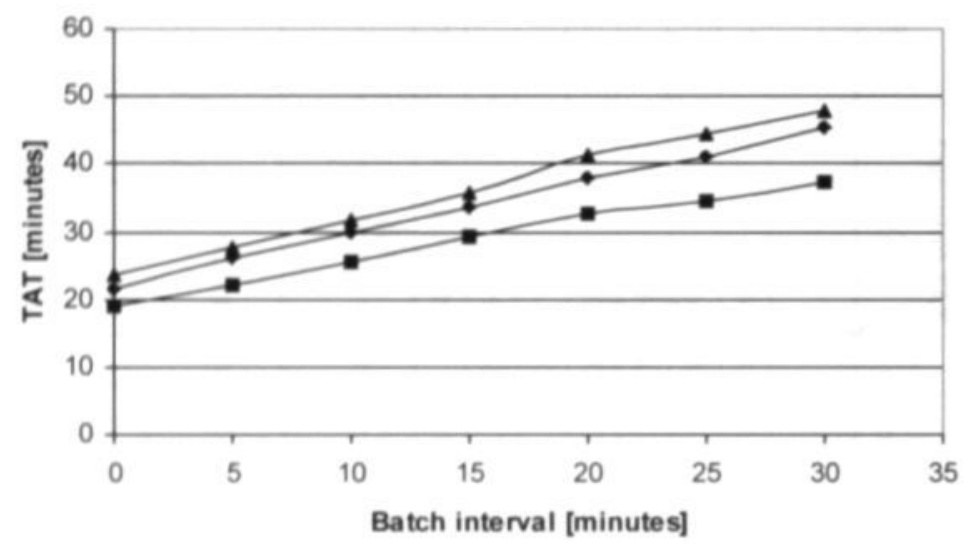

Figure 4-7: The median of the TAT for the DAX analyzer for different batch intervals and different sample arrival patterns. - arrival pattern at AXON, $\triangle$ arrival pattern at Immuno-1, • arrival pattern at DAX.

patterns for the AXON the difference in the TAT value was less than $2 \%$. Both the Immuno-1 and the DAX had to process more than 200 samples and the effects of a "peak" arrival pattern on the TAT will be stronger compared to the AXON analyzer.

\subsubsection{Experiment 2}

Using the second batching method - the fixed interval method - the technician operates the analyzer on average at fixed time points. This means that e.g. every 20 minutes all samples that arrived at the desk of the analyzer are placed on the analyzer. The interval is in principle constant, but a natural disturbance was modeled by means of a normal distribution with standard deviation of 3 minutes. Figure 4-7 shows that a decrease in the batch intervals will decrease the TAT. This explains why despite the occasional malfunctioning of the DAX due to the use of short batch sizes and or short batching intervals the observed value of the TAT was lower compared to the simulated value of a normally functioning DAX (see Table 4-2).

Using the average batching interval of 10 minutes, the number of samples that will be placed in the analyzer was about 11 for the DAX, about 2 for the AXON and about 7 for the Immuno-1. Using the fixed batch size method, the average time between two successive batches will be about 40 minutes (batch size 50) for the DAX, about 24 minutes (batch size 5) for the AXON and about 60 minutes (batch size 45) for the Immuno-1 analyzer. A fixed batch size can be converted into an average batching intervals by dividing the operating time of the analyzer by the number of batches during 1 day. As an example, in Figure 4-8 the TAT values of both batching methods are presented for the DAX. It shows that on average the TAT values using both batching methods are the same. Graphs for the DAX and the Immuno-1 show similar results.

Figure 4-5 - Figure 4-7 show that an increase of the interval time results in an increase of the TAT. In all cases when the arrival pattern for the Immuno-1 was 


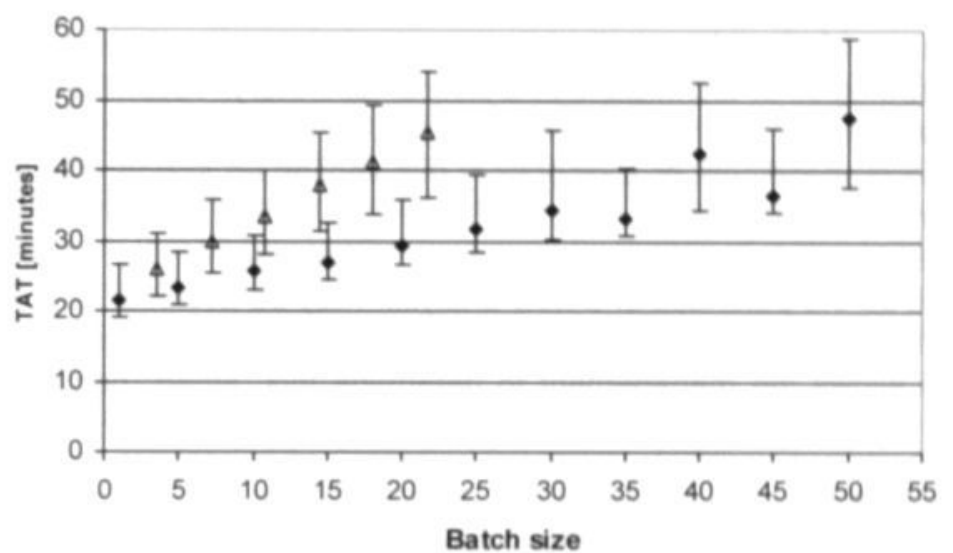

Figure 4-8: The median of the TAT for the DAX analyzer. The fixed batch sizes were converted into average batch interval values. Vertical lines indicate the $25^{\text {th }}$ and $75^{\text {th }}$ percentiles.

- interval, $\Delta$ size.

forced on the analyzers this resulted in the highest TAT values. The second highest values for the TAT were obtained when the arrival pattern for the DAX was forced on the analyzers (Figure 4-6 and Figure 4-7). The reason for this is that both patterns are peak patterns and a sizeable amount of the samples arriving within a peak had to wait before being processed, and this caused the TAT to rise. So nonpeak arrival patterns are preferred over peak arrival patterns because they result in lower TAT values.

The TAT value of a sample increases when the sample belongs to the first samples in a batch or when a re-run has to be carried out. A combination of these factors may result in the maximum TAT values shown in Table 4-3 and Table 4-4.

In general, an interval-based batching method is preferred over a fixed size batching method. Using the fixed interval method, the waiting time for samples to be placed in the analyzer can be controlled. Using the fixed batch size method this is not the case. In case of a steady sample flow, the fixed batch size method will approach the fixed interval method.

Small batch sizes or small batching intervals reduce the risk of high TAT values. Breakdowns affect only those samples that have to be processed. The number of those samples depends on the batch size or batching interval. If one uses a large batch size, in general there is a considerable number of samples waiting to be processed when the breakdown occurs. After a problem has been solved, larger batch sizes can be used to process the samples that are waiting. If the batch size is small only a few samples would be waiting to be processed at the moment the breakdown occurs.

The difference in staff utilization between the two batching strategies is caused by the time a technician needs to process the samples. It is assumed that the time needed to process a batch will have a constant and a variable part. The variable part is assumed be proportional to the number of samples to be processed in the batch. We did not include the time a technician needs to process a batch in our 
models.

Van Merode et al [9, 15] extensively investigated the application of different assignment strategies of technicians in a clinical laboratory. Technicians need to be at the analyzer when batching has to be done. If a certain batching strategy is chosen by the management of a laboratory this implies an assignment strategy for the technicians.

A "smart" batching strategy may result in a better use of the capacity of the analyzers and so the purchase of a new analyzer may be avoided. This is often the case when the utilization of an analyzer is near its maximum. A simulation model is a tool, which allows the management to determine this "smart" batching strategy. and by doing so save the cost of the purchase of a new analyzer.

\subsubsection{Applications}

A laboratory can assess the suitability of an analyzer using a (validated) simulation model. Using such simulation model one can predict the expected TAT using the corresponding arrival pattern of the samples and the proposed batching procedure. If the value of the TAT is higher than the value one wants to achieve with the new analyzer, one can change the batching procedure to decrease the TAT. If no satisfactory TAT can be achieved by changing the batching procedure, one has to consider another analyzer. The type of the batching procedure may also have implications for the number of technicians needed to operate the analyzer. For example, if one wants to use the fixed time interval batching method with an interval value of 30 minutes, the technician can perform some other tasks. If one uses a 5 minute interval this will not be the case. The number of technicians available may restrict the applicability of some batching procedures.

If one expects an increase in the number of samples to be analyzed and/or a change in the arrival pattern in the future, one can predict the TAT using the simulation model. Such knowledge is very useful when negotiating service levels.

In the past in situations such as mentioned above the TAT was only known after a new analyzer was installed (see for example Brombacher et al. [16]). By means of a simulation model one is able to predict these effects before the analyzer is purchased. Based on the results presented above it can be concluded that validated simulation models provide valuable information about the TAT for the corresponding analyzers. Using these simulation models, one is able to assess the effects of changes in the arrival pattern or batching strategy on the TAT.

Although in a manual clinical laboratory the shortest TAT is achieved in the random access mode, this will need higher staffing levels, so the fixed interval mode provides an efficient alternative that copes with a currently decreasing number of technicians. The fixed batch size method can be applied too, but this method needs a constant availability of technicians. Further research on the effects of a combination of interval batching and fixed batch size mode on the TAT and the criteria that determine when to switch between these batching methods has to be carried out. Such a study would come closer to daily practice. Simulation has proven to be a good tool to analyze the effects of batching methods on the TAT. 


\subsection{Conclusion}

A simulation model of three different analyzers to study the TAT could be constructed. These models can be validated. Simulation proved to be a good tool to analyze the TAT of analyzers in a clinical laboratory. It allows the user to study the effects of different batching strategies on the TAT. The effects of different sample arrival patterns on the TAT were also assessed by means of a simulation model. A validated simulation model of an analyzer is a valuable tool for the management of a laboratory to assess the influences of changing circumstances on the TAT.

\section{Acknowledgements}

We like to thank the personnel of the Centralized Department of Clinical Chemistry and Hematology Laboratory of the St. Elisabeth Hospital in Tilburg. The Netherlands for their cooperation during this study. The financial support of the Bayer Corporation, Tarrytown, USA is gratefully acknowledged.

\subsection{References}

[1] Slutsky AS, Cunningham AA. A simulation model for determination of the economic production rate of the auto analyzer system. Clin Biochem 1975;8:87-95

[2] Dankbar GC, Shellum JL, Bennet KE. The Use of Simulation to Evaluate Automated Equipment for Clinical Processing Laboratory. In: Swain JJ, Goldsman D, Crain RC, Wilson JR, eds. Winter Simulation Conference. Arlington VA: New York, NY : Institute of Electrical and Electronics Engineers, 1992:1065 - 70

[3] Vogt W, Braun SL, Hanssmann F, Liebl F, Berchtold G, Blaschke H, Hoffmann GE, Kloze S. Realistic Modeling of Clinical Laboratory Operation by Computer Simulation. Clin Chem 1994; $40: 922-8$

[4] Berchtold G, Hanssmann F, Liebl F, Blaschke H, Braun SL, Vogt W, Eckert M, Hoffmann G, Klose S. Simulation Modeling as a Tool to Evaluate Alternative Configurations of Clinical Laboratories. Simulation 1994;63:108-20

[5] Hoffmann GE. Computer Simulation as a Tool for Reorganization and Automation Planning. Journal of the Association for Laboratory Automation 1998;3:57-8

[6] Hoffmann GE, Slapansky P. Tlstak R. Redesigning your laboratory on a PC: New tools for simulation-based workflow analysis. Laboratory Robotics and Automation 1998;10:215-21

[7] Clark B, Crawford E. A Model to Predict Workflow Benefits of Radom Access and Consolidation. 3rd and 4th Technicon Immuno 1 International Symposia. Paris France, San Francisco, USA: Bayer Diagnostics, 1995:34-7

[8] van Merode GG. Decision support for clinical laboratory capacity planning [PhD. Thesis]. Maastricht: University of Limburg, 1994. 183 p

[9] van Merode GG, Hasman A, Derks J, Schoenmaker B, Goldschmidt HMJ. Advanced management facilities for clinical laboratories. Comput Methods Programs Biomed 1996;50:195-205

[10] Banks J. Principles of Simulation. In: Banks J, ed. Handbook of Simulation. New York: John Wiley \& Sons, 1998; 3-30.

[11] Sargent RG. Verification and validation of simulation models. In: Tew JD, Manivannan S, Sadowski DA, Seila AF, eds. Winter Simulation Conference. Orlando FL: New York, NY: Institute of Electrical and Electronics Engineers, 1994:77-87 
[12] MedModel homepage. ProModel Inc. http://www . promodel.com/products/medmodel

[13] van Merode GG, Hasman A, Derks J, Goldschmidt HMJ, Schoenmaker B, Oosten M. Decision support for clinical laboratory capacity planning. International Joumal of Biomedical Computing 1995:38:75-87

[14] Brombacher PJ, Marell GJ, Westerhuis LWJJM. Laboratory work flow analysis and introduction of a multi-functional analyser. Eur J Clin Chem Clin Biochem 1996;34:287-92 


\section{Application of computer simulation analysis to assess the effects of relocating a hospital phlebotomy department}

\section{Abstract \\ Background}

This study describes a systematic approach to assess the effects of relocating a hospital department.

\section{Methods}

Using the phlebotomy service as an example, computer simulation was applied to predict changes in performance indicators, such as patient turnaround time when planning a procedural and/or architectural re-design.

\section{Results}

Average patient turnaround time fell from 12 to 8 min enabling the department to cope with any increase in patient numbers.

\section{Conclusion}

This type of study can provide useful information in assessing the consequences of future changes in location of a hospital department. 


\subsection{Introduction}

Moving a hospital department to a new location almost always results in changes in operational procedures, as well as the physical layout. There may therefore be a need for a business process redesign (BPR) to obtain an optimally running department. BPR has been advocated as one of the research priorities in health informatics [1].

Because most health care organizations are complex it is difficult to assess the effects of a departmental relocation and/or redesign. In this article we present a systematic approach that can be used for this purpose. We use a computerized simulation technique to calculate performance measures under different circumstances and have investigated the usefulness of this approach.

In the provision of a phlebotomy service, managers aim to employ the minimum number of staff that can process patients in a timely cost-effective manner. In practice, a compromise is reached between the time a patient has to wait and the number of staff required. Additional constraints may include the quality of medical care delivered and work satisfaction. In The Netherlands and in many other countries, the phlebotomy service may be the first service used by patients when they visit hospital. Therefore the impression this service makes on the patients is important for the hospital as a whole.

To assess the performance of the phlebotomy service an indicator is needed which can be used to compare different situations. Commonly used standards are the average turnaround time (TAT), costs per blood draw, patient satisfaction, average quality of the blood samples and the error-rate of the technicians. In this study, the average turnaround time is the main performance indicator used. This was also used by Klafehn and Connolly [2], who used a simulation model to assess the number of staff needed for a new phlebotomy service to obtain reasonable TATs. They distinguished between clerical and technical staff and studied the impact of employing cross-trained clerical staff. Who, they believed, would make the laboratory more efficient. The results of the study were used to convince the management of the presence of bottlenecks that had already been observed by the technical staff. They did not study layout or procedural changes.

In the manufacturing industry simulation is used to analyse the flow in a designed layout of a plant [3]. Slack et al. [4] argue that simulation is one of the most powerful tools for designing a process.

The phlebotomy service in the present study is located in a general hospital. Users of this service include medical specialists from the local hospital and regional general practitioners. Because of a planned renovation of the hospital, the phlebotomy service will be moved to a new location. This necessitates the development of a floor plan of the phlebotomy service at the new location. The management of the hospital had determined to which location the blood drawing service had to move, therefore several design parameters such as dimensions and location of the entrance were already defined. The relocation provided an opportunity to introduce new technologies. It is expected that the number of patients that visit the phlebotomy service will rise in the near future, as more patients visit the hospital. Before constructing the new facility it is important to know whether the 
proposed layout will be an improvement over the current situation, given the expected trends.

\subsection{Method}

\subsubsection{Delineation of problem}

This study deals with the effects of both the redesign of the architectural layout and changes in organizational procedures on selected performance indicators of the

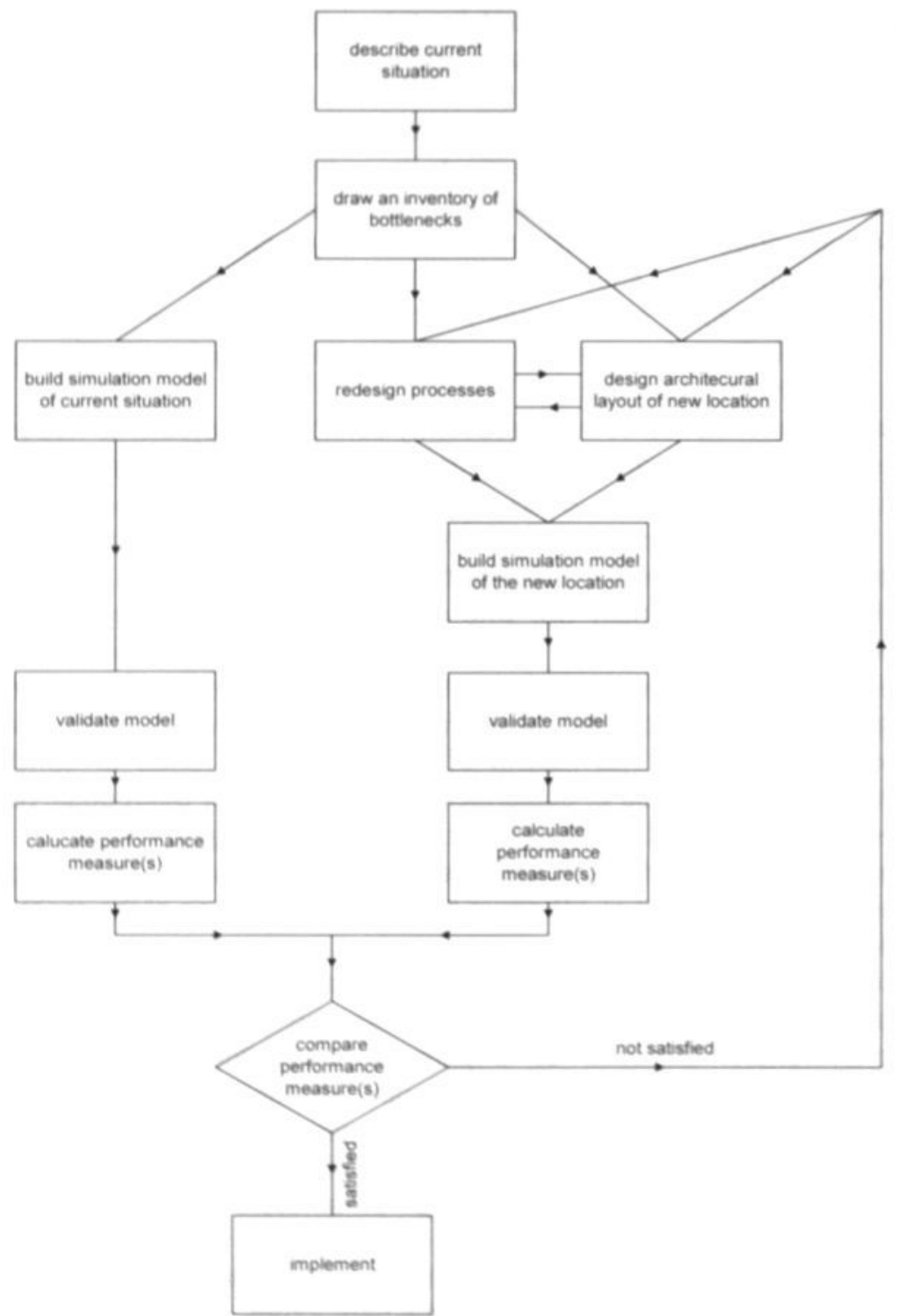

Figure 5-1: The process of assessing the effects of relocating a department of a health care organisation. 
phlebotomy service.

Figure 5-1 illustrates the process of analysing the effects of a relocation of a department within a hospital setting. First, the different processes carried out in the current situation are described and the observed TAT of the patients is measured. On the basis of these data, a simulation model of the current situation is developed. In the next step an inventory of existing bottlenecks is made. The processes are now redesigned in such a way that bottlenecks are removed or reduced and a floor layout of the future location is made. After finishing these activities, a simulation model of the future phlebotomy service is developed. Using the simulation models, performance measures may be calculated for both the current and proposed layout. These performance measures can be compared and a decision made either to implement the proposed processes and architectural layout or create another model. This procedure is repeated until acceptable results are obtained.

\subsubsection{General approach to modelling}

The technique used to compare the current and proposed layout is simulation. Simulation is defined as ... "the imitation of the operation of a real-world process or system over time". While running a simulation model, an artificial history of the system is created. A simulation model can be used as a tool for predicting the impact of a change in an existing system and can provide an answer to "what if" questions concerning the behaviour of the system under study. It is one of the most widely used and accepted tools in operational research and systems analysis. Some of the advantages of simulation are (see Banks [5] for a extensive list):

- The effects of new organizational or operational procedures can be assessed without changing the operations of the real system.

- Bottlenecks can be identified (with simulation) and a solution tested without changing the real system.

- $\quad$ "What if ?" analyses can be performed and the results analysed.

Besides these advantages there are also some disadvantages (see Banks [5] for a extensive list):

- Model building is half an art, half a science [6]. Model building can be time consuming. The modeller has to be familiar with the topic under study and spend time talking with those more familiar with the issues.

- People with (some) simulation background are needed to perform the simulation study. However, simulation software is user-friendly; the skills needed today are less than those needed 10 years ago.

- A simulation experiment is an experiment in which a model (always a simplification) of an organisation is used. It is not a real-life experiment.

A simulation study consists of several steps $[7,8]$. Two important steps are verification and validation. In verification, the operation of the model is investigated. Does the proposed model run properly? In the validation step, the results of the simulation model are compared with actual observations of the modelled system.

When using the validated model for investigating new situations in which a modified simulation model is used, one may expect that the outcome of a simulation is also valid for the new situation. Every simulation model has a certain "bandwidth" within which modifications do not influence the validity of the model. However, there may 
be changes in the model that may invalidate it and this is not always predictable. It is therefore always useful to report not only how the model was validated but also whether the predictions for the new situation were correct.

There are several methods that may be used to validate a simulation model: animation and historical data validation are two examples [9, 10]. In general, a validated simulation model can be used to analyse different scenarios and therefore it can be used as a decision support tool.

A simulation model of patient flow in a health care organisation can be characterized as a queuing model [11]. Using discrete event simulation, utilization of resources and average service times can be calculated. Different queuing principles like "first in first out" or "last in first out" can be tried out.

In this study MedModel [12] was used to implement the simulation model. MedModel is a discrete event simulation package with a graphical user interface. It is based on the description of processes in a health-care facility. The different locations are depicted with icons. The patients take part in various processes and patient activities and the use of specific resources (e.g. the blood-drawing by a nurse in the cubicle) form part of the process description. The duration of these activities is described by statistical distribution functions. The patients move between the various locations on so called "path networks", which are an implementation of queuing networks. During simulation, animation visualizes the movement of the patients through the organization.

\subsubsection{Development of the phlebotomy service model}

The floor plan of the current phlebotomy service is shown in Figure 5-2.

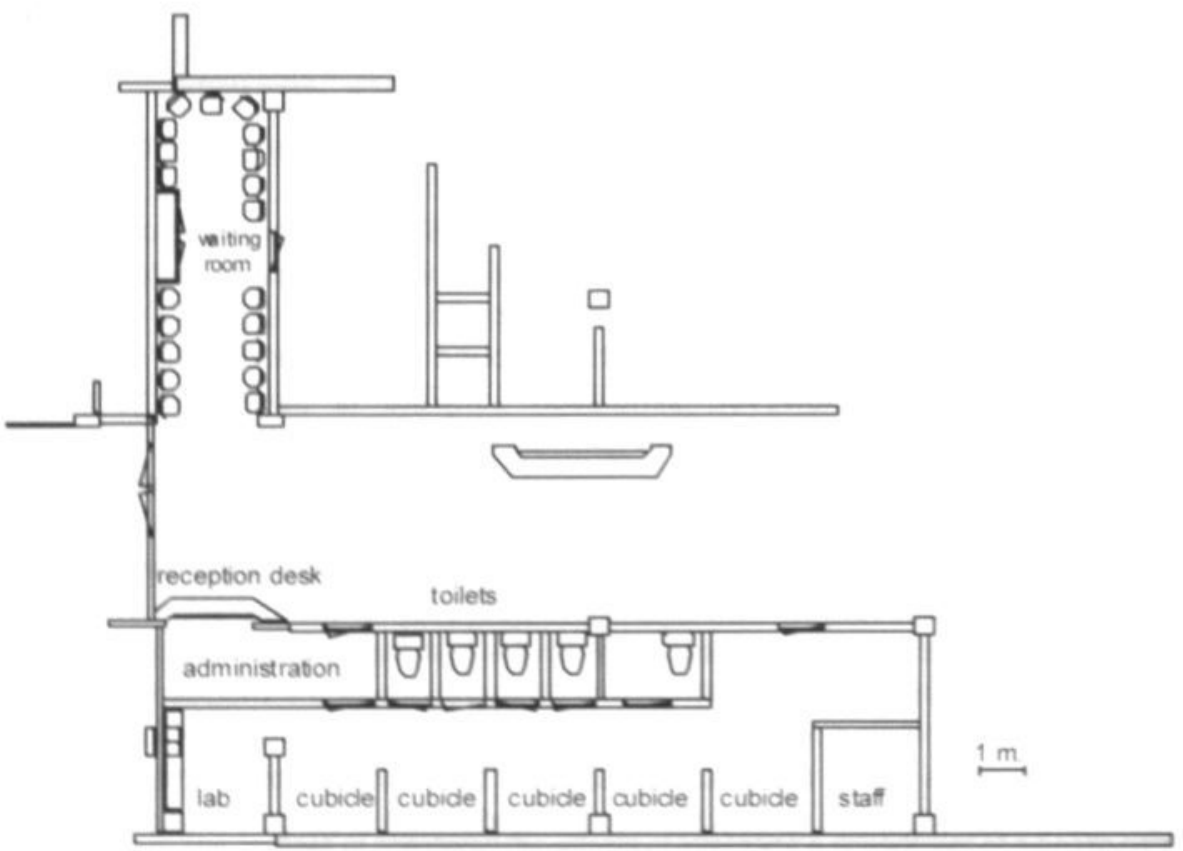

Figure 5-2: Floor plan of the current phlebotomy service location. 
The department consists of nine employees [5.8 full-time equivalents (FTE)] including nurses who also take blood from the patients at the wards. At any one time a maximum of five nurses (4.5 FTE) provide the service, one of them continuously manning the reception desk. The other nurses work in the cubicles, in which the blood is taken. Departmental opening hours are from 0800 until $1700 \mathrm{~h}$ and on average, about 271 patients visit the department daily. Patients are referred to the department from outpatient clinics or by a general practitioner. At time $T 1$, the patient arrives in the department. At time $T 2$, they report to the reception desk where they identify themselves and hand over the request form. On average this takes $48 \mathrm{~s}$. Only one patient at a time can be served at the reception desk. After a nurse has checked the forms, the patient is sent to the waiting room, which has a capacity of 18 chairs. In instances where blood is not required, patients only hand over urine or faecal samples and then leave.

When a nurse is available, the patient is guided from the waiting room to one of the four cubicles or to one of the five toilets at time T3. Depending on the request, the patient has to give blood and/or urine. The patient leaves the service at time T4. If the request is a STAT, a nurse brings the sample directly to the clinical laboratory, located at a distance of 279 meters. On average, the total distance a nurse walks per patient is 37.5 meters (STAT samples not included). There is no difference in the procedure between patients referred from outside the hospital and patients referred from the outpatient clinic.

A brief international survey showed that the process described above is very similar in five European countries. In some countries the process of blood drawing is not centralised; it is performed in various departments within the hospital.

A workflow analysis was carried out. During one working day all patients who visited the phlebotomy service had their times of arrival at the different locations recorded. For all the patients the test request forms were examined and the different request types were scored.

The following bottlenecks in the system were identified by means of the workflow analysis [13] :

- STAT samples are time consuming for the nurses; the samples have to be directly taken to the laboratory.

- The process of calling a patient and guiding him/her from the waiting room to the cubicles by a nurse is time consuming.

- Too little capacity is available at the reception desk (only one nurse).

- There is little privacy at the reception desk.

Based on these observations a number of changes were suggested for the new phlebotomy service. The introduction of a pneumatic tube to transport samples to the laboratory would reduce the time wasted by nurses in transporting STAT samples to the laboratory. At the counter a second workplace will be created, which unlike the first counter will not be constantly attended; but, if there were patients waiting in the queue, the first nurse that was available would attend the second counter instead of going to patients in the waiting room.

A callboard would direct patients to a specific cubicle or toilet, obviating the need for the nurse to guide the patient. However, it is assumed that currently, on average, 


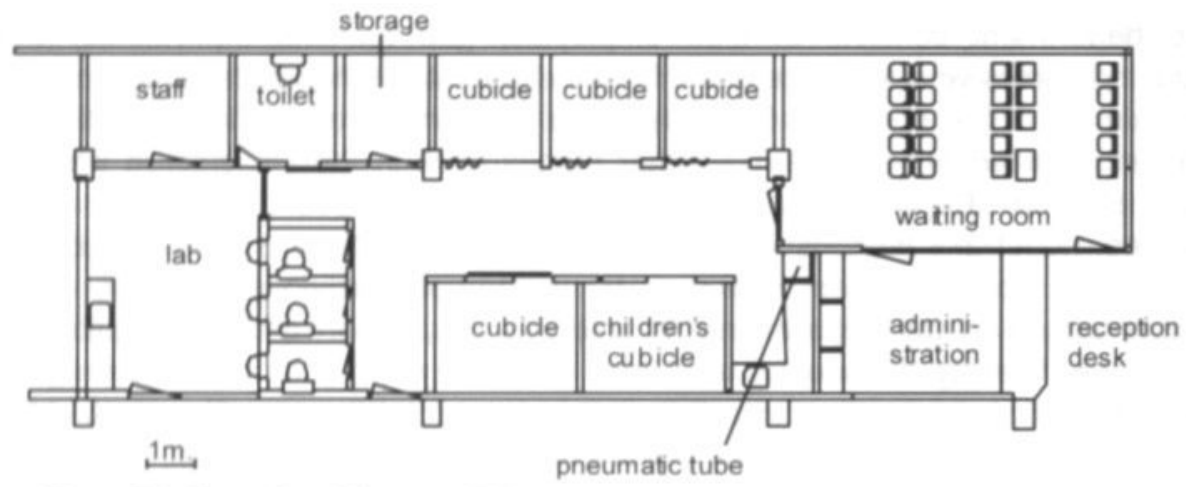

Figure 5-3: Floor plan of the new phlebotomy area.

$50 \%$ of the patients have to be accompanied by a nurse from the waiting room to the cubicle or toilet because of their mental or physical condition.

\subsubsection{Implementation of the simulation models}

While building the model several decisions were made:

- Patient arrivals were modelled using an arrival cycle. The arrival cycle, a MedModel phrase, indicates the measured percentage of patients arriving in 30 min time windows (Figure 5-4). Within these time frames the arrivals are assumed to be uniformly distributed.

- No distinction was made between individual nurses. All nurses performed all tasks within a task specific time-frame.

- There were eight different procedures in the cubicle and one (urine collection) in the toilets.

- TATs were calculated only for patients who visited a cubicle and/or a restroom.

- Coffee breaks and lunch breaks are included in the model. These occur at fixed times although all on-going procedures are completed before breaks are

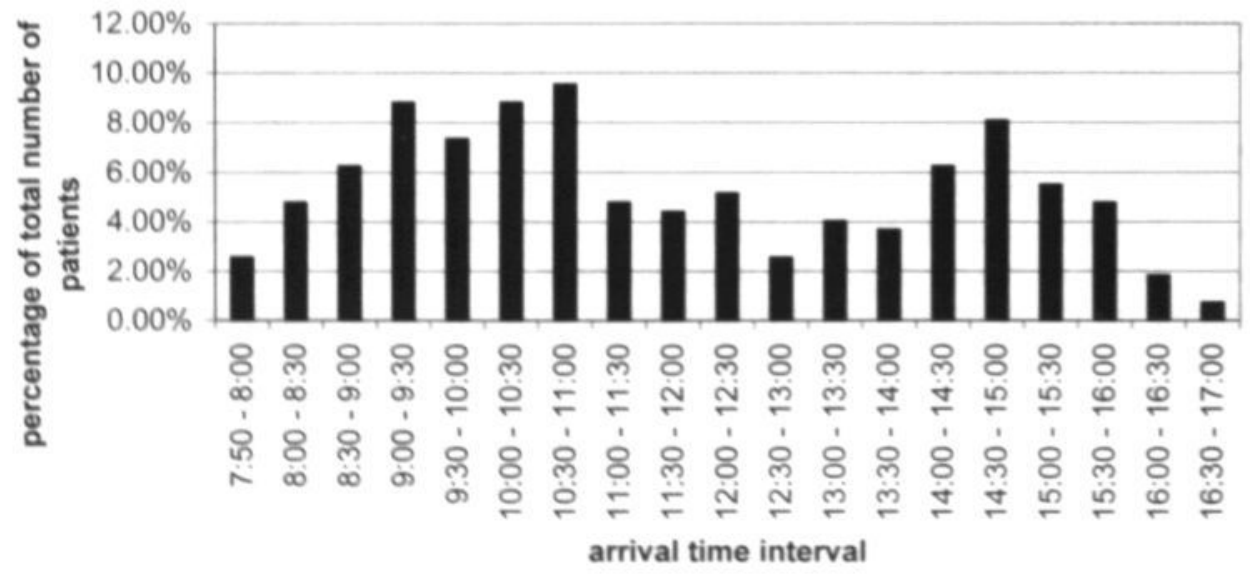

Figure 5-4: Arrival cycle of patients at the phlebotomy area. The percentage of the total number of patients arriving at the area is indicated for each time-frame. 
taken.

- The time taken for each patient consultation at the reception desk depends on the number of patients in the queue. For example individuals in a queue of ten patients are more likely to ask fewer questions than those in a queue of two because they would delay mere people by holding up a longer queue. If there are no patients in the queue, then individuals may ask more elaborate questions. Nurses behaved similarly when answering the patients' questions. They took longer to answer questions from patients who were in short queues than from patients in long queues.

The time taken to process 53 patients at the reception desk was measured together with the number of patients in the queue when the first patient was processed. Three situations were identified depending on whether there were (1) zero, (2) one or two, or (3) more than two additional patients in the queue. A statistical tool included in MedModel was used to fit these data with suitable probability distribution functions. Based on the aoodness-of-fit asvmmetric distributions like Weibull, Pearson V and Pearson VI (see Law and Kelton [7] for more details on distribution functions and about fitting of distributions) were chosen and their parameters were obtained.

- Figure 5-2 shows the floor plan for the simulation. The dimensions of the cubicles are known, and the pathways were scaled to real-life.

- In the future situation the medical laboratory will use new equipment resulting in a reduction of the number of tubes that need to be collected from the patient and the number of forms that need to be completed. This will reduce the time spent in the cubicle.

\subsubsection{Model validation}

To validate the model, the output of the simulation model is compared with the data of the actual system [7]. Validation of the model is an important step in any simulation study and several methods have been described to validate a simulation model $[5,9,10]$. In one of these[9], the author stresses that actual results (including determined variances) should be published to convince users of the correctness of the model and its results. In addition, as explained earlier, it would be good to show that the suggestions of a validated simulation model for a new situation are correct. The outcomes of decisions based on simulations are usually not reported in the literature, although the outcome can shed additional light on the adequacy of a model. It demonstrates the power of simulation as a tool for redesign.

\subsubsection{Experiments}

To assess the predictive power of our simulation model a new situation was created by the introduction of a second workplace at the reception desk and this was then modelled. The effects on the TATs were simulated and compared with observed values (experiment 0 ). In Situation $A$ the number of workspaces is one and in Situation B the number of workspaces is two; in both situations the layout of the current department is used. Situation B is the experimental situation specially created for this study. When the observations regarding situation B were made new equipment was in use in the laboratory. As this required fewer tubes and request 
Table 5-1: Summary of main differences between Situation A, B C and D.

\begin{tabular}{|c|l|l|l|l|}
\hline Situation & Layout & $\begin{array}{l}\text { Number of work- } \\
\text { spaces at desk }\end{array}$ & $\begin{array}{l}\text { STAT samples to } \\
\text { laboratory }\end{array}$ & $\begin{array}{l}\text { Process time in } \\
\text { cubicle }\end{array}$ \\
\hline A & Figure 5-2 & 1 & walking & normal \\
\hline B & Figure 5-2 & 2 & walking & reduced \\
\hline C & Figure 5-3 & 1 & pneumatic tube & reduced \\
\hline D & Figure 5-3 & 2 & pneumatic tube & reduced \\
\hline
\end{tabular}

forms, the process times in the cubicles were sometimes reduced.

In experiment 1 the effect of the new layout on the TAT was investigated. The need for one or two workspaces at the reception desk in the new layout was also ascertained. In Situation C the future layout was used with one workspace at the desk; in Situation D another workspace is added. The number of patients was kept fixed at the current level. In this way both the effect of the new layout and the presence of one or two workspaces could be studied. The main characteristics of Situation A - D are summarized in Table 5-1.

In experiment 2 the number of patients was varied to study the effects on the TAT when varying numbers of patients visit the phlebotomy department. The number of staff was fixed at the current value.

The duration of patient contact at the reception desk influences the number of patients in the queue at the counter. If for some reason the counter is staffed with non-specialized personnel, the duration of the contacts at the counter will likely increase. On the other hand if the request forms are printed out and the nurses do not have to identify what is written on the request form a decrease of the duration of the contact with the patient at the counter can be expected. To investigate these effects in experiment 3 the minimum value of the time spent at the counter (one of the parameters of the distribution) was varied for both the current and the future layout (one and two workspaces at the counter). It is assumed that the shape of the probability distribution describing the contact time remains the same.

Taking into account the frequencies of the different types of phlebotomy requests for different laboratory disciplines and the average time needed for carrying out each of these request types, the average TAT at the cubicle and/or lavatories is $4 \mathrm{~min} 19 \mathrm{~s}$. The average time a patient spends at the counter was $46 \mathrm{~s}$. Therefore, a patient will on average spend $5 \mathrm{~min} 5 \mathrm{~s}$ in the phlebotomy department (walking and waiting not included). If one accepts the criterion that, on average, a patient should not wait longer than the time needed to be served $(5 \min 5 \mathrm{~s})$, the average TAT at the phlebotomy service should be equal to or less than, $10 \mathrm{~min}$ and $10 \mathrm{~s}$.

\subsection{Results}

\subsubsection{Validation of the model}

Two methods were used to validate the model of situation $A$, one based on animation and validated by nursing staff and the other using actual historical data. 
Table 5-2: Observed and simulated turn-around times ( $\min : \mathbf{s}$ ) for the current and future layout. $T 2-T 1$ is calculated for all patients; $T 3-T 2, T 4-T 3$ and $T 4-T 1$ are calculated only for patients who visited a cubicle or a toilet.

\begin{tabular}{|c|r|r|r|r|r|r|}
\hline \multirow{2}{*}{$\Delta t$} & \multicolumn{2}{|c|}{$\begin{array}{c}\text { Observed } \\
\text { Situation A }\end{array}$} & \multicolumn{2}{c|}{$\begin{array}{c}\text { Simulated } \\
\text { Situation A }\end{array}$} & \multicolumn{2}{c|}{$\begin{array}{c}\text { Simulated } \\
\text { Situation D }\end{array}$} \\
\cline { 2 - 7 } & Mean & \multicolumn{1}{c|}{ SD } & Mean & \multicolumn{1}{c|}{ SD } & Mean & \multicolumn{1}{c|}{ SD } \\
\hline$T 2-T 1$ & $2: 19$ & $2: 12$ & $1: 15$ & $1: 44$ & $0: 26$ & $0: 30$ \\
\hline$T 3-T 2$ & $5: 40$ & $4: 39$ & $6: 29$ & $5: 35$ & $3: 41$ & $3: 58$ \\
\hline$T 4-T 3$ & $4: 12$ & $2: 24$ & $4: 20$ & $1: 05$ & $3: 49$ & $1: 04$ \\
\hline$T 4-T 1$ & $11: 52$ & $5: 59$ & $12: 04$ & $6: 19$ & $7: 57$ & $4: 18$ \\
\hline
\end{tabular}

The observed data were obtained during one day. In total 20 simulation runs were carried out (the statistics are presented in Table 5-2). In each simulation run one day is simulated in which 271 patients arrive at the blood drawing service according to the arrival pattern shown in Figure 5-4. Average values of e.g. T4-T1 over all runs are calculated by taking into account only those patients who actually visited a cubicle and/or a lavatory (so excluding patients that only handed over urine or faecal samples).

A histogram of the observed and simulated TATs is presented in Figure 5-5 and the distributions of $T 4-T 1$ do not differ significantly $\left(\chi^{2}=12.36\right.$, df $\left.=6, P=0.95\right)$. The average observed and simulated values of $T 4-T 1$ do not differ significantly too $(\Delta=12 \mathrm{~s}, t=0.52$, df $=5620, P=0.80$; two sample $t$-test). Based on these results it is concluded that the model of Situation $A$ is valid.

The models of the future layout (situations $C$ and D) were validated using animation.

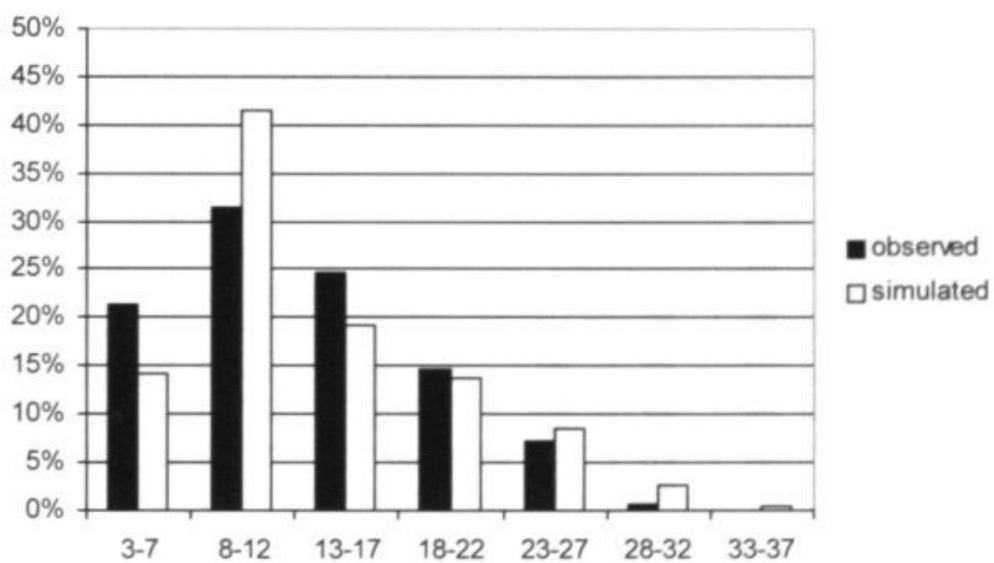

Figure 5-5: Frequency distribution of the observed and simulated values of turn-around time (TAT) (T4 - T1) in situation A. Observed data are obtained from observations of 261 patients. Simulated data are obtained from 20 simulation runs (days). On each simulated day 270 patients arrive at the phlebotomy service. 
Table 5-3: Observed and simulated data (min:s) for situation A (current layout with one workspace) and situation B (current layout with two workspaces at the desk). Simulated data are based on 20 runs. The observed values in Situation A are based on 256 observations made on one single day. The observed values in Situation B are based on 62 observations made during three days. $S D=$ standard deviation .

\begin{tabular}{|c|r|r|r|r|r|r|r|r|}
\hline & \multicolumn{2}{|c|}{$\begin{array}{c}\text { Situation A } \\
\text { Observed }\end{array}$} & \multicolumn{2}{c|}{ Simulated } & \multicolumn{2}{c|}{$\begin{array}{c}\text { Situation B } \\
\text { Observed }\end{array}$} & \multicolumn{2}{c|}{ Simulated } \\
\cline { 2 - 9 }$\Delta t$ & Mean & \multicolumn{1}{c|}{ SD } & Mean & SD & Mean & SD & Mean & SD \\
\hline$T 2-T 1$ & $2: 19$ & $2: 12$ & $1: 15$ & $1: 44$ & $0: 57$ & $1: 11$ & $0: 32$ & $0: 36$ \\
\hline$T 3-T 2$ & $5: 40$ & $4: 39$ & $6: 29$ & $5: 35$ & $6: 19$ & $6: 42$ & $5: 22$ & $4: 49$ \\
\hline$T 4-T 3$ & $4: 12$ & $2: 24$ & $4: 20$ & $1: 05$ & $3: 11$ & $1: 22$ & $3: 51$ & $1: 05$ \\
\hline$T 4-T 1$ & $11: 52$ & $5: 59$ & $12: 04$ & $6: 19$ & $10: 26$ & $7: 09$ & $9: 37$ & $5: 10$ \\
\hline
\end{tabular}

\subsubsection{Simulation experiments}

For each experiment, 20 simulation runs were carried out. During each day 271 patients visited the phlebotomy area.

\subsubsection{Experiment 0}

In Experiment 0 the simulated value of $T 4-T 1$ in situation B was compared with the observed values of T4-T1 in the new situation. The observations in situation B are sampled during morning hours at four different days. The average of the simulated and observed values of T4-T1 are shown in Table 5-3 and they do not differ significantly $(\Delta=49 \mathrm{~s}, t=1.24, \mathrm{df}=5398, P=0.80$; two-sample $t$-test). A histogram of the observed and simulated values of T4-T1 in situation B is shown in Figure 5-6.

The distributions of the observed and simulated values of T4-T1 do not differ

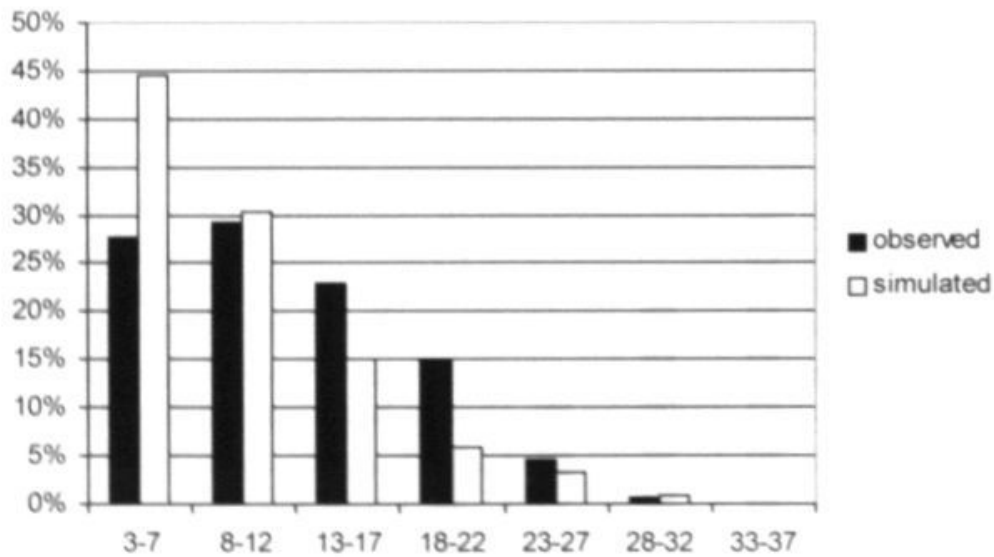

Figure 5-6: Frequency distribution of the observed and simulated values of the turn-around time (TAT) (T4 - T1) in situation B (current layout with two workspaces at the desk). Observed data are obtained from 62 observations. Simulated data are derived from 20 simulation runs (days). On each simulated day 270 patients arrive at the phlebotomy service. 
Table 5-4: Simulated turn-around times (min:s) in situation A (current layout), C and D (future layout with one workspace at the counter and with two workspaces at the counter. respectively). $T 2-T 1$ is calculated for all patients; $T 3-T 2, T 4-T 3$ and $T 4-T 1$ are calculated only for patients who visited a cubicle or a toilet.

\begin{tabular}{|c|r|r|r|r|r|r|}
\hline \multirow{2}{*}{$\Delta t$} & \multicolumn{2}{|c|}{ Situation A } & \multicolumn{2}{c|}{ Situation C } & \multicolumn{2}{c|}{ Situation D } \\
\cline { 2 - 7 } & Mean & \multicolumn{1}{c|}{ SD } & Mean & \multicolumn{1}{c|}{ SD } & Mean & \multicolumn{1}{c|}{ SD } \\
\hline$T 2-T 1$ & $1: 15$ & $1: 44$ & $1: 06$ & $1: 10$ & $0: 26$ & $0: 30$ \\
\hline$T 3-T 2$ & $6: 29$ & $5: 35$ & $3: 20$ & $3: 34$ & $3: 41$ & $3: 58$ \\
\hline$T 4-T 3$ & $4: 20$ & $1: 05$ & $3: 49$ & $1: 05$ & $3: 49$ & $1: 04$ \\
\hline$T 4-T 1$ & $12: 04$ & $6: 19$ & $8: 15$ & $4: 10$ & $7: 57$ & $4: 18$ \\
\hline
\end{tabular}

significantly $\left(\chi^{2}=13.96\right.$, $\left.\mathrm{df}=6, P=0.98\right)$.

By comparing situation A and situation B by means of simulation the combined effect on the TAT of a second reception desk and the requirement for less tubes to be taken and less paperwork to be completed is shown. The TAT in situation B is significantly lower than in situation $A(\Delta=2 \min 27 \mathrm{~s}, t=21.95$, df $=10697$, $P<0.001$; two sample $t$-test).

\subsubsection{Experiment 1}

Experiment 1 dealt with the question whether the new layout would increase efficiency. Therefore the results of situation A and situation $\mathrm{C}$ were compared (see Table 5-4). The average TAT per patient was $3 \mathrm{~min} 49 \mathrm{~s}$ shorter in situation C. The average TATs (T4 - T1) of situation A and situation C differ significantly $(\Delta=3$ min 49s, $t=36.93$, df = 10692, $P<0.001$; two sample $t$-test).

The mean simulated TATs for situations B (see Table 5-3) and D (see Table 5-4) also differ significantly $(\Delta=1 \mathrm{~min} 40 \mathrm{~s}, t=15.09$, df $=10679, P<0.001$; two sample $t$-test). The TAT was also studied as a function of the arrival time of the patient. The relationship between the TAT and the arrival time at the department are presented for situations $A$ and $D$ in Figure 5-7.

It can be deduced from Figure 5-7 that the spread in the TATs in the future layout as function of the time of the day is less than the spread in the TATs in the current layout.

Another performance measure is the utilization of nursing time. Utilization is defined as the percentage of the scheduled time a nurse is 'working'. A high utilization means that the nurses do not often have to wait for new patients. The men utilization of the nurses is presented in Table 5-5. The differences $(\Delta)$ in terms of percentage utilization between the current and new layout are statistically significant (A - C: $\Delta=12.73 \%, t=34.27, \mathrm{df}=38, P<0.001 ; \mathrm{A}-\mathrm{D}: \Delta=12.11 \%, t=31.44$, df $=38, P<0.001$; B $-\mathrm{C}: \Delta=6.80 \%, t=21.49$, df $=38, P<0.001$; B $-\mathrm{D}$ : $\Delta=6.18 \%, t=18.59, \mathrm{df}=22, P<0.001$; two-sample $t$-test).

A different layout will also affect the percentage of the scheduled time nurses are walking. In situations $C$ and D they do not have to take STAT requests to the laboratory and they do not have to guide all patients from the waiting room to the cubicles or restrooms. The values of this performance measure are shown in Table 5-5. The percentage of time the nurses are walking as part of their work is almost 


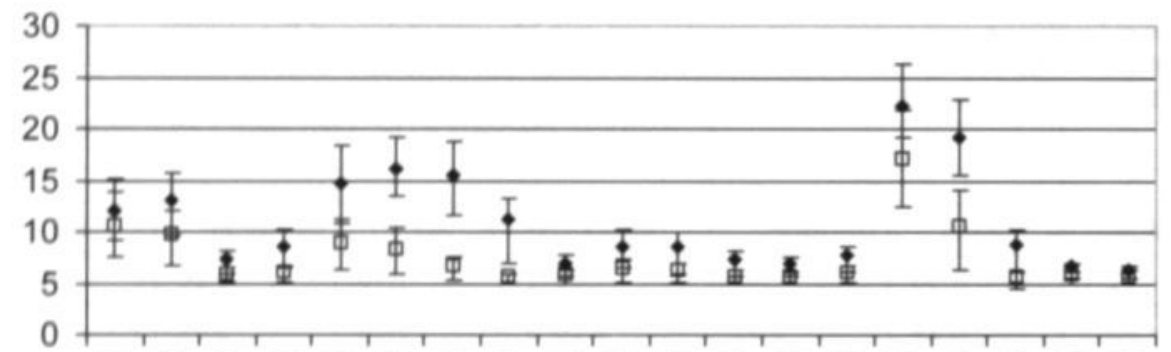

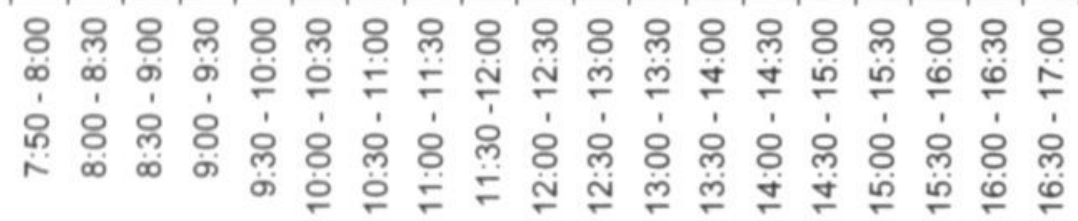

- Situation A ם Situation D

Figure 5-7: Simulated turn-around time (TAT) (in minutes) as a function of the arrival time for situation $A$ and situation D. The lower end of the vertical lines indicate the value of the 25 th centile; the top indicates the value of the 75 th centile. Simulated data are obtained from 20 runs.

the same in situation $C$ as in situation $D$. Situation A differs significantly from situation C $(\Delta=2.29 \%, t=14.97, \mathrm{df}=38, P<0.001$; two sample $t$-test); situation B also differs significantly from situation $\mathrm{C}(\Delta=3.08 \%, t=25.03, \mathrm{df}=38, P<0.001$; two sample $t$-test).

\subsubsection{Experiment 2}

In experiment 2, the effects on the TAT of an increase or decrease in the number of patients per day was investigated. The number of patients was decreased and increased in $10 \%$ increments. The results are shown in Figure 5-8. For practical reasons the 25 th and 75 th centile values are presented.

\subsubsection{Experiment 3}

In experiment 3 the effect of changes in the minimum value of the contact-time at the reception desk upon TAT were studied. The results are shown in Table 5-6.

Compared to the current minimum value of the contact time, a $30 \mathrm{~s}$ increase will cause a $40 \%$ (from $12 \mathrm{~min} 4 \mathrm{~s}$ to $16 \mathrm{~min} 53 \mathrm{~s}$ ) increase in the average TAT. In the future layout, a $30 \mathrm{~s}$ increase of the minimum time will cause an increase in the average turnaround time of $34 \%$ (from $8 \mathrm{~min} 15 \mathrm{~s}$ to $11 \mathrm{~min} 3 \mathrm{~s}$ ) in situation $\mathrm{C}$ and of $22 \%$ (from $7 \mathrm{~min} 57 \mathrm{~s}$ to $9 \mathrm{~min} 49 \mathrm{~s}$ ) in situation $\mathrm{D}$.

Table 5-5: Utilization of nurses and percentage of time walking in the different situations. Data based on 20 simulated days.

\begin{tabular}{|l|r|l|l|l|l|l|l|l|}
\hline & \multicolumn{3}{|l|}{ Situation A } & \multicolumn{2}{l|}{ Situation B } & \multicolumn{2}{l|}{ Situation C } & \multicolumn{2}{l|}{ Situation D } \\
\cline { 2 - 10 } & \multicolumn{1}{|c|}{ Mean } & SD & Mean & \multicolumn{1}{l|}{ SD } & Mean & \multicolumn{1}{l|}{ SD } & \multicolumn{1}{l|}{ Mean } & \multicolumn{1}{l|}{ SD } \\
\hline Utilization & $75.22 \%$ & 1.45 & $69.29 \%$ & 1.16 & $62.49 \%$ & 0.81 & $63.11 \%$ & 0.93 \\
\hline \% walking & $9.06 \%$ & 0.66 & $9.85 \%$ & 0.52 & $6.77 \%$ & 0.18 & $6.77 \%$ & 0.15 \\
\hline
\end{tabular}


Table 5-6: Turn-around time of patients and utilization of nurses as function of the change in the minimum value of the contact time at the counter in situation $A, C$ and D. Standard deviations are shown between parentheses.

\begin{tabular}{|c|c|c|c|c|c|c|c|c|c|c|c|c|}
\hline & \multicolumn{12}{|c|}{ Change in minimum contact time ( $\mathrm{min}: \mathrm{s}$ ) } \\
\hline & \multicolumn{4}{|c|}{ Situation A } & \multicolumn{4}{|l|}{ Situation C } & \multicolumn{4}{|c|}{ Situation D } \\
\hline & $-0: 06$ & $0: 06$ & $0: 18$ & $0: 30$ & $-0: 06$ & $0: 06$ & $0: 18$ & $0: 30$ & $-0: 06$ & $0: 06$ & $0: 18$ & $0: 30$ \\
\hline$T 3-12$ & $\begin{array}{r}6.59 \\
(6: 08) \\
\end{array}$ & $\begin{array}{r}6: 17 \\
(6: 04)\end{array}$ & $\begin{array}{r}8: 35 \\
(6: 56)\end{array}$ & $\begin{array}{r}9: 23 \\
(7: 13)\end{array}$ & $\begin{array}{r}3: 04 \\
(3: 20)\end{array}$ & $\begin{array}{r}3: 43 \\
(3: 52)\end{array}$ & $\begin{array}{r}3: 56 \\
(4: 07)\end{array}$ & $\begin{array}{r}4: 23 \\
(4: 29)\end{array}$ & $\begin{array}{r}3: 32 \\
(4: 08)\end{array}$ & $\begin{array}{r}4: 07 \\
(4: 19)\end{array}$ & $\begin{array}{r}4: 37 \\
(4: 29)\end{array}$ & $\begin{array}{r}5: 22 \\
(4: 54)\end{array}$ \\
\hline $\begin{array}{l}\text { Utiliza- } \\
\text { tion of } \\
\text { nurses } \\
(\%)\end{array}$ & $\begin{array}{l}74.71 \\
(1.73)\end{array}$ & $\begin{array}{l}76.33 \\
(1.07)\end{array}$ & $\begin{array}{l}79.14 \\
(1.05)\end{array}$ & $\begin{array}{l}81.79 \\
(1.97)\end{array}$ & $\begin{array}{l}60.99 \\
(1.16)\end{array}$ & $\begin{array}{l}63.70 \\
(0.90)\end{array}$ & $\begin{array}{l}66.31 \\
(0.64)\end{array}$ & $\begin{array}{l}68.21 \\
(0.77)\end{array}$ & $\begin{array}{l}61.30 \\
(0.89)\end{array}$ & $\begin{array}{l}64.28 \\
(0.90)\end{array}$ & $\begin{array}{l}67.13 \\
(0.81)\end{array}$ & $\begin{array}{l}69.70 \\
(0.97)\end{array}$ \\
\hline
\end{tabular}


(a)

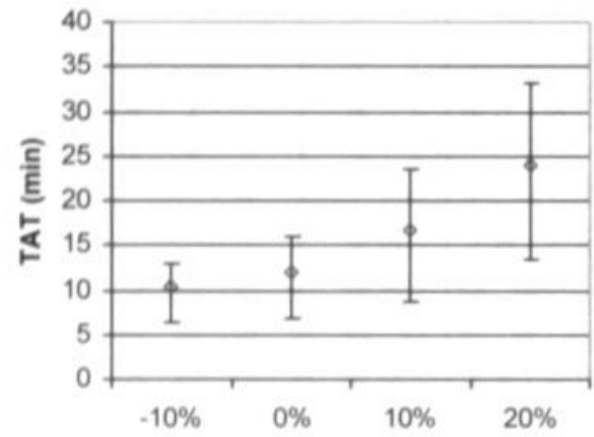

Change in daily patients numbers (b)

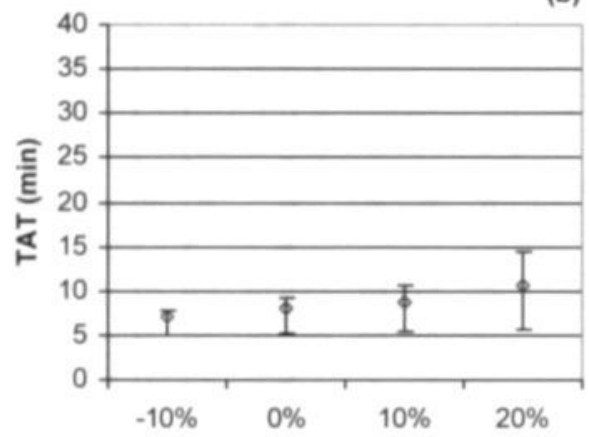

Change in daily patients numbers

Figure 5-8: The average turn-around time (TAT) at the phlebotomy department ( $T 4-T 1$ ) as a function of the number of patients for (a) situation $A$ and (b) situation D. The lower point of the vertical lines represent the 25 th centile; the upper point represents the 75 th centile.

\subsection{Discussion and conclusions}

To assess the effects of a relocation of a department, the steps described in Figure 5-1 were carried out using the phlebotomy service as an example. The TAT of patients at the department was chosen as the main performance indicator. The data relating to the status quo were collected during one working day. During this day no irregularities occurred and it was classified by the nursing staff as a normal day. Both data analysis and model building took about two weeks. The implementation of a queuing model in MedModel proved to be successful.

\subsubsection{Validation of the simulation model}

The results of the historical data validation showed that the values of the turnaround time obtained by simulating the model were in agreement with the data observed. The differences between the observed values of $T 2-T 1$ and $T 3-T 2$ and the simulated values (see Table 5-2) can be explained by the fact that patients have to cross the queue to go to another department (see Figure 5-2), which leads to delays. Often, another person accompanied a patient so there are more people present in the small area in front of the reception desk which disturbs the flow of patients. These circumstances are not included in the simulation model.

Klafehn and Connolly [2] only used animation to validate their model of an outpatient haematology laboratory. We believe that this should not be the only validation method used. A more quantitative validation method should also be carried out. We agree with the opinion of Bailey and D'Angelo [14] that a good visualisation of a simulation model is important but animation should not be the only validation method used.

\subsubsection{Experiments}

It is assumed in all the experiments, that the nursing staff will work in the new 
situation in the same way they do now. Furthermore, no distinction is made between patient type, i.e. the elderly, children, disabled, etc. The contact time at the reception desk and the time in the cubicle may differ for these groups. Incorporating these distinctions will probably lead to a more accurate model but will require a large amount of data to determine the corresponding distributions and its parameters. As we stated before, because of these simplifying assumptions it is good practice to test the predictive power of such models and to publish the results. Differences between prediction and actual results may be used to update the model.

Because during some periods of the day patients can be served immediately, and in other periods the patients have to wait, relatively high standard deviations of the TAT were found.

\subsubsection{Experiment 0}

In experiment 0 we wanted to demonstrate the predictive power of the model. We simulated the addition of a second workspace in the old situation and actually added a second workspace. The results of the simulation runs of this model are in good agreement with the observations. The relatively small number of observed low TATs can be explained by the higher number of patients at the time of the observations although the total number of patients that were bled was normal. It shows that our simulation model has the predictive power to assess the TAT in a new situation.

\subsubsection{Experiment 1}

In experiment 1 we investigated whether the new layout will improve the efficiency. The results of the simulation show that the average TAT in situation C (see Table $5-1$ ) indeed is significantly lower ( 3 min $49 \mathrm{~s}$ ) than in situation A (see Table 5-4).

The addition of an additional workspace (situation D) results in significant decrease of the average TAT compared with situation $C(\Delta=18 \mathrm{~s}, t=3.66$, df $=10685$, $P<0.001$; two sample $t$-test). The addition of a workspace at the counter reduces the average waiting time ( $T 2-T 1$ ) with $43 \mathrm{~s}$ (originally $1 \mathrm{~min} 15 \mathrm{~s}$ ) in the old layout and in the new layout reduces it to $40 \mathrm{~s}$ (originally $1 \mathrm{~min} 6 \mathrm{~s}$ ).

With one workspace at reception, the time between leaving reception and entering the cubicle or lavatory (T3-T2) is less compared to the corresponding values obtained with two workspaces at the counter. This is because having bled the patients, nursing staff return to reception to ascertain whether assistance is required. They stay at reception until no patients remain in queue. This therefore results in fewer nursing staff being available for phlebotomy. However, this increase in waiting time after reception is more than compensated by the decrease in waiting time at reception. The utilization of nursing staff is less in situation B than in situation A due to the changes in the laboratory. They have to collect fewer blood samples and have to complete less paper work.

\subsubsection{Experiment 2}

In experiment 2 the effect on the TAT of varying the number of patients per day was investigated. As shown in Figure 5-8 an increase in the number of patients per day will lead to an increase of the average TAT since more patients have to be dealt with by the same number of staff. Also an increase in the range between the 25 th 
and 75th centile values can be observed. In the current layout the increase is larger compared with the future layout. Experiment 1 showed that utilization of nursing staff in the future layout was less compared to that in the current layout. In the future layout the nurses on average have time left to serve more patients. So the TAT will increase less in situation D compared with that in the current layout.

It was assumed that the age of the patient population remains the same. However if an increase in the number of patients is caused solely by an increase in the number of elderly people then consultation times (e.g. in the cubicle) may increase. These changes will cause an increase in the TAT.

\subsubsection{Experiment 3}

In experiment 3 the effects of changes in the contact time at the counter were studied. It was assumed that the shape of the different distribution functions describing the contact times remain the same and that only the minimum value of the different distribution functions changes. Table 5-6 shows the effects of these changes on the TAT. The time spent at reception may be longer with new, inexperienced nurses. It is shown in Table 5-6 that an increase in the minimum value will result in an increase of the average value of the TAT (T4-T1). Again, the increase is higher in the current layout than in the future layout. A patient waiting in the queue has to wait longer before being served at the desk. In situation $D$ two nurses can work at the desk so the time a patient has to wait will be shorter compared with situation $A$ and $C$ (see Table 5-1). If the minimum value increases by $6 \mathrm{~s}$ the chance that when a patient arrives another patient is served at the desk increases. This will cause the value of $T 2-T 1$ to rise. In situation D a nurse attends the second workspace if there are patients waiting in front of the desk. At that moment he/she is not available to help patients in the cubicle or instruct them in the lavatories. This will increase the value of $T 3-T 2$ as was shown in experiment 1 . The rise in the value of $T 3-T 2$ is also caused by the increase in the contact time.

During a working day a maximum of five nurses simultaneously provide the phlebotomy service. The effect of assigning an extra nurse to the second workspace was also studied. When the minimum value of the contact time was increased, the value of $T 4-T 1$ slightly increased, the value of $T 2-T 1$ hardly changed and the value of $T 3-T 2$ increased as much as the minimum value since there were enough nurses to serve the patients in the waiting room. The utilization of the extra nurse was low. Thus the provision of an extra nurse solely to attend the workspace is an expensive solution to reduce the TAT when for some reason the contact time at the desk has increased.

Simulation experiments allowed us to assess the effects on the performance indicators without carrying out real-life experiments. We could verify some of the predictions of the simulations. In the case of the phlebotomy service under study, it was shown that the proposed changes could significantly decrease the average TAT of each patient by about $4 \mathrm{~min}$. In the new layout the utilization of the nurses is less than in the current layout. Therefore in the future layout an increase in the number of patients or an increase of the contact time at the desk will influence the TAT less. The approach presented in Figure 5-1 proved to be a useful way to assess the 
effects of the relocation of a department, in this case a phlebotomy service, within a health care organisation. We think that modelling and simulation can be used on a much larger scale in health care than is now the case. At this moment future managers are trained when to apply simulation, how to use simulation software and how to interpret the results [15]. This combined with the increasing user-friendliness of the software leads us to expect an increase in the application of simulation in health care.

\section{Acknowledgements}

We thank the personnel of the phlebotomy service at the St. Elisabeth Hospital, Tilburg. The Netherlands, for their cooperation in this study.

\subsection{References}

[1] Brender J, Nøhr C, McNair P. Research needs and priorities in health informatics. Int J Med Inf 2000;58-59:257-89

[2] Klafehn KA, Connolly M. The simulation/animation of a new outpatient hematology laboratory. In: Anderson JG, Katzper M, eds. 1993 Western Multi Conference: Simulation in the Health Sciences and Services. La Jolla, CA: SCS - Society for Computer Simulation, San Diego CA., 1993:12-5

[3] Sule DR. Manufacturing facilities; locations, planning and design. (second ed.) Boston: PWS Publishing Company, 1994.

[4] Slack N, Chambers S, Harland C, Harrison A, Johnston R. Operations Management. (second ed.) Harlow: Pearson Education, 1998.

[5] Banks J, Carson II JS, Nelson BL. Discrete-Event System Simulation. (Second ed.) Upper Saddle River, NJ: Prentice-Hall, 1996. (Fabrycky WJ, Mize JH, eds. Prentice-Hall International Series in Industrial and Systems Engineering:

[6] Shannon RE. Systems Simulation: the art and science. Englewoods Cliffs, New Jersey: Prentice-Hall, 1975.

[7] Law AM, Kelton WD. Simulation Modeling and Analysis. (Second ed.) New York, USA: McGraw-Hill, 1991. (Riggs JL, ed. McGraw-Hill Series in Industrial Engineering and Management Science;

[8] Banks J. Principles of Simulation. In: Banks J, ed. Handbook of Simulation. New York: John Wiley \& Sons, 1998; 3-30.

[9] Sargent RG. Verification and validation of simulation models. In: Tew JD, Manivannan S, Sadowski DA, Seila AF, eds. Winter Simulation Conference. Orlando FL: New York, NY : Institute of Electrical and Electronics Engineers, 1994:77-87

[10] Balci O. Verification, validation and testing. In: Banks J, ed. Handbook of Simulation. New York: John Wiley \& Sons, 1998; 335- 93.

[11] Fishwick PA. Simulation model design and execution : building digital worlds. Englewood Cliffs, New Jersey: Prentice Hall, 1995. Prentice Hall International Series in Industrial and Systems Engineering:

[12] MedModel homepage. ProModel Inc. http://www.promodel.com/products/medmodel

[13] Drupsteen EJ. Innovation and replacement decisions using workflow simulation [masters thesis]. Maastricht: Maastricht University, 1999. 60 p

[14] Bailey KA, D'Angelo S. Computer-simulation modeling of clinical laboratories. Laboratory 
Robotics and Automation 1999;11:312-5

[15] Groothuis S, van Merode GG. Discrete Event Simulation in the Health Policy and Management Program. Methods Inf Med 2000;39:339-42 


\section{Predicting capacities required in cardiology units for heart failure patients via simulation}

\section{Abstract}

The management of a department of cardiology has to plan the capacity of both elective and non-elective patients. Heart failure (HF) patients are admitted to the hospital in a non-elective way. The precision with which the capacity needed for non-elective patients can be predicted determines the degree of flexibility in planning the admission of elective patients. In this study we want to determine how accurately we can predict the bed occupancy for HF patients using a simulation model.

Data of the year 2000 were used to obtain the necessary probability distribution functions. Data from the year 2001 were used for determining the prediction accuracy.

The results show that the number of new HF patients arriving can be adequately predicted. However, the bed occupancy by new and especially current patients can be predicted less accurately. Still in $70 \%(90 \%)$ of the days of a 5-day prediction interval the error is at most one (two) bed(s). The results will probably improve if the cardiologist predicts the length of stay of the current patients.

Submitted for publication as: Siebren Groothuis, Arie Hasman, Petra E.J. van Pol, Nicole H.M.K. Lencer, Josianne J.J. Janssen, Jacqueline D.M-J. Jans, Jan L.M. Stappers, Willem R.M. Dassen, Pieter A.F.M. Doevendans and Godefridus G. van Merode, Predicting capacities required in cardiology units for heart failure patients via simulation. 
Chapter 6 


\subsection{Introduction}

The number of patients with chronic heart failure (HF) is growing leading to increased mortality and (re-)admissions to the hospital [1, 2]. Although recently instituted, out-patient heart failure programs had a positive effect on mortality and morbidity, re-admission rate, quality of life, compliance and health care costs, the burden of patients with heart failure admitted to the cardiology department is considerable [3, 4]. Of particular interest are stage F III - F IV patients according to the New York Heart Association (NYHA). Moreover due to the fact that the treatment for heart failure during the few first days often includes intravenous medication, which limits the involvement of patients in their activities of daily living $(A D L)$, thus necessitating intensive nursing care. The ADL status of the patient and their treatment will naturally be expected to change during the course of their stay in hospital.

In addition to these non-elective patients, the cardiology department schedules elective patients who have to undergo other diagnostic or therapeutic procedures. In order to optimally use the available beds it is necessary to be able to predict the number of non-elective patients and their acuity so that elective patients can be scheduled and the workload optimized. It is essential for a manager to be able to assess the risk of reserving too few beds for HF patients,.

Since we have experience using simulation for capacity planning problems our research question is whether simulation is a suitable instrument for solving this prediction problem.

The HF patients that will be present in the unit consist of two groups: the HF patients that were present at the start of the simulation and the HF patients that will be admitted during the simulation period. To be able to adequately plan capacities it should be possible:

1 to predict how many patients will be admitted each day (arrival pattern)

2 to predict their ADL at admission, the subsequent changes in ADL status and when they will be discharged.

3 to predict how the ADL status of the patients present at the beginning of the simulation period, will develop during their stay in the unit and when they will be discharged.

For the predictions we therefore need to know the arrival pattern, the number of non-elective patients and the distribution of the periods that patients stay in each ADL phase. An arrival pattern indicates for each time slot within the considered interval, which percentage of all patients arriving in the interval arrive in that specific time slot. This distribution can be determined from existing databases. In this study, we used the data of patients admitted in 2000 to determine the above mentioned probability distributions and the arrival pattern.

The goal of the study is to assess how accurately the probability that one or more beds are occupied by $\mathrm{HF}$ patients as a function of time can be predicted. A manager can use this information to determine the risk that more HF patients require admission to the unit than there are beds available. In addition the workload caused by the HF patients will be predicted. This information will help the manager in 
planning the capacity required in terms of both the number of beds potential available for elective admissions as well as staffing.

\subsection{Methods and Materials}

\subsubsection{Patient data}

At the department of Cardiology of the Maastricht Academic Hospital the MAaStriCHt heart failure database (MASCH) contains data about all HF patients admitted at the Maastricht University Hospital since January 1998. From the first of January 2000, also the ADL status and "waiting" status of the patients are recorded in MASCH. The latter status refers to patients who cannot be discharged because their 'home' situation is not suitable and a bed in a nursing home is not immediately available. From a cardiological point of view the treatment in the hospital has ended but the patient still occupies a hospital bed.

The addition of patients into MASCH is done after the patient has left the hospital. A cardiologist examines the patient record and decides whether the patient can be classified as a HF patient. The admission corresponding to the first entry of a patient in MASCH is called a first admission even when the patient had been previously admitted. The data of the year 2000 are used for learning the distributions for this study. Data of 2-week periods starting January $15^{\text {th }}$, February $15^{\text {th }}$, March $15^{\text {th }}$ and April $15^{\text {th }} 2001$ referred to as the test periods) are used to test the accuracy of the probability distribution functions and to assess the quality of the bed occupancy predictions. An interval of half a month between the end and start of successive test periods was chosen to reduce the probability that the same patient is contained in two test periods.

\subsubsection{Patient trajectories}

Knowledge about the distribution of ADL among patients is important because this determines the workload of nurses. During the first days after admission heart failure patients may need a lot of assistance when they are not able to perform the activities of daily living (these patients are called fully ADL dependent). After some days their situation may improve and the patient becomes partly ADL dependent. During the last period of their hospital stay patients may be able to perform all activities (the patient becomes $\mathrm{ADL}$ independent). However not all the patients follow exactly this sequence. Some patients will remain in the same ADL phase during their stay in the hospital while other patients may skip one of the phases. All possible trajectories through the different ADL phases and "waiting" status are shown in Figure 6-1. Each patient will follow one of these trajectories. In these trajectories no distinction is made whether a patient dies or leaves the hospital alive.

\subsubsection{Modeling the patient's stay in the unit}

To predict the capacity needed for HF patients, discrete event simulation is used. "Discrete event simulation concerns the modeling of a system as it evolves over time by a representation in which state variables change instantaneously at separate points in time" [5]. A simulation model was designed that predicts the 


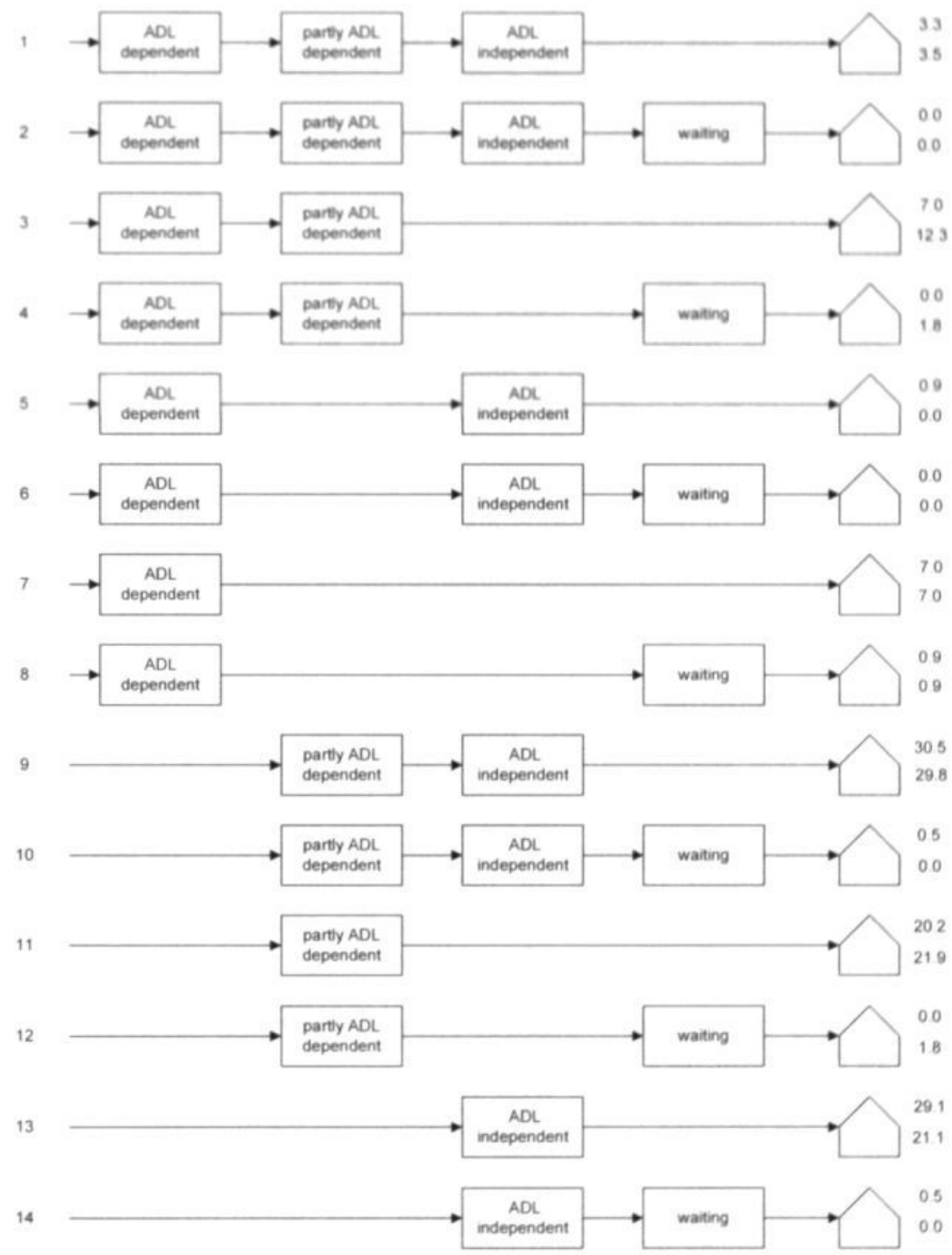

Figure 6-1: All possible trajectories a HF patient can traverse. The numbers to the left indicate the trajectory number. The symbol to the right means that the patient has left the unit. The numbers on the right represent the percentage of patients that followed a trajectory. The upper value is the percentage of first admissions $(\mathrm{N}=213)$, the lower value the percentage of readmissions $(\mathrm{N}=114)$. 
arrival and length of stay of patients. The model distinguishes patients admitted for the first time and re-admissions. The model both predicts the number of patients in the different ADL phases and the number of patients who are "waiting" as a function of time.

The simulation model was implemented in MedModel [6]. MedModel is a discrete event simulation package with a graphical user interface. It has been used by us in several health care domains. Koppelman et al. [7] e.g. used simulation to investigate several ways to reduce the length of stay at the emergency room. The effects of relocating a phlebotomy service were evaluated using simulation by Groothuis et al. [8]

The simulation model will be used to get insight in how accurately bed occupancy can be predicted. The model consists of various parts. The first component determines when new patients arrive at the department. The assignment of a trajectory to a patient is done by a second component. Another component determines the duration of a patient in each of the ADL phases of that trajectory.

During the simulation run the number of patients in the unit, the number of first admissions, the number of re-admissions and the number of patients in each of the ADL stages or waiting status are determined on each day at $12: 00 \mathrm{pm}$ and recorded.

The model uses a number of probability functions.

\subsubsection{Arrivals of patients}

Although the probability that a HF patient will be admitted should be independent of the day of the week, it may be that at weekends fewer patients will contact the hospital and hence there will be fewer admissions. To be on the safe side we assume that the number of admissions depends on the day of the week. Since the average number of patients arriving each weekday is considered to be constant, we hypothesize that the arrival patterns can be described by Poisson distributions, one for each weekday.

\subsubsection{Probability distribution functions for the duration in each phase per trajectory}

Each patient will follow one of the trajectories depicted in Figure 6-1. The distribution of patients over the various trajectories is also shown in Figure 6-1. The time a patient will stay in a certain phase of a trajectory is described by an analytic probability distribution function (see Law and Kelton [9] for an extensive discussion about probability distribution functions and their applications). The best fitting distribution is obtained using Stat::Fit, a tool incorporated in MedModel [6] and the parameters of these distributions are calculated based on historic data (from the $\mathrm{MASCH}$ database). If no analytic distribution could be fitted to the data a discrete distribution function based on the observed values and their frequencies was used. It was ascertained that there is no correlation between the length of the periods patients stay in each of the ADL phases. Therefore the distributions describing the stay in each of the phases can be determined and used independently. The distributions may depend on the trajectory, however. Therefore if enough patients 
are available in a trajectory, the distributions will be determined for that specific trajectory.

\subsection{Predicting the bed occupancy by HF patients}

To predict the bed occupancy we have to consider both the patients already occupying beds (current patients) and newly admitted patients. Each newly arriving patient is assigned to a trajectory in agreement with the distribution of patients over all trajectories. Then the duration in each of the phases of the selected trajectory is determined by sampling the corresponding distribution functions.

Current patients usually cannot be uniquely assigned to a particular trajectory. The initial part of more than one trajectory may match the history of the patient. To predict the future of the patient therefore first a single trajectory is selected from the matching ones, taking the relative frequencies of these trajectories into account. This is the trajectory a patient will traverse. Then it is determined how long the patient will still remain in the ADL phase (s)he is currently in. This is done by sampling the distribution of durations belonging to this phase and trajectory. If the duration is shorter than or equal to the time the patient is already in this phase a new sample is taken until a duration is obtained that is larger than the length of the current stay. The durations in the remaining phases of the trajectory are determined in the same way as for new patients.

\subsection{Experiments}

In the first two experiments the accuracy of the probability distribution functions is assessed. In experiments 3 and 4 the predictions of the length of stay in the unit of new and current HF patients are compared with the observations in the test periods. Finally in experiment 5 the bed occupancy is predicted and compared with the data observed during the test periods. In all experiments the predicted average values are rounded off first before subtraction.

\subsubsection{Experiment 1: arrival pattern}

On the basis of the data from MASCH over the year 2000 it is determined whether Poisson distributions indeed fit the data. Separate Poisson distributions are obtained for each of the weekdays (one Poisson distribution describing the admissions on Mondays, another Poisson distribution describing the admissions on Tuesdays, etcetera).

The data from the test periods are used to assess the accuracy of the modeled arrival pattern. This is done by determining the distribution of the difference between the actual and average predicted number of admissions per day and by comparing the observed variance of this distribution with the expected one.

\subsubsection{Experiment 2: assessing the quality of the distribution functions}

In this experiment first the various probability distribution functions describing the length of stay in each of the phases of the trajectories is determined. Data from the test periods are used to assess their accuracy. The bed occupancy is predicted using these distributions and the actual arrival pattern. This way only the effects of 
the distribution functions on bed occupancy are determined. The quality of the distribution functions is assessed on the basis of the differences between observed and simulated average bed occupancy.

\subsubsection{Experiment 3: predicting the number of new patients in the unit}

In this experiment the arrivals of new patients and their stay in the unit in the test periods is predicted. The model uses as input the arrival patterns based on the Poisson distributions obtained in experiment 1 and the distribution functions as determined in experiment 2 .

\subsubsection{Experiment 4: predicting the number of current patients in the unit}

In this experiment the future of HF patients who were already occupying a bed at the start of the test periods is predicted, using the distribution functions determined in experiment 2 .

\subsubsection{Experiment 5: predicting the bed occupancy}

The bed occupancy during the test periods is predicted in experiments 3 and 4 . From the data the distribution of the number of occupied beds for each weekday can be determined. This distribution is used to determine the cumulative probability that up to a certain number of beds will be occupied per day. This distribution will be compared with the cumulative distribution observed during the test periods.

\subsection{Results}

\subsubsection{Patient data}

The arrival data were obtained from MASCH. Figure 6-2 shows the monthly number of first admissions starting in 1998. In Figure 6-3 the monthly number of readmissions is shown. Each of the percentages of the first and re-admitted HF patients following a specific ADL trajectory is shown in Figure 6-1. In 2000233 patients were admitted for the first time with heart failure (see Table 6-1). Data concerning ADL and "waiting" status were available for 213 of these patients. The number of re-admissions was 123 in that year (see Table 6-1). Data concerning ADL and "waiting" status were available from 114 patients. The average stay in the unit for first admissions was 9.4 days and for re-admissions 11.3 days.

Table 6-2 shows that day of discharge is not equally spread over the week. Cardiologists apparently discharge patients before the weekend when it is possible from a cardiological point of view so that the patients can spend the weekend home. The observed number of admissions during the first four months of 2001 is shown in Table 6-3.

\subsubsection{Experiment 1: arrival pattern}

Although there are variations in the number of admissions over the week these differences are not statistically significant. The daily admissions in the year 2000 were matched to a Poisson distribution, one for each workday. In Table 6-4 the average number of daily admissions and their variance are shown. For Poisson 


\section{first admissions}

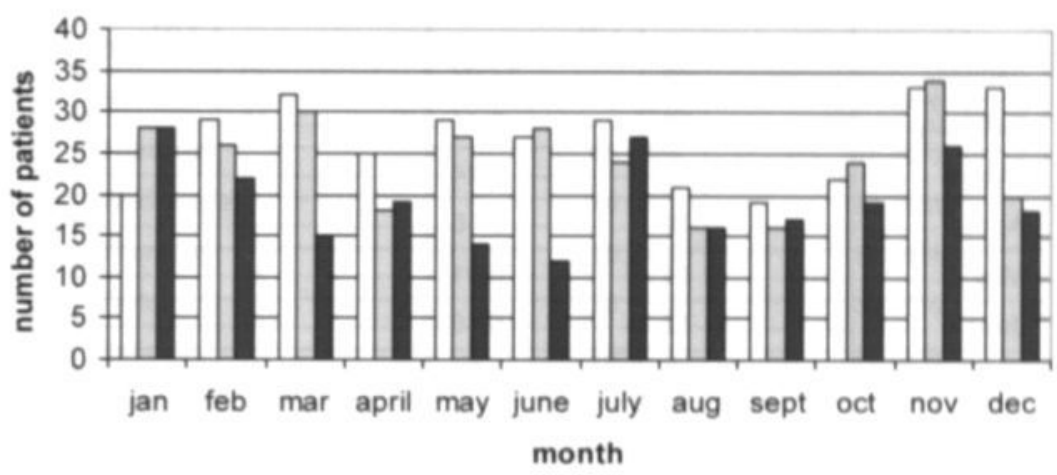

ㄴ1998 ㅁ1999 $\mathbf{\square} 2000$

Figure 6-2: Monthly number of first admissions in 1998, 1999 and 2000.

distributions both values should be the same. The optimal fit with the Poisson distribution was determined using the Kolmogorov-Smirnov test. A high p-value indicates that the sample is likely to be obtained from the fitted distribution and therefore the fit should not be rejected. The fitting of all distributions resulted in a pvalue of 1.

In Figure 6-4 the distribution of the observed minus the average predicted number of admissions per day during the test periods is shown (first admissions, average: 0.61 , variance: 1.01 ; re-admissions: average: 0.79 , variance: 0.75 ).

\section{re-admissions}

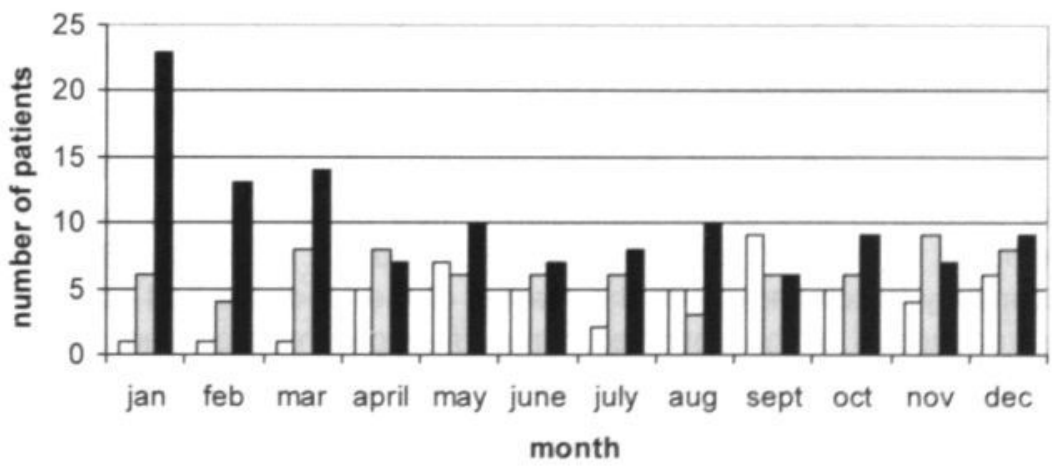


Table 6-1: Admissions of patients with heart failure in 2000.

\begin{tabular}{|c|c|c|c|c|}
\hline Month & $\begin{array}{l}\text { First admis- } \\
\text { sions }\end{array}$ & $\begin{array}{l}\text { First admis- } \\
\text { sions } \\
(\%)\end{array}$ & $\begin{array}{l}\text { Re- } \\
\text { admissions }\end{array}$ & $\begin{array}{l}\text { Re- admis- } \\
\text { sions } \\
(\%)\end{array}$ \\
\hline January & 28 & 12.02 & 23 & 18.70 \\
\hline February & 22 & 9.44 & 13 & 10.57 \\
\hline March & 15 & 6.44 & 14 & 11.38 \\
\hline April & 19 & 8.15 & 7 & 5.69 \\
\hline May & 14 & 6.01 & 10 & 8.13 \\
\hline June & 12 & 5.15 & 7 & 5.69 \\
\hline July & 27 & 11.59 & 8 & 6.50 \\
\hline August & 16 & 6.87 & 10 & 8.13 \\
\hline September & 17 & 7.30 & 6 & 4.88 \\
\hline October & 19 & 8.15 & 9 & 7.32 \\
\hline November & 26 & 11.16 & 7 & 5.69 \\
\hline December & 18 & 7.73 & 9 & 7.32 \\
\hline
\end{tabular}

\subsubsection{Experiment 2: assessing the quality of distribution functions}

The observed frequencies for the different trajectories are shown in Figure 6-1. For some phases in some trajectories data of only a few patients are available. To estimate the distribution functions of these phases patient data of different trajectories were combined. For example to determine the distribution function describing the duration of the totally $A D L$ dependent phase for first admissions, data of all patients that were in that phase was used, irrespective of the trajectory. For some phases combination was not possible (for example the waiting status) and no analytic distribution function could be determined. In those cases a discrete probability distribution was used based on the observed values and their frequencies.

The results of 100 simulation runs were obtained using the actual arrival patterns observed during the test periods. In Figure 6-5 the distribution of the difference between the average predicted and observed length of stay during the test periods is presented (first admissions: average: -0.20 , variance: 3.80 ; re-admissions: average: 0.25 , variance 0.52 ).

\subsubsection{Experiment 3: predicting the number of new patients in the unit}

The bed occupancy due to the admission of new patients during the test periods was predicted. In total 100 replications were carried out. In Figure 6-6 the observed bed occupancy is compared with the median of the predicted bed occupancy. The relative frequencies of the observed minus average predicted bed occupancy for new patients during the test periods is shown in Figure 6-7 for prediction intervals with different lengths ( 5 days, 7 days and 14 days). The prediction intervals all start on the first day of the test periods. The corresponding standard deviations and variances are shown in Table 6-5. 
Table 6-2: Discharge day as function of the day of admission for admissions in 2000.

\begin{tabular}{|l|r|r|}
\hline Day of discharge & First admissions & Re-admissions \\
\hline Sunday & $2.15 \%$ & $4.88 \%$ \\
\hline Monday & $8.58 \%$ & $8.94 \%$ \\
\hline Tuesday & $15.45 \%$ & $15.45 \%$ \\
\hline Wednesday & $14.59 \%$ & $23.58 \%$ \\
\hline Thursday & $16.74 \%$ & $13.01 \%$ \\
\hline Friday & $26.18 \%$ & $20.33 \%$ \\
\hline Saturday & $16.31 \%$ & $13.82 \%$ \\
\hline Number of admissions & 233 & 123 \\
\hline
\end{tabular}

Table 6-3: Number of admissions of patients with heart failure during the first four months of 2001.

\begin{tabular}{|l|l|r|r|}
\hline Year & Month & First admissions & Re-admissions \\
\hline 2001 & January & 27 & 12 \\
\hline 2001 & February & 20 & 9 \\
\hline 2001 & March & 40 & 10 \\
\hline 2001 & April & 24 & 7 \\
\hline
\end{tabular}

Table 6-4: Average and variance of the observed distributions.

\begin{tabular}{|l|l|l|r|r|r|r|r|r|}
\hline & & \multicolumn{1}{|c|}{ Mon } & \multicolumn{1}{l|}{ Tue } & \multicolumn{1}{l|}{ Wed } & \multicolumn{1}{l|}{ Thu } & \multicolumn{1}{l|}{ Fri } & \multicolumn{1}{l|}{ Sat } & \multicolumn{1}{l|}{ Sun } \\
\hline First admission & Avg. & 0.55 & 0.58 & 0.81 & 0.65 & 0.62 & 0.45 & 0.34 \\
\hline & Var. & 0.48 & 0.64 & 0.98 & 0.62 & 0.63 & 0.41 & 0.31 \\
\hline Re-admission & Avg. & 0.35 & 0.35 & 0.50 & 0.25 & 0.35 & 0.19 & 0.15 \\
\hline & Var. & 0.31 & 0.39 & 0.41 & 0.23 & 0.43 & 0.19 & 0.13 \\
\hline
\end{tabular}

Table 6-5: Average, standard deviation and variance of the predicted error in the bed occupancy for different prediction intervals and different patients groups.

\begin{tabular}{|l|l|l|l|l|l|l|l|l|l|l|}
\hline & \multicolumn{3}{|l}{ 14-day period } & \multicolumn{3}{l|}{ 7-day period } & \multicolumn{3}{l|}{ 5-day period } \\
\hline & avg. & $\begin{array}{l}\text { st. } \\
\text { dev. }\end{array}$ & var. & avg. & $\begin{array}{l}\text { st. } \\
\text { dev. }\end{array}$ & var. & avg. & $\begin{array}{l}\text { st. } \\
\text { dev. }\end{array}$ & var. \\
\hline $\begin{array}{l}\text { New first admis- } \\
\text { sions }\end{array}$ & 1.14 & 1.70 & 2.89 & 1.14 & 1.30 & 1.68 & 0.70 & 1.13 & 1.27 \\
\hline New re-admissions & 0.04 & 1.08 & 1.16 & 0.50 & 1.17 & 1.37 & 0.50 & 1.10 & 1.21 \\
\hline Total New patients & 1.16 & 1.94 & 3.77 & 1.57 & 1.60 & 2.55 & 1.57 & 1.23 & 1.52 \\
\hline Current patients & -1.61 & 1.70 & 2.90 & -1.43 & 1.79 & 3.22 & -1.15 & 1.69 & 3.65 \\
\hline All patients & -1.77 & 2.39 & 5.71 & -1.21 & 1.97 & 3.87 & -1.15 & 1.66 & 2.77 \\
\hline
\end{tabular}




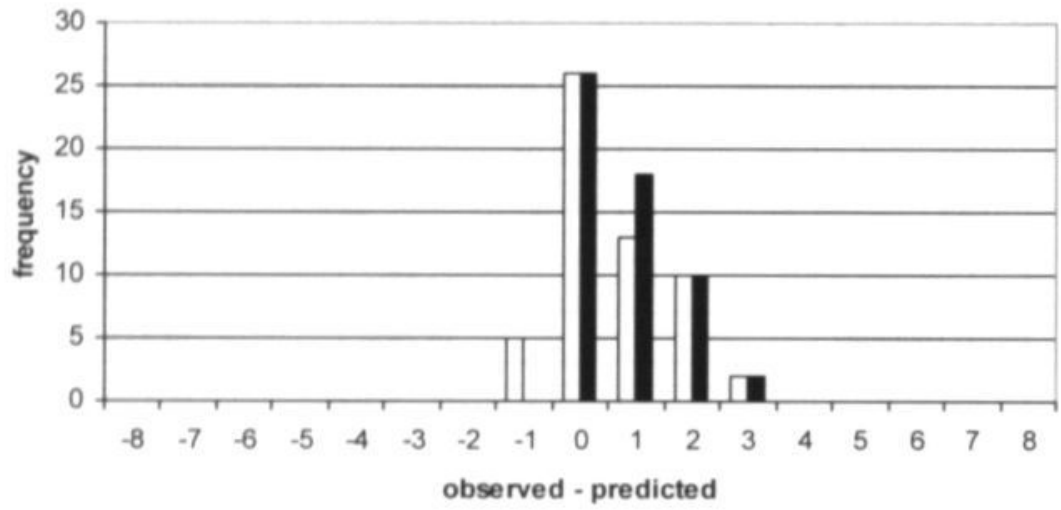

$\square$ first admissions $\mathbf{a}$ re-admissions

Figure 6-4: Observed minus predicted rounded off average number of admissions for four test periods.

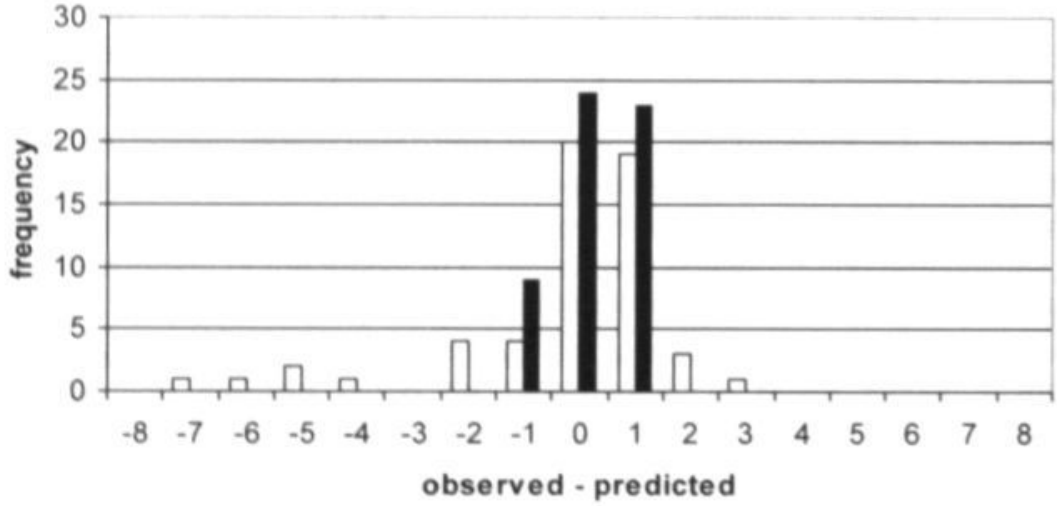

$\square$ first admissions $\mathbf{a}$ re-admissions

Figure 6-5: The difference between observed and predicted rounded off average bed occupancy by new patients in the test periods using the observed arrival pattern in the test periods.

\subsubsection{Experiment 4: predicting the number of current patients in the unit}

The number of beds occupied by HF patients that were already present in the unit at the start of the simulation periods was determined using the probability distribution functions determined in the earlier experiments. The average stay of current $\mathrm{HF}$ patients who were admitted for the first time was 5.26 days at the beginning of the prediction period. The average stay of the re-admitted patients at the beginning of the prediction period was 4.63 days. In Figure 6-8 the predicted median and observed number of HF patients is shown for patients who were in the unit on March $15^{\text {th }}, 2001$. The difference between the observed and average predicted bed occupancy by HF patients already in the unit at the start of the tests periods is 


\section{new patients}

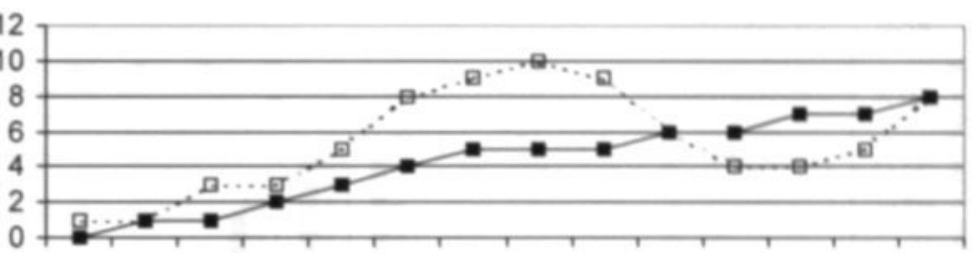

15- 16- 17- 18- 19-20-21-22-23-24-25- 26- 27- 28-

02- 02- 02- 02- 02- 02- 02- 02- 02- 02- 02- 02- 02- 02-

$\begin{array}{llllllllllllll}01 & 01 & 01 & 01 & 01 & 01 & 01 & 01 & 01 & 01 & 01 & 01 & 01 & 01\end{array}$

date

\section{$\longrightarrow$ median …… observed}

Figure 6-6: The observed bed occupancy and the predicted average bed occupancy of HF patients admitted at or after February $15^{\text {th }}$ 2001. The median value is based on 100 replications.

shown in Figure 6-9.

The few patients who were admitted in 2000 but were still hospitalized on the chosen days were excluded. For one patient admitted on March 15, 2001 no prediction could be made because the patient followed a trajectory that no patients in 2000 followed (re-admission and trajectory 10, see Figure 6-1).

\subsubsection{Experiment 5: predicting bed occupancy}

In this experiment we combined the simulation results of experiment 3 and experiment 4 to predict the bed occupancy for the four test periods. An example of the total number of HF patients in the unit in one of the periods is depicted in Figure 6-10. In Figure 6-11 again the observed minus the average predicted bed occupancy for all HF patients during the test periods is shown for the three prediction intervals. For a 5-day prediction interval for $70 \%$ of the days the prediction error is maximally one bed, for $90 \%$ of the days the prediction error is maximally 2 beds.

In Figure 6-12 the difference between observed number and predicted average number of patients in the three ADL phases is shown for the test periods.

In Figure 6-13 the simulated distribution of the number of beds occupied on Sundays is shown. This distribution was obtained by adding the simulated distributions obtained in experiment 3 and 4 for that day. With the help of such a distribution one can determine the cumulative probability that not more than a given number of beds are occupied by HF patients. This simulated cumulative probability was compared with the cumulative probability determined from the actual data in the test periods.

To determine whether the simulated cumulative probabilities are well calibrated these probabilities were compared with the actual ones. The results are shown in Figure 6-14. 


\section{first admissions}

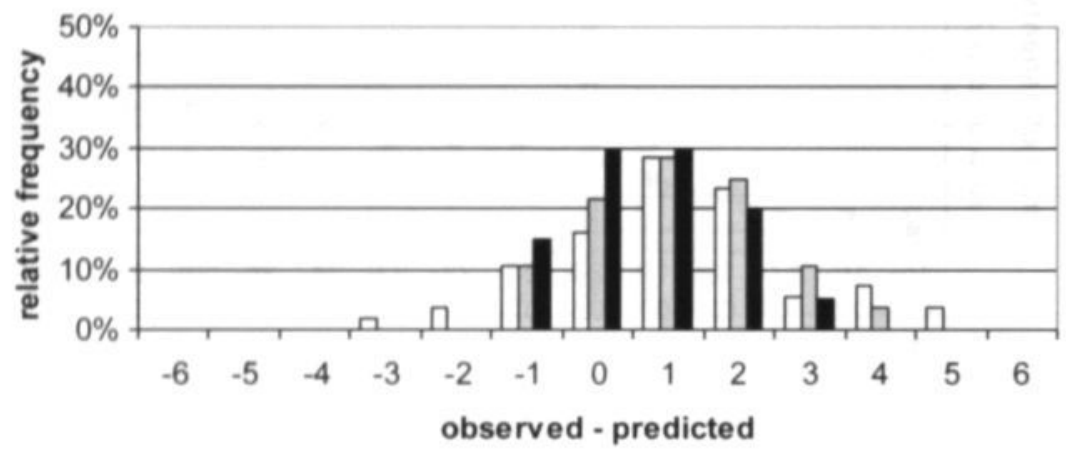

$\square 14$ day period $\square 7$ day period $\mathbf{a} 5$ day period

re-admissions

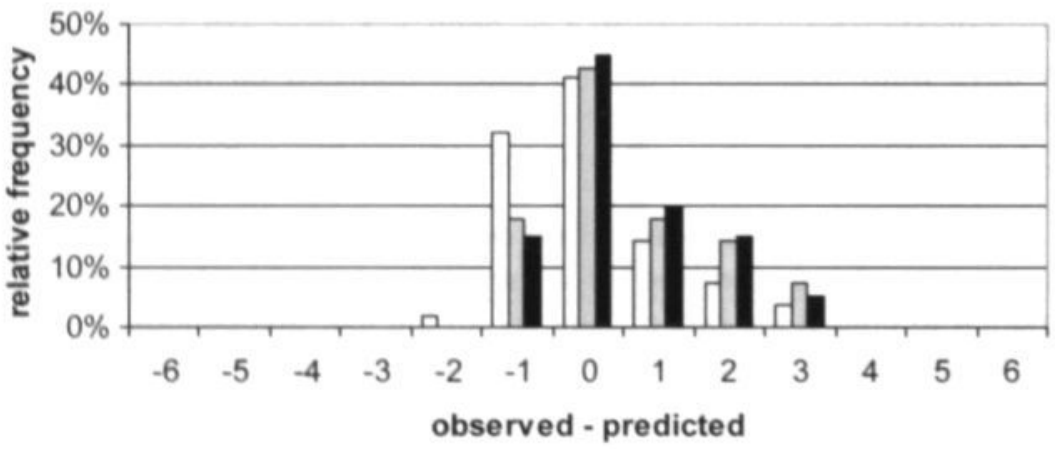

$\square 14$ day period $\square 7$ day period $\mathbf{a} 5$ day period

Figure 6-7: Observed bed occupancy minus predicted averaged bed occupancy of newly admitted patients in the test periods.

\subsection{Discussion}

\subsubsection{Patient data}

As mentioned earlier the collection of data from patients with heart failure started in 1998. Since January $1^{\text {st }}, 2000 \mathrm{ADL}$ data from the patients is collected. Every patient who does not have a record in the MASCH database is called a first admission. This explains the low numbers of re-admissions in 1998, since the probability that the patient was already known in the database in that year is low. Also the fact that in 1998 the number of re-admissions increases and the number of first admissions slowly decreases during the year can be explained in this way. Although this source of errors is much smaller in 2000 we do not know the exact error rate. 


\section{current patients}

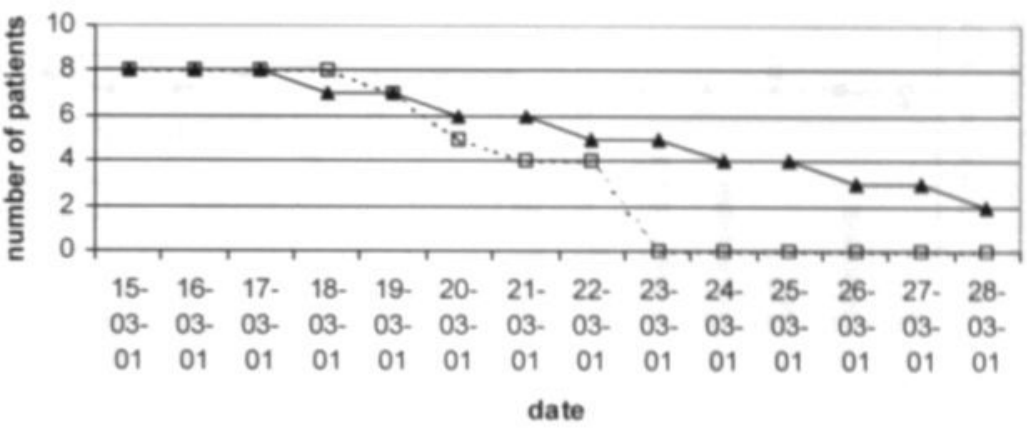

$\longrightarrow$ median .... E... observed

Figure 6-8: Observed number and the median value of the predicted number of HF patients that were in the unit on March $15^{\text {th }}$ 2001. Results are based on 100 replications.

\section{current patients}

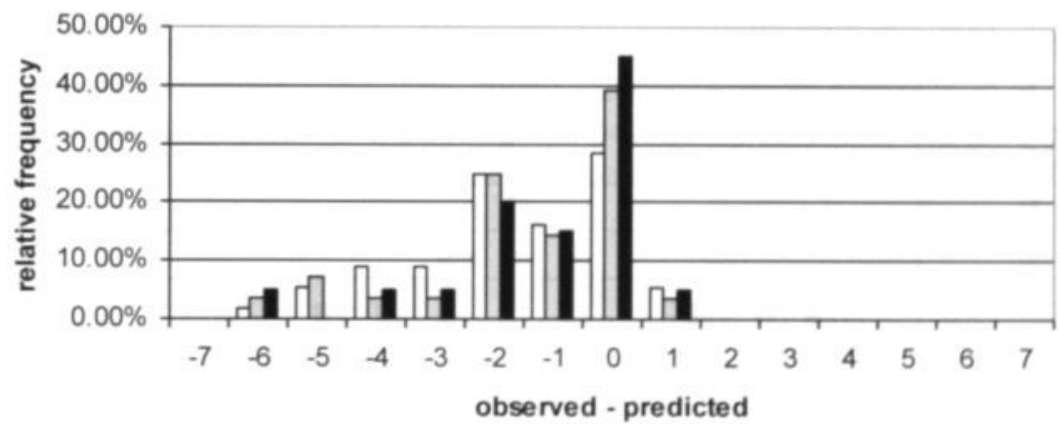

$\square 14$ day period $\square 7$ day period $\mathbf{m} 5$ day period

Figure 6-9: Observed bed occupancy minus average predicted bed occupancy of patients that were in the unit on the $15^{\text {th }}$ in the test periods.

In some cases data about ADL was not known (the data of 20 first admissions and 9 re-admissions). It concerns patients admitted at another ward because the complaints did not indicate heart failure. After some time it was clear that the patient suffered from heart failure and they were then transferred to the cardiology ward. In those cases not all ADL data was entered into the database and therefore these patients were not taken into account in our study.

The number of patients in the database is still too small to determine all probability distribution functions accurately. 


\section{all patients}

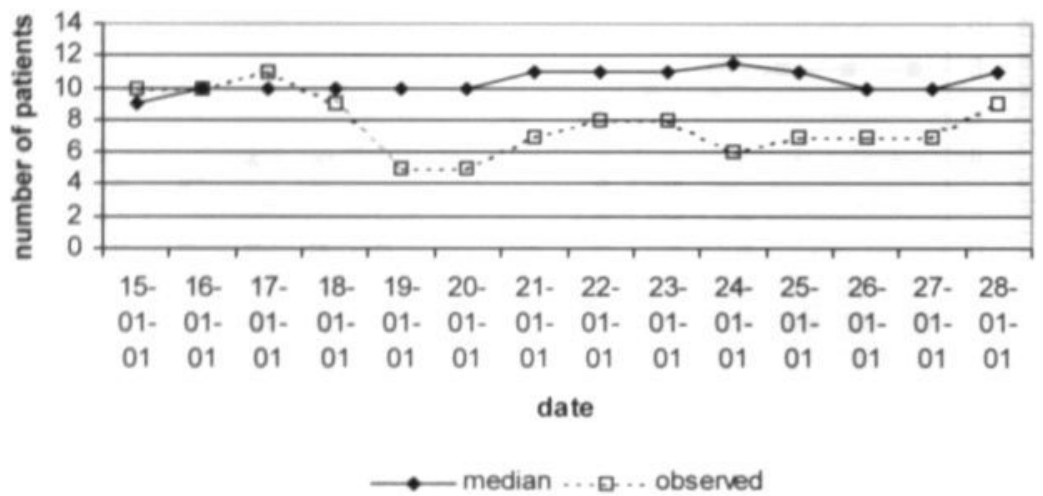

Figure 6-10: Observed number and the median value of the predicted number of HF patients in the unit. Simulation results are based on 100 replications.

all patients

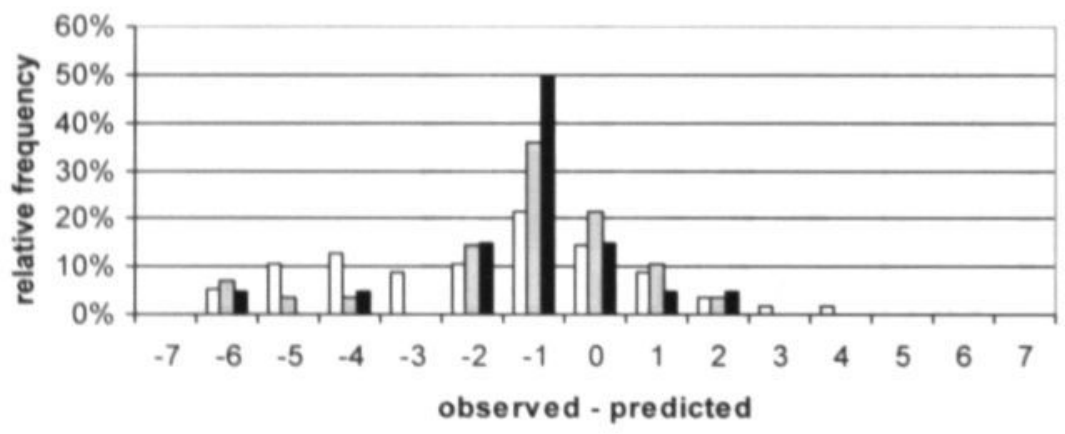

$\square 14$ day period $\square 7$ day period $\mathbf{a} 5$ day period

Figure 6-11: Observed minus rounded off predicted average bed occupancy by HF patients during the test period using a 5, 7 and 14-day prediction period.

\subsubsection{Experiment 1: arrival pattern}

In Figure 6-2 and Figure 6-3 the monthly number of first admissions and readmissions are shown. Both figures show fluctuations in the monthly number of admissions. A comparison of the data from 2001 with the data of 2000 (see Table 6-1 and Table 6-3) shows that there are some striking differences. The number of first admissions during the first 4 months of 2001 is larger than during the first four months of 2000. In March 2001 the number of first admissions is nearly three times the number in March 2000. There is no explanation (like a flue epidemic) for this high number of first-admissions in March 2001. In April 2001 the number of first 


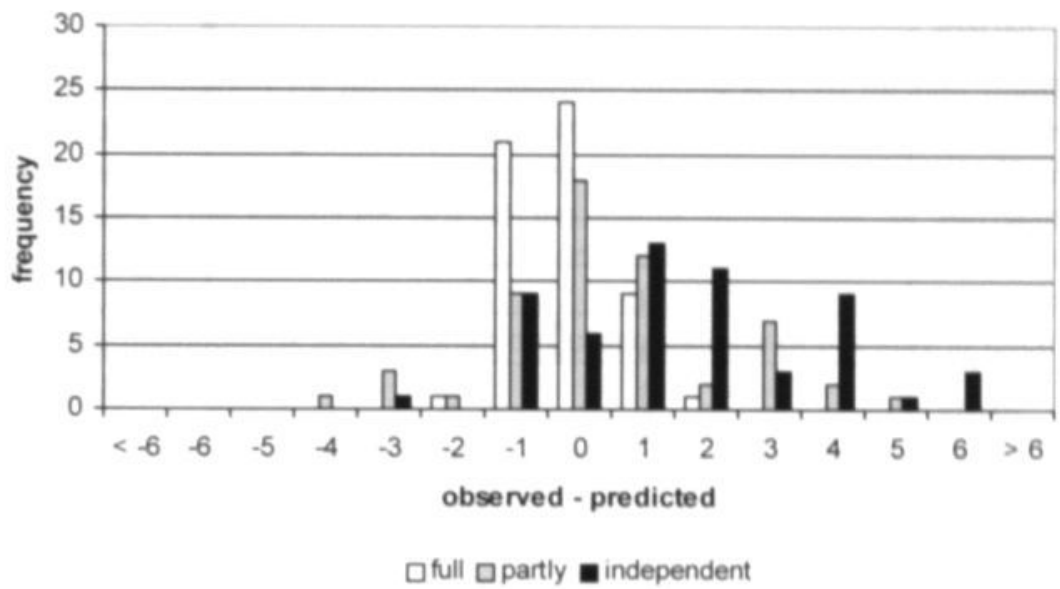

Figure 6-12: Observed minus predicted average number of patients in the different ADL phases during the test period.

admission increased with more than $25 \%$ compared to April 2000. During the first four months of 2000 the number of re-admitted patients was 57 (see Table 6-1) and in the first four months of 2001 only 38 (see Table 6-3). This difference might be caused by the intensive guidance of the patients via a special outpatient clinic that started in January 2001. The aim of this guidance is to prevent or at least to postpone the re-admission of a patient. The probability functions describing the readmissions used in the simulation model were determined from the year 2000 and may therefore not be totally correct.

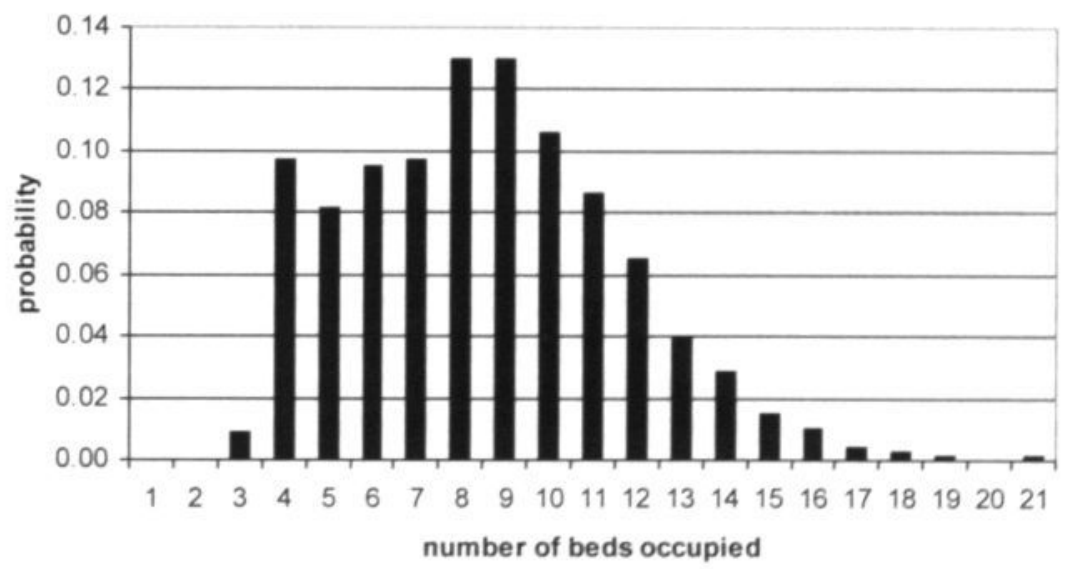

Figure 6-13: Simulated probability distribution of the number of beds occupied by HF patients on Sundays. 


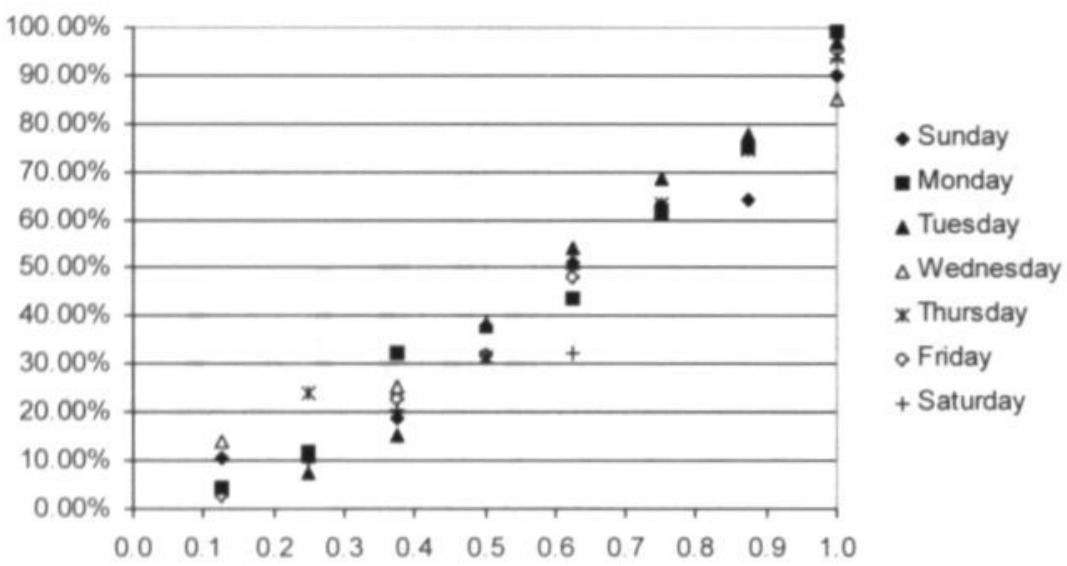

Figure 6-14: The cumulative percentage of the predicted distribution as function of the cumulative fraction of the observed values for each day of the week accumulated on the four different intervals.

From the results it can be concluded that the Poisson processes accurately model the admission patterns.

Figure 6-4 shows the distribution of the observed minus predicted average number of admissions. The average variance of the number of first admissions per day in 2000 is 0.59 and for the re-admissions 0.31 . The variance of the observed minus the predicted average number of admissions is for the first admissions 1.01 and for the re-admissions 0.75 . The difference in variance is mainly caused by the rounding off of the simulated average bed occupancy values. Another source of error are the different number of admissions in the first four months in 2001 as compared to 2000 (see Table 6-1 and Table 6-3), leading to non zero average values of the prediction errors. Since the main difference between actually observed bed occupancy and predicted average occupancy is caused by the rounding off of the latter values we conclude that a variance of 1.01 for the first admissions and of 0.75 for the readmissions is the best one can obtain. Whether this is accurately enough for practical use will be discussed later.

\subsubsection{Experiment 2: determining the quality of the distribution functions}

In Figure 6-5 the difference between observed and predicted average bed occupancy for new patients is presented. The differences are caused by inaccuracies in the probability distribution functions for the various phases in the different trajectories. The influence of the arrival pattern on the bed occupancy was eliminated by using the actual arrival pattern. Figure 6-5 shows deviations between observed and predicted average bed occupancy in the range of $-4,-7$. These values occur in the period of February $24^{\text {th }}-28^{\text {th }}$. From Sunday $25^{\text {th }}$ until Tuesday $27^{\text {th }}$ there is a local holiday (Carnival). If it is possible from a cardiological point of view, cardiologists will discharge patients so that the patients can spend the holiday 
at home with their relatives. The effects of public holidays were not incorporated in the simulation model. If we exclude the data from this period the variance of the observed minus rounded off predicted average values is 1.10 for first admissions and $\mathbf{0 . 4 9}$ for re-admissions. The simplification that some of the distribution functions were determined from the same phase but from different trajectories has contributed to the variance. The variances are of the same magnitude as the variances observed with the admissions patterns. In addition the averages of the prediction errors in the first and re-admissions is 0.37 and 0.39 respectively. Therefore we consider these distributions as reasonable representations of the stay in each of the phases of the patient trajectories.

\subsubsection{Experiment 3: predicting the number of new patients in the unit}

As can be seen from Figure 6-6 the bed occupancy of new patients decreases strongly at February $23^{\text {rd }}$ (Friday) and February $24^{\text {th }}$ (Saturday). Again this was caused by the public holiday as mentioned above. During this holiday no patients were admitted and a number of patients were discharged. Probably patients postpone their visit to a GP or cardiologist until after the holidays. The simulation model does not yet take into account public holidays and their effects on the admission and discharge of patients. Since most holiday periods do not recur at the same dates each year, the influence of holidays has to be modeled as a correction. In Figure 6-7 the relative frequencies of the difference between observed and predicted average bed occupancy by new patients for different prediction intervals are presented and in Table 6-5 the corresponding averages, standard deviations and variances are shown. The -3 and -2 values for the first admissions in Figure 6-7 are caused by the holiday period.

The average prediction error in the 5-day and 7-day prediction interval is more than one bed. This is mainly due to the larger number of patients admitted in 2001 as compared to the year before. The public holiday was outside these prediction intervals. The variance of the prediction error is not much larger as the variances observed in experiment 2 . This again is an indication of the fact that the admission pattern is reasonably accurately described by a Poisson distribution. For the 14-day prediction interval the variance rises. This is due to the fact that patients are discharged early before weekends and the presence of the public holiday.

\subsubsection{Experiment 4: predicting the number of current patients in the unit}

In this experiment the length of stay of HF patients already admitted in the unit was predicted. Figure 6-8 shows that e.g. on March $23^{\text {rd }}$ (Friday) the actual number of patients occupying beds decreases sharply. Other test periods show the same behavior on Fridays. We already observed this phenomenon with the new patients. For patients that were already occupying a bed at the start of the simulation this phenomenon occurs earlier because they are longer at the ward. In general a cardiologist wants to discharge a patient when it is possible from a medical point of view. However for the patient it is more relaxing to be at home during the weekend than to be in the hospital. Therefore a patient will be discharged more often on a Friday or a Saturday (see Table 6-2). 
In Figure 6-9 the relative frequencies of the observed minus predicted average bed occupancy by current patients for different observation periods is shown. In Table 6-5 the average, standard deviation and variance of the prediction error is presented. For the current patients the variance of the prediction error decreases with the length of the prediction interval. This is due to the fact that both the actual and predicted number of beds occupied by current patients decrease to zero, especially in the second week. Therefore it is better in this case only to consider the prediction accuracy in the first week.

The fact that not all variances add up in Table 6-5 is also due to rounding off. For the totals first the simulated values are added and only then rounded off.

The prediction of the length of stay of current patients has a larger variance than that of new patients. Perhaps it is therefore better to ask the physician to predict whether the patient will be discharged in the coming week and on what day.

\subsubsection{Experiment 5: predicting bed occupancy}

By combining the results of experiments 4 and 5 the bed occupancy by HF patients is predicted. In Figure 6-10 the observed and predicted median bed occupancy by HF patients for January $15^{\text {th }}-28^{\text {th }}, 2001$ is shown. Figure 6-11 shows the relative frequency of the difference between observed and predicted mean bed occupancy. The values of the observed minus predicted number of patients in the different $A D L$ phases is shown in Figure 6-12. The large prediction errors for $A D L$ independent patients result from the high number of admissions in April. Nearly all these patients were $A D L$ independent during their stay in the unit.

From the distribution presented in Figure 6-13 we determined for each day the cumulative probability that up to a certain number of beds will be occupied. One minus this cumulative probability gives a manager an indication of the risk that more than this number of beds will be needed. In the test periods we determined for each day of the week the number of occupied beds. From the distribution of these numbers an observed cumulative distribution was obtained. Figure 6-14 presents the correlation between the predicted and observed cumulative probabilities. As can be deduced from Figure 6-14 the predicted cumulative probability is on average smaller than the actually observed cumulative probability. Therefore the predicted risk that more than a certain number of beds will be needed on a certain day is somewhat higher than the actual risk. Yet, we can conclude that the risk predictions are rather well calibrated.

The range of the errors made when predicting the number of beds is about 8 beds, which is rather large in comparison with the actual average number of beds occupied by HF patients (during the 5 -day prediction periods the average bed occupancy was 7 beds). However, for a 5-day prediction interval in $70 \%$ of the days the error is maximally 1 bed. The manager can increase the number of beds to be reserved for $\mathrm{HF}$ patients to a value with acceptable risk that more beds are necessary. However, it is up to the manager to decide whether the simulation data will be used for practical purposes. Beds that will not be occupied by HF patients can be rather easily replaced by patients on the waiting list. If the number of beds reserved for HF patients appears to be too low a manager has to look for beds in other departments. 


\subsection{Conclusion}

The aim of our study is to determine whether simulation is a suitable instrument to assist the management in predicting the needed capacity for patients with heart failure. Discrete event simulation was used to determine how accurately the capacity can be predicted. The arrival pattern of patients can be adequately predicted. Also the probability distribution functions for the ADL phases in the various trajectories can be determined with reasonable precision.

The predictions of bed occupancy show relatively a small average error. The variance is however quite large. Since about $70 \%$ of the days the bed occupancy can be predicted for 5-day prediction interval with an error of at most one bed the simulation results may be useful in practice. The result will probably improve if the cardiologist would predict the length of stay of current patients because the cardiologists have a better insight in the patient's status.

The parameters of the distribution functions of the simulation model should be determined from a larger data set. The effects of weekends and public holidays on the discharge date of the patients should be incorporated in the simulation model. These refinements may result in a better prediction of the stay of the current patients.

We observed differences in the number of patients admitted in 2001 as compared to 2000. Such differences may lead to systematic errors on the predicted average number of beds. Such fluctuations in the admission rate can hardly be taken into account.

\subsection{References}

[1] Reitsma JB, Mosterd A, de Craen AJ, Koster RW, van Capelle FJ, Grobbee DE, Tijssen JG. Increase in hospital admission rates for heart failure in The Netherlands, 1980-1993. Heart 1996;76:388-92

[2] Mosterd A. Epidemiology of heart failure [PhD. Thesis]. Rotterdam: Erasmus University, 1997. $145 \mathrm{p} \mathrm{p}$

[3] Lucas CMHB, Cleuren G, Jaarsma T, van Pol P, Lencer N, Cheriex EC, Wellens HJJ. Hartfalenpoliklinieken: selectie van patiënten (Heart failure out-patient clinics: the selection of patients). Cardiologie 2001;8:3-10

[4] Grady KL, Dracup K, Kennedy G, Moser DK, Piano M, Warner Stevenson L, Young JB. Team Management of patients with heart failure. Circulation 2000;102:2443-56

[5] Banks J, Carson II JS, Nelson BL. Discrete-Event System Simulation. (Second ed.) Upper Saddle River, NJ: Prentice-Hall, 1996. (Fabrycky WJ, Mize JH, eds. Prentice-Hall International Series in Industrial and Systems Engineering)

[6] MedModel homepage. ProModel Inc. http://www.promodel.com/products/medmodel

[7] Koppelman Y, van Merode F, Groothuis S. Simulation as Decision Support at the Emergency Department. In: Anderson JG, Katzper M, eds. 1999 Western MultiConference - 1999 Health Science Simulation Conference. San Francisco, CA: SCS - Society for Computer Simulation International, San Diego CA, 1999:28-32

[8] Groothuis S, Goldschmidt HMJ, Drupsteen EJ, de Vries JCM, Hasman A, van Merode GG. Application of computer simulation analysis to assess the effects of relocating a hospital 
phlebotomy department. Ann Clin Biochem 2002;39:261-72

[9] Law AM, Kelton WD. Simulation Modeling and Analysis. (Second ed.) New York, USA: McGraw-Hill, 1991. (Riggs JL, ed. McGraw-Hill Series in Industrial Engineering and Management Science). 


\section{Discrete event simulation in the health policy and management Program}

\section{Abstract}

Students in Health Policy \& Management at the Faculty of Health Sciences of Maastricht University must learn to analyze and design workflow processes in health care. To attain this, a discrete event simulation training, using MedModel is used.

This paper describes the training in two consecutive years. In both years the training was evaluated systematically. The evaluation results of these demonstrate that the simulation training increased the students' knowledge about analyzing and designing workflow processes in health care. Students considered the training as a very important part of their program. 


\subsection{Introduction}

Students in Health Policy \& Management of the faculty of Health Sciences at Maastricht University need to learn about analyzing and designing work processes in healthcare. This topic is one of the subjects of the "Management Control" block that is offered to third year undergraduate students in the Health Policy and Management program. Discrete event simulation is one of the techniques used to analyze and design work processes. The question is whether discrete event simulation is a suitable method for students to learn how to analyze and design work processes. To answer this question one must design a simulation training and evaluate the effect of the training. This article reports on the training process where students learn to use a discrete event simulation tool called MedModel ${ }^{\mathrm{TM}}$ [1] $^{\mathrm{T}}$ and also the evaluation of that training.

\subsubsection{Health Policy, Administration \& Management}

In the Health Policy \& Management program attention is focused on management control theory and operations management. These topics are concentrated in the block, Control in health care provision. During this block (a six week period) students study different aspects of a central theme using the problem based learning approach $[2,3]$. The concept behind the Control in health care provision block is to clarify that a management process includes both of planning and control. Planning is the process of deciding on the objectives of an organization, the resources used to attain these objectives and on the procedures to govern the resources. Control is directed to the efficient and effective execution of the plan in such way that the goals of the organization are realized.

A simulation training was added to the course. Students must be familiar with the use of simulation techniques as a management tool. They must have practical experience with the key elements of a simulation project.

\subsection{MedModel}

MedModel is a discrete event simulation package with a graphical user interface. It is based on a two-dimensional layout of a healthcare organization. MedModel is an easy system to model the patient flow in a healthcare organization, e.g. an outpatient clinic. During the simulation, animation shows the ongoing changes. In MedModel the patients are subjected to different processes at different locations in the system and patients are moved from one location to the other on path networks that are created by clicking and moving the mouse. Locations are illustrated using icons from a medically oriented graphics database. In MedModel physicians and nurses can have several interactions with patients during these processes. The duration of the activities within these processes is described in terms of statistical distribution functions. Physicians and nurses are also illustrated by using icons. The results of the simulation runs are shown in a tabular way, but some of the results can be displayed graphically. 


\subsection{Key concept of the simulation training}

The main goal of the training is to teach the students to analyze and design work processes in healthcare. Patient logistics and (medical) capacity management are concepts in work processes in healthcare. Since our students are not familiar with discrete event simulation two conditions must be satisfied to use discrete event simulation. First the software must be user-friendly and intuitively to use. Second the students must get acquainted with the software by working on an operational model before building their own model. The first condition could be met by using MedModel. The second condition by first letting the students work on a simple operational model. After that, they must design a small simple model themselves. After completing this model, students should be aware of the major problems he/she will encounter during model building.

\subsection{Concept of the simulation training}

The training (scheduled in the first three weeks of the block) was composed of four different parts: (1) an introductory lecture with demonstration of simulation software; (2) an explanatory task; (3) an exercise task; and (4) the final task. After the introductory lecture a handout (composed from the text of the help files of the program) was distributed to the students. Students were supposed to have read this before the first session, the explanatory task. Students had to answer some specific questions about an operational simple simulation model to become familiar with the program. In the exercise task students must design and build a small model. The final task was to make a simulation model of the practice of a dental surgeon. Emergency operations had to be included and the $x$-ray rooms had to be shared with other departments. Students had to determine an optimal situation. A paper had to be written about the results of the final task pointing out which assumptions had been made and why. The papers had to be submitted on the first day of week four of the block course for review by the authors and formed part of the final examination of the block. Thus in the training most elements of a simulation study $[4,5]$ are incorporated, except data acquisition. Validation was done by animation. The set-up of the training incorporates an increasing degree of difficulty. In the first part students are familiarized with the program; in the second part they build a small model themselves and in the third part they design and build their own model.

In the academic year 1997-1998 we extended the training from three to five weeks. We added the cost aspect to be more realistic and for this a brief introduction to Excel was incorporated. The time for the exercise task was increased to 9 hours and that for the final task to 22 hours.

\subsection{Setup of the evaluation}

To see the effects of a training one must assess the students' knowledge of the subject both before and after the training; the best way to assess their knowledge is to ask them to solve a problem before and after training. One part of the students should not follow the training; by comparing the results of the subgroups allows to assess the effect of the training. For practical reasons however this was not 
possible. Therefore we asked the students' opinion about their knowledge and asked them to complete two questionnaires. The first questionnaire had to be completed before the training started and the second had to be completed in the first week after completion of the training. Questions concerned the use of the simulation software, their attitude towards management problems, economic topics, computers etc. Opinions were expressed on a five-point Likert scale which is commonly used at the Faculty of Health Sciences by students to evaluate the various blocks. The second questionnaire contained the same questions but with some additional questions about the support during the training and the benefit of the training. Students were asked to judge the training on a ten-point scale.

Since the first author was a trainer during the training. students' observations and impressions gathered during informal discussions were included in the evaluation. Based on the results of the evaluation, possible changes in the setup may be necessarily.

Thus, the evaluation had two goals. One was to assess whether the knowledge of the students about the design and analysis of work processes had increased and the second whether the setup of the training was appropriate. We performed the evaluation during two consecutive years (1996/1997 and 1997/1998).

\subsection{Evaluation of the simulation training}

In the academic year 1996/1997 the first questionnaire was completed by 59 of the 63 students; 38 of the 59 students also completed the second questionnaire. Four students quit the block. We did not receive the completed questionnaires of two groups due to a miscommunication with the tutors. Thirty-four students completed both questionnaires.

The results of the questionnaire before training (Table 7-1) show that $72.4 \%$ of the students $(N=58)$ had never worked with a simulation package and $3.4 \%$ of them did not know whether they ever had done so. From Table I it can be concluded that students have a positive attitude towards economic and organizational subjects as well as towards the use of computers. According to the students, computers are not very useful in the process of work process redesign.

The results of the questionnaire after training (Table 7-1) show that students think that the training increased their knowledge about optimizing work processes and analyzing capacity problems and that MedModel is a user-friendly program. The feeding of a model into MedModel was considered not easy; this can be explained by the fact that the drawing of a path-network using a mouse was not simple. especially when the path-network had to be extended or when a queue had to be added. During the first three parts of the training no attention was paid to these latter subjects.

Assessment of the students' papers showed that they were able to build a simulation model that could be used to look for solutions of the problem; they succeeded in finding a solution. They indicated in informal discussions that they did not have time to experiment with different models; this was confirmed by the review of the papers. The final test was completed by 63 students and the average mark 
Table 7-1: Results of the questionnaires in the academic year 1996/1997.

\begin{tabular}{|c|c|c|c|c|c|c|c|c|}
\hline \multirow{2}{*}{$\begin{array}{l}\text { Question } \\
(1=\text { totally disagree, } 5 \text { totally agree })\end{array}$} & \multicolumn{4}{|c|}{ Before the training } & \multicolumn{4}{|c|}{ After the training } \\
\hline & $\mathrm{N}$ & Mean & s.d. & median & $\mathrm{N}$ & Mean & s.d. & median \\
\hline Computers are bloody things to work with & 59 & 2.07 & 1.06 & 4.00 & 38 & 1.82 & 0.77 & 2.00 \\
\hline $\begin{array}{l}\text { I know how to design work processes that are as efficient and effective as } \\
\text { possible }\end{array}$ & 59 & 1.85 & 0.66 & 2.00 & 38 & 3.13 & 0.78 & 3.00 \\
\hline In my opinion computers do not have any use in designing work processes & 59 & 1.88 & 0.85 & 2.00 & 38 & 1.66 & 0.97 & 1.00 \\
\hline I like to work on economical subjects & 59 & 3.73 & 0.85 & 4.00 & 38 & 3.89 & 0.89 & 4.00 \\
\hline I like to work on subjects from the organisational theory & 59 & 3.81 & 0.82 & 4.00 & 38 & 4.00 & 0.70 & 4.00 \\
\hline The training increased my knowledge about improving work processes & & & & & 38 & 3.74 & 0.86 & 4.00 \\
\hline The training increased my knowledge about analysing capacity problems & & & & & 38 & 3.66 & 0.71 & 4.00 \\
\hline MedModel is a user-friendly program & & & & & 38 & 3.47 & 0.95 & 4.00 \\
\hline A paper simulation model can easily feed into MedModel & & & & & 38 & 2.95 & 0.90 & 3.00 \\
\hline The training is a relevant part of the block & & & & & 38 & 3.74 & 0.89 & 4.00 \\
\hline $\begin{array}{l}\text { How many hours did you spend working on the model except the time you } \\
\text { spent at the computer }\end{array}$ & & & & & 38 & 9.00 & 3.37 & 9.00 \\
\hline Reward the assistance of the training on a ten-point scale & & & & & 38 & 6.93 & 0.92 & 7.00 \\
\hline Reward the training on a ten-point scale & & & & & 38 & 7.02 & 0.82 & 7.00 \\
\hline Mark for the final examination & & & & & 37 & 6.69 & 1.35 & 6.68 \\
\hline
\end{tabular}


was $6.7(\mathrm{sd} .=2.5)$.

In the academic year $1996-199748$ of the 52 students completed the questionnaire. The results of this questionnaire are shown in Table 7-2.

The second questionnaire (for 1997/1998) was completed by the students after they had finished the training. This questionnaire was almost the same as the previous year but with some additional questions.

Because 8 students did not participate in the training and two tutors did not return all the completed questionnaires of their groups, the number of completed questionnaires after the training was less than before the training. On average the impressions are the same as in the academic year 1996/1997. Again, the students considered the training relevant for the block and scored the training 7.6 on a tenpoint scale. The assistance during the training was scored a 7.9 on the ten-point scale. The students considered the addition of the cost aspect relevant for the training.

\subsection{Analysis of the results}

Further analysis of the data of the academic year 1996/1997 shows a correlation between the scores given by the students for the training and their scores on the final examination $(r=0.34, p<0.05)$. There is also a correlation between the answer to the question concerning the relevance of the training and the score given for the training $(r=0.342, p<0.05)$.

To determine some effects of the training a paired t-test was used to compare the answers on the questions common to the questionnaires. The test shows a significant difference in the answers to the questions on the design of effective and efficient work processes $(t=-8.2, d f=33, p<0.001)$; see Table $7-1$ for the exact text of the questions. Knowledge on the design of the work processes had increased. The paired t-test also shows a significant difference in the answers on the questions concerning the assessment of effects of changes in work processes $(t=-8.8$, df $=33, p<0.001)$; the student is better able to assess the effects of changes in work processes.

In the academic year 1997/1998 analysis of the data of the first and the second questionnaire using paired t-tests shows some significant changes in the students' opinion before and after the training (see Table 7-2). A significant difference was found in the answers to the questions on the design of effective and efficient work processes $(\mathrm{t}=-8.1$, $\mathrm{df}=35 \mathrm{p}<0.001)$. The answers to the question "I know how to assess the effects of changes in work processes" show also a significant change $t=-11.0, \mathrm{df}=34, \mathrm{p}<0.001$. The usefulness of computers in designing work processes also shows a significant change $(t=2.3, d f=35, p=0.026)$.

There is a correlation between the between the score given by the students for the training and their mark for the final examination $(r=0.40, p<0.05)$. There is also a correlation between the answer to the question on the relevance of the training and the mark given for the training $(r=0.40, p<0.05)$. Examination of the final models and the final papers shows that the models they had built were more complex than in the previous year.

Comparing the results of the two years we see a significant change in the judgment 
Table 7-2: Results of the questionnaire completed in the academic year 1997/ 1998.

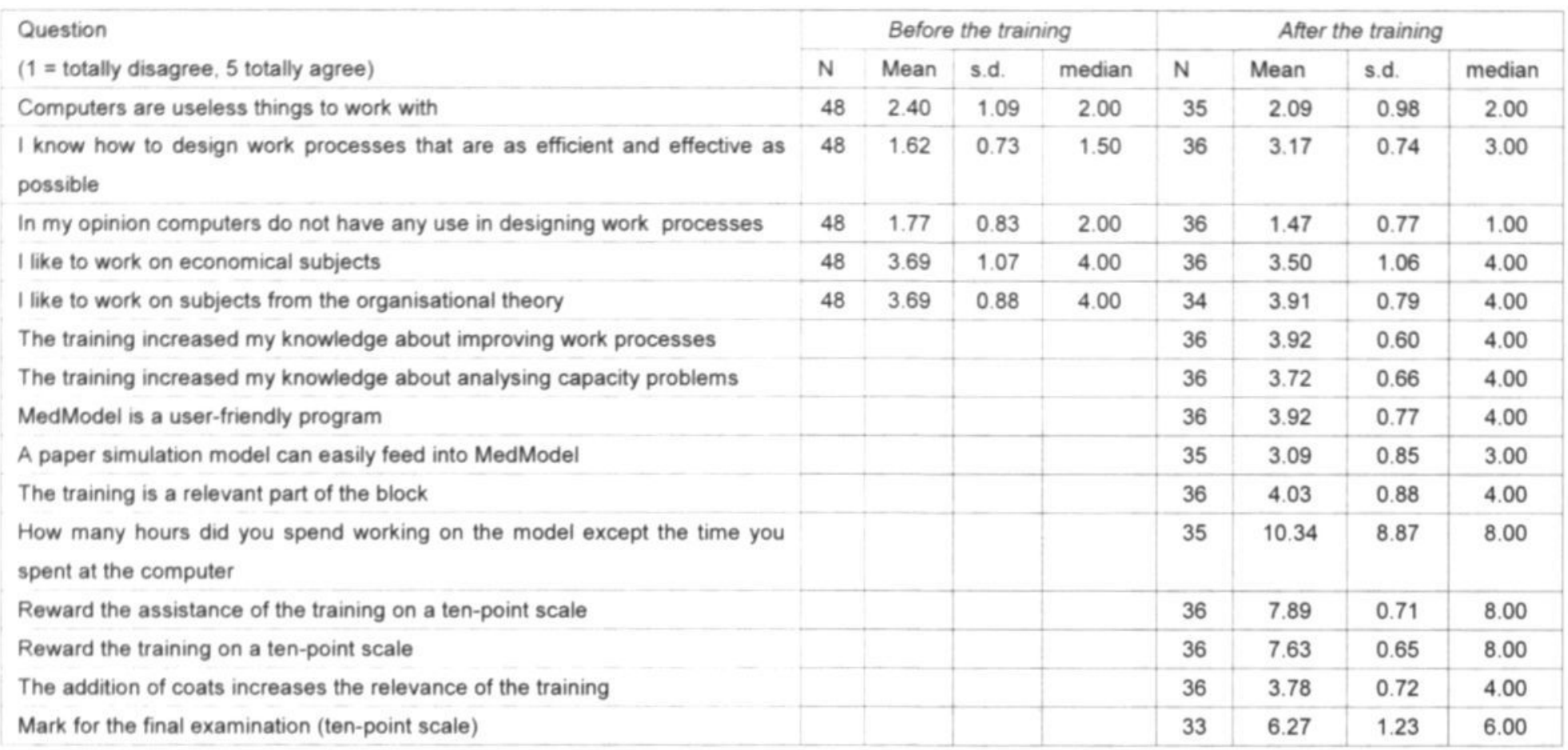


of the training $(t=3.5$, df $=72, p<0.01)$ and the judgment of the training support $(t=5.1, d f=72, p<0.001)$.

\subsection{Discussion}

Unfortunately, we were not able to measure the gain of knowledge of our students by letting them solve problems before and after the training. Therefore, we asked them to judge their own knowledge on a five-point Likert scale before and after the training. This way of assessing the simulation training provided useful information. By comparing the scores on the questions before and after the training the students think that their knowledge on work processes increased; this result was found in both years we evaluated the training.

The tool MedModel was judged as not difficult to handle but it was not easy to implement a paper model into MedModel. Defining processes that will determine the patient flow through the system can be seen as a kind of programming. Our students do not receive any programming training and MedModel is not an educational program but a real-life tool. This may explain the students' opinions about MedModel.

Although we increased the length and complexity (by adding financial aspects) of the training in the second year, we see a significant increase in the reward of the training by the students.

\subsection{Conclusion}

Students in Health Policy and Management must be able to analyze and design work-flow processes in healthcare. They must be able to handle patient logistics and (medical) capacity problems. A simulation training was designed to meet this objective. MedModel is a tool that enables us to give training focused on the modeling of work processes. Evaluation of the training during two successive years showed that the students considered the training relevant for the block. The aims of the training were met since the students gained insight in how to assess the consequences of changes in the organization using simulation techniques. Nearly all elements of a simulation study (except data acquisition) were incorporated in the training. The setup of the training proved to be successful as shown by the results of the evaluations.

Although the setup of the assessment of the training was not the ideal one for practical reasons, it was useful. By asking the same questions concerning subjects dealt with during the training, before and after the training and by comparing the scores we were able to assess the effects of the training.

\section{Acknowledgments}

The authors wish to thank Mrs. Yvonne J.M. Koppelman for assistance during the training and her comments on earlier versions of this article. We also like to thank Professor A. Hasman for his comments on earlier versions of this article. 


\subsection{References}

[1] MedModel homepage. ProModel Inc. http://www.promodel.com/products/medmodel

[2] Schmidt HG. Problem-based learning: rationale and description. Med Educ 1983;17:11-6

[3] Hasman A. Education of Health Professionals. In: Mantas J, ed. Advances in health Telematics Education. IOS Press, 1998; 41-5. (Studies in Health Technology and Informatics; vol 51)

[4] Law AM, Kelton WD. Simulation Modeling and Analysis. (Second ed.) New York, USA: McGraw-Hill, 1991. (Riggs JL, ed. McGraw-Hill Series in Industrial Engineering and Management Science)

[5] Banks J, Carson II JS, Nelson BL. Discrete-Event System Simulation. (Second ed.) Upper Saddle River, NJ: Prentice-Hall, 1996. (Fabrycky WJ, Mize JH, eds. Prentice-Hall International Series in Industrial and Systems Engineering) 
Discussion and conclusions 


\subsection{Introduction}

The aim of our study is to investigate how simulation of the functioning of a department or service can increase the manager's knowledge of the system so that he is able to make better decisions. To answer this question several simulation studies were carried out and were reported in the previous chapters. In this chapter we first will discuss some general aspects of simulation studies described in the previous chapters and continue with the answers to the questions posed in the introduction.

\subsection{Modeling arrivals}

We used two different ways to model arrivals in our systems. In chapter 4,5 and 6 a measured arrival pattern was used to model the arrivals of new entities. The arrival patterns were based on one sample. The obtained arrival patterns were discussed with experts and were in their opinion representative.

In chapter 7 we used the Poisson distribution to model the arrivals of patients. This choice could be made on theoretical grounds. Since the number of admissions is not the same for each day of the week we used a different Poisson distribution for each day of the week. In this way we were able to model the lower number of admissions on Saturdays and Sundays compared to the other days of the week. To obtain the parameter of a Poisson distribution one needs at least 50 samples [1] (other authors like Banks et al. [2] say 100 samples). To apply this technique to model the number of arrivals for different time slots representing the time intervals during a day, one has to collect data during these intervals for at least 50 days. This makes the data collection using this way of modeling arrivals very time consuming. In case of the HF model (chapter 7) data of one year (51-52 weeks) were available, so we could apply this method.

To model the number of patients arriving in each interval one can use a Poisson distribution. However the process should be stationary and this may a be a problem in practice. The possibility to obtain data samples from information systems might be a practical precondition to model the arrivals of entities by Poisson distributions.

\subsection{Input modeling}

The tool Stat::Fit (a tool incorporated in MedModel) was used to determine the best fitting theoretical distribution describing the observed distribution. The distribution was inferred from the set qualified for the problem. Since in most cases the number of observed data points was limited, the best fitting distribution may not exactly match the real distribution. However in these cases there are no theoretical considerations that prescribe the use of a certain distribution. If no distribution could be obtained to describe the observed data because not enough data points were available, an empirical distribution was used. 


\subsection{Model validation}

In chapter 2 we described the setup of a simulation study. The validation of a simulation model is an important step in such a simulation study; it is a precondition that must be satisfied to perform simulation experiments. Sargent [3] describes several validation methods. In several simulation studies in health care the results of the validation of the simulation model are not presented (e.g. $[4,5])$ or the only method used was animation (e.g. [6]).

We used two methods: animation and historical data validation. Since most of the experts in the field were not familiar with simulation the animation provided by MedModel made it clear to them what was happening. After seeing the animation it was easy for them to decide whether the model was valid (face validity). The second validation method makes use of historical data. In the analyzer study the model was validated based on the median value of the turn around time (TAT). A two-sample ttest was used to compare these values. Because of malfunctioning of the DAX analyzer we were not able to validate that model in the same way as we validated the other analyzers (see Table 4-2). In the phlebotomy study (chapter 5) not only the median value of the TAT was compared with the observed median value. At four different points in the routing of a patient, the time was recorded for each patient: based on these data four interval values were calculated. We validated the model by comparing values of these four observed intervals with the simulated values. We also compared the frequency distributions of the observed and simulated distribution of the TAT by means of a $\chi^{2}$-test (see Figure 5-5). In this study were we also able to realize two workspaces at the desk in the current situation (Situation B); by doing so we partly realized the future situation (Situation D). We observed patients in this situation and compared the median observed TAT with the median of the simulated TAT. Again the frequency distributions were compared using a $\chi^{2}$-test (see Figure 56 ). By this extensive validation we showed that our model was valid and has a predictive power to assess the TAT in the new situation.

In case of the heart failure study (Chapter 6) we compared the predicted number of admissions with the observed number of admissions. Based on the observed admissions we compared the predicted bed occupancy with the observed values. The two components of the model we validated independently.

As described above by means of the validation of the simulations models we are able to give an indication to the management concerning the predictive power of the simulation experiments.

\subsection{Research questions}

Let us return to the research questions posed in the introduction (chapter 1). The first question was:

Is simulation an appropriate method to study the relation between patient scheduling strategies and resource utilization?

In chapter 3 a simulation study is described concerning capacity planning of a catheterization room. Simulation proved an appropriate tool to study the effects of scheduling strategies on the resource utilization. We were able to assess the effects 
of the different scheduling strategies on working overtime.

The utilization of the nurses in the phlebotomy service (chapter 5) could be studied in several situations. We not only could study the utilization but also the percentage of the scheduled time nurses are walking which was needed to be known in order to compare different layouts.

The second question was:

How accurately can one predict the arrival of new patients and their stay at a department?

The answer to this question is given in chapter 6 in which a study is described, which aimed to predict the needed capacity for HF patients. The way we modeled the arrivals of patients is discussed above. It was shown that the arrivals of patients could be predicted adequately; errors are introduced by rounding off the results of the simulations. The bed occupancy could be predicted with a relatively small systematic error but the variance was quite high; in $70 \%$ of the days, a correct 5day prediction of the bed occupancy can be made. The results are promising but the research in this domain should be continued.

The third question to be answered is:

Can simulation be used to assess the effect of organizational and layout changes of a department in a hospital?

In chapter 5 the results of a simulation experiment concerning the relocation of a phlebotomy department in a hospital are described. We were able to assess the effect of a new layout and some organizational changes. We also could show that the results of our simulations could accurately predict a new situation as discussed above. So the answer to this question is positive.

The next question that has to be answered is:

Do simulation experiments provide insight in which factors determine the flow of entities (patients or samples)?

In chapter 4 and chapter 5 the flow of entities through a system is modeled. In chapter 4 the effects on the TAT of the arrival pattern and the batching strategies on the flow of samples through three different analyzers, were investigated using simulation. Simulation proved to be a valuable tool to analyze the TAT. In the case of the phlebotomy service we used a simulation model to study the effects of relocating a phlebotomy department and some organizational changes on the TAT. The simulation model provided information about e.g. the time patients have to wait before being served at the desk. The results of the simulation model of the new situation showed that the average TAT is reduced about 4 minutes compared to the current situation. Furthermore the simulation experiment showed that the minimum value of the contact time at the desk has a great influence on the average TAT. To conclude we gained insight in the flow of entities and the factors, which influence this flow. 
The last question to be answered is:

Is simulation an appropriate method to teach students how to analyze the functioning of a health care organization and if so, how should it be used?

In chapter 7 the setup and evaluation of a training which aims to teach students of the health policy and management track of the Faculty of Health Sciences at Maastricht University to analyze and design work processes in health care. The different parts of the training had an increasing level of difficulty. In two consecutive years the training was evaluated. The results show that the students agree that their knowledge about analyzing and designing workflow processes in health care increased due to the use of simulation.

Based on the answers to the questions discussed above we are able to provide an answer to the question: how simulation of the functioning of a department or service in a health care organization can increase the managers' knowledge of the system so that he is able to make better decisions.

Based on the answers to the questions listed above we can conclude that simulation studies do indeed increase our knowledge about the functioning of a department or service in a health care organization. Analysis of the results of the different experiments provides knowledge about how different factors influence the performance measures of the department or service. This knowledge can be used to make better decisions.

\subsection{References}

[1] Law AM, Kelton WD. Simulation Modeling and Analysis. (Second ed.) New York, USA: McGraw-Hill, 1991. (Riggs JL, ed. McGraw-Hill Series in Industrial Engineering and Management Science;

[2] Banks J. Carson II JS, Nelson BL. Discrete-Event System Simulation. (Second ed.) Upper Saddle River, NJ: Prentice-Hall, 1996. (Fabrycky WJ, Mize JH, eds. Prentice-Hall International Series in Industrial and Systems Engineering:

[3] Sargent RG. Verification and validation of simulation models. In: Tew JD, Manivannan S, Sadowski DA, Seila AF, eds. Winter Simulation Conference. Orlando FL: New York, NY: Institute of Electrical and Electronics Engineers, 1994:77-87

[4] Lacroix M, Ricard J, Perry MJ. Simulation of a Pulmonary Clinic. In: Anderson JG, Katzper M, eds. 1997 Western MultiConference: Simulation in the Medical Sciences. Phoenix, Arizona: SCS - Society for Computer Simulation International, San Diego CA, 1997:25-9

[5] McGuire F. Using simulation to reduce length of stay in emergency departments. $J$ Soc Health Syst 1997;5:81-90

[6] Klafehn KA, Connolly M. The simulation/animation of a new outpatient hematology laboratory. In: Anderson JG, Katzper M, eds. 1993 Western Multi Conference: Simulation in the Health Sciences and Services. La Jolla, CA: SCS - Society for Computer Simulation, San Diego CA. 1993:12-5 


\section{Summary}

The main question answered in this thesis is how simulation of the functioning of a department or service can increase the manager's knowledge of the system so that he is able to make better decisions. To answer this question several simulation studies were carried out.

In chapter 2 the use of simulation is described regarding the analysis and design of a workflow management system for a clinical laboratory. Attention is paid to the process of designing and validating a simulation model. This way of building. running and validating models is used in all studies described in this thesis.

In chapter 3 a study describing different scheduling strategies of patients for a catheterization room is reported. Two procedures are distinguished: a diagnostic catheterization and a PTCA. The effects of the scheduling strategies on the number of patients treated per day and the length of a working day are assessed using a validated simulation model. Some scheduling strategies showed an improvement compared to the current strategy. Using the duration of the simulated working day for the different scheduling strategies it is calculated in which percentage of the working days one has to work in overtime to finish the treatment of the last patient.

In chapter 4 a study is described which aimed to provide laboratory managers knowledge about how factors like batching and arrival pattern influence the turnaround time (TAT). Batching strategies like fixed batch size and interval batching were applied to three different analyzers. The observed arrival patterns of these three analyzers are applied to all analyzers using the different batching methods to determine the dependency of the TAT to changes in the arrival pattern.

The effects of a relocation of a phlebotomy department on the turn-around time of the patients were studied in chapter 5 . The relocation introduces also some organizational changes in the phlebotomy service. Due to new equipment some procedures will change too. A simulation model of the current situation was built and validated. Based on this validated model a model of the future situation was built. The result of the simulation runs show a decrease of the average TAT with about 4 to 8 minutes. The effects of changes in the number of patients per day on the TAT were investigated using the simulation models for both situations.

In chapter 6 the result of a study to predict the needed capacity for patients with heart failure are reported. A distinction was made between first admission and readmissions. The simulation model consists of three different components, one to predict the arrivals of the patients, one for assigning the type of stay at the hospital to each patient and the last one to predict the length of stay. To determine the 
parameter values in the different components data of patients admitted in 2000 were used. The model was tested on data of the first four months of 2001. The arrivals of new HF patients can be adequately predicted. The predicted bed occupancy by new and especially current patients could be predicted less accurately. Still in $70 \%(90 \%)$ of the days of a 5-day prediction interval the error is at most one (two) bed(s). Further research should be carried out.

In chapter 7 the setup of a simulation training for students in the Health Policy and Management Program, which aims to increase their knowledge about the design and analysis of work processes in health care is described. The setup of the evaluation of the training and the results of the evaluation of two sequential years are reported. According to the students' opinion their knowledge about the design and analysis of work processes in health care has increased. They also considered the training an important part of their program.

Based on the results of the studies described in the previous chapters, it is concluded in chapter 8 that simulation studies do increase our knowledge about the functioning of a department or a service in a health care organization and that insight is gained in how different factors influence the performance measures of the department or service. 


\section{Samenvatting}

De hoofdvraag die in dit proefschrift beantwoord wordt is of een simulatiestudie de kennis van managers over hun afdeling of dienst vergroot, zodat zij in staat zijn betere beslissingen te nemen.

In hoofdstuk 2 wordt het gebruik van simulatie beschreven ten behoeve van de analyse en het ontwerp van een workflow managementsysteem voor een klinischchemisch laboratorium. Hierbij wordt aandacht besteed aan factoren, waarmee tijdens het ontwerpproces en bij de validatie van het simulatiemodel rekening moet worden gehouden. De in dit hoofdstuk beschreven manier van aanpak van modelleren is gebruikt in alle studies die in dit proefschrift beschreven worden.

In hoofdstuk 3 wordt een onderzoek naar verschillende planningsmethoden voor het gebruik van de vaatkamer beschreven. De effecten van de planningsmethoden op het aantal patiënten dat per dag behandeld kan worden en op de duur van de werkdag zijn met behulp van een gevalideerd simulatiemodel bepaald. Sommige planningsmethoden lieten een verbetering ten opzichte van de huidige planningsmethode zien. Voor de verschillende planningsmethoden is bepaald in welk percentage van de werkdagen men moet overwerken om de behandeling van de laatste patiënt af te maken.

In hoofdstuk 4 is een studie beschreven die tot doel had managers van laboratoria inzicht te geven op welke wijze factoren als groeperen ('batching') en het aankomstpatroon van monsters de looptijd door de analyser beïnvloeden. Verschillende 'batching'-strategieën, zoals het starten van de analyse als er een bepaald aantal monsters aanwezig is of na een bepaalde periode, werden toegepast op drie verschillende analysers. De aankomstpatronen van de afzonderlijke analysers zijn op alle drie de analysers toegepast om bij de verschillende 'batching'-strategieën de afhankelijkheid van de doorlooptijd van veranderingen in het aankomstpatroon te bepalen.

De effecten van een verhuizing van een bloedafnamedienst op de doorlooptijd van de patiënten zijn bestudeerd in hoofdstuk 5. De verhuizing was aanleiding voor de bloedafnamedienst om ook enkele organisatorische veranderingen door te voeren. Door de aanschaf van nieuwe apparatuur vonden ook enige procedurele veranderingen plaats. Een simulatiemodel van de huidige situatie werd gebouwd en gevalideerd. Gebaseerd op dit gevalideerde simulatiemodel werd een simulatiemodel van de toekomstige situatie gebouwd. De resultaten van de simulatieruns laten een afname van de gemiddelde doorlooptijd van ongeveer 12 minuten in de huidige situatie tot ongeveer 8 minuten in de toekomstige situatie 
zien. De effecten van veranderingen in het aantal patiënten per dag op de gemiddelde doorlooptijd is voor beide situaties onderzocht.

In hoofdstuk 6 worden de resultaten van een studie naar de benodigde capaciteit in een ziekenhuis voor patiënten met hartfalen gerapporteerd. In de studie wordt verschil gemaakt tussen eerste opnames en heropnames. Het simulatiemodel bestaat uit drie verschillende componenten, één om de opname van de patiënten te voorspellen; één om de verschillende stadia die de patiënt doorloopt te voorspellen en de laatste om de verblijfsduur in die stadia te voorspellen. Om de parameters van de verschillende componenten te bepalen zijn gegevens uit het jaar 2000 gebruikt. Het model werd getest met behulp van gegevens uit de eerste vier maanden van 2001. Het aantal opnames van nieuwe patiënten kan adequaat voorspeld worden. De bedbezetting door nieuwe en reeds opgenomen patiënten kan minder nauwkeurig voorspeld worden. Toch is de fout in $70 \%(90 \%)$ van de dagen bij een vijfdaagse voorspelling maximaal één (twee) bed(den). Onderzoek op dit gebied moet worden voortgezet.

In hoofdstuk 7 is de opzet van een simulatietraining voor studenten Beleid en Beheer van de Gezondheidszorg beschreven. De training heeft als doel hen meer kennis over het ontwerp en de analyse van processen in de gezondheidszorg bij te brengen. De simulatietraining is geëvalueerd. De resultaten hiervan voor twee opeenvolgende jaren worden gerapporteerd. Naar de mening van de studenten is hun kennis over het ontwerpen en over de analyse van processen in de gezondheidszorg door de training toegenomen. Naar hun mening vormt de training een belangrijk onderdeel van hun studie.

Op basis van de resultaten van de studies beschreven in de voorafgaande hoofdstukken wordt in hoofdstuk 8 geconcludeerd dat simulatiestudies zeer nuttig zijn om meer inzicht te verkrijgen in het functioneren van een afdeling of dienst van een gezondheidszorginstelling. In het bijzonder neemt de kennis over de wijze waarop verschillende factoren de prestatiematen van een afdeling of dienst beïnvloeden toe. 


\section{Publications}

van Merode GG, Groothuis S. Reengineering en simulatietechnieken in de gezondheidszorg. TMI 1996;25:129-34

Groothuis S, van Merode F. Onderwijs met MedModel voor Studenten Gezondheidswetenschappen. In: van der Lei J, Beckers WPA, Ceusters W, van Overbeeke JJ, eds. Medisch Informatica Congres MIC'97. Veldhoven: VMBI, 1997:101-8

Groothuis S, van Merode F, Koppelman Y. Experience with Medmodel in health policy management program. Promodel user conference: Survival 98. Jackson Hole WY: Promodel Company. 1998:26

Groothuis S, van Merode F. MedModel in the Health Policy and Management Program at Maastricht University. In: Anderson JG, Katzper M, eds. 1998 Westem MultiConference: Medical Sciences Simulation. San Diego, CA: SCS - Society for Computer Simulation International, San Diego CA, 1998:187 - 91

Koppelman Y, van Merode F. Groothuis S. Simulation as Decision Support at the Emergency Department. In: Anderson JG, Katzper M, eds. 1999 Westem MultiConference - 1999 Health Science Simulation Conference. San Francisco, CA: SCS - Society for Computer Simulation International, San Diego CA, 1999:28-32

Groothuis S, Van Merode F, Hasman A, Bär F. Cost Calulations at the Catheterization Room using a Simulation Model. In: Anderson JG, Katzper M, eds. 1999 Western MultiConference - 1999 Health Science Simulation Conference. San Francisco, CA: SCS - Society for Computer Simulation International, San Diego CA, 1999:33-8

Groothuis S, van Merode F, Hasman A. Simulatie als hulpmiddel bij het oplossen van capaciteitsvraagstukken in de gezondheidszorg. In: Koppelman YJM, Helder JC, eds. MIC99 " 2000... en wat nog?". Veldhoven: VMBI, 1999:81-9

van Merode GG, Groothuis S, Goldschmidt HMJ. Workflow management: changing your organization through simulation. Accred Qual Assur 1999;4:438-42

Goldschmidt HMJ, Groothuis S, Pequeriaux NCV, de Vries JCM, van Merode GG. Monsterstromen tussen ziekenhuis laboratorium locaties onderzocht middels werkstroom analyse en simulatie. In: De Moor G, De Clercq E, eds. MIC 2000. Brugge: MIM, 2000:109-19

Groothuis S, van Merode GG. A Scenario Analysis of an Emergency Department model. In: Anderson JG, Katzper M, eds. 2000 Wester Multi Conference: Health Sciences Simulation 2000. San Diego CA: SCS - Society for Computer Simulation International, San Diego CA, 2000:21- 6

Groothuis S, van Merode GG. Discrete Event Simulation in the Health Policy and Management Program. Methods Inf Med 2000;39:339-42

Groothuis S, Goldschmidt HMJ, E.J. D, de Vries J, van Merode GG. A simulation model as a tool to study turn-around times of chemical analysers. In: Mocarelli P. Solberg HE, eds. Proc XIIIth Int Conf on CLL: The e-laboratory in the healthcare of the future. Milaan: Milan University, 2000

Groothuis S, van Merode GG, Flos BDB, Broeren S. An analysis of nursing systems through simulation. In: Anderson JG, Katzper M, eds. 2001 Western MultiConference: Simulation in the Health and Medical Sciences 2001. Phoenix AZ: SCS: Society for Computer Simulation International, San Diego CA, 2001:12-7 
Groothuis S, van Merode GG, Hasman A. Simulation as decision tool for capacity planning. Comput Methods Programs Biomed 2001;66:139-51

Groothuis S, van Pol P, Lencer N, Stappers J, Jans J, Janssen J, Dassen W, Doevendans P, Baljon M, Hasman A, van Merode GG. Discrete Event Simulation to Support Capacity Planning for Heart Failure Patients. In: A. M, ed. Computers in Cardiology. Rotterdam, 2001:137-40

van Merode F, Schoenmakers M, Boersma H, Groothuis S. Designing a cytostatic drugs system. In: Anderson JG, Katzper M, eds. 2001 Western MultiConference: Simulation in the Health and Medical Sciences 2001. Phoenix AZ: SCS - Society for Computer Simulation International, San Diego (CA), 2001:18-23

van Merode F, Groothuis S. Wachtlijsten simuleren. ZorgVisie 2001;31:34-5

Groothuis S, Goldschmidt HMJ, Drupsteen EJ, de Vries JCM, Hasman A, van Merode GG. Application of computer simulation analysis to assess the effects of relocating a hospital phlebotomy department. Ann Clin Biochem 2002;39:261-72

Groothuis S, Goldschmidt HMJ, Drupsteen EJ, de Vries JCM, Hasman A, van Merode GG. TurnAround Times for Chemical and Endocrinology Analyzers Studied Using Simulation. Clin Chem Lab Med 2002;40:174-81

van Merode GG, Groothuis S, Hasman A, Blokzijl C. Enterprise Resource Planning in Health Care. In: Anderson JG, Katzper M, eds. 2002 Western MultiConference: Health Sciences Simulation 2002. San Antonio TX: SCS - Society for Modeling and Simulation International, San Diego CA, 2002:17-22

Groothuis S, van Merode GG, Hasman A, Blokzijl C. Enterprise Resource Planning in Health Care: the role of simulation. In: Anderson JG, Katzper M, eds. 2002 Western MultiConference: Health Sciences Simulation 2002. San Antonio TX: SCS - Society for Modeling and Simulation International, San Diego CA, 2002:23-8

van Merode GG, Groothuis S, Schoenmakers M, Boersma HH. Simulation studies and the alignment of interests. Health Care Management Science 2002; 5:97-102

Tange HJ, Groothuis S, Hasman A, van Merode F. Informaticaonderwijs in de gezondheidszorgopleidingen aan de Universiteit Maastricht. Informatie \& Zorg 2002;31:74-8

An actualized list of our publications concerning simulation in health care and related topics can be found on:

http://www.mi.unimaas.nl/projects/simulation 


\section{Curriculum Vitae}

Siebren Groothuis werd op 30 mei 1957 geboren te Meppel. Hij slaagde in 1975 voor het diploma Gymnasium B aan de Rijksscholengemeenschap Meppel. Aan de Rijksuniversiteit Utrecht behaalde hij het kandidaatsexamen Sterrenkunde. Na een afstudeeronderzoek in het Ooglijdersgasthuis te Utrecht behaalde hij in 1984 zijn doctoraal Experimentele Natuurkunde met een $1^{\circ}$ graads onderwijsbevoegdheid voor natuurkunde, wiskunde en sterrenkunde. Van 1 juli 1983 tot 20 februari 1985 vervulde hij zijn vervangende dienstplicht bij de vakgroep Natuurkunde didactiek waarbij hij assisteerde bij nascholingscursussen voor natuurkundeleraren over het gebruik van de computer in het natuurkundeonderwijs.

Vanaf 1 maart 1985 was hij gedurende 3 maanden verbonden als leraar (WPOplaats) aan het Sint Bonifatius College te Utrecht om computerprogramma's voor het natuurkundeonderwijs te ontwikkelen. Van 1 juni 1985 tot 1 juli 1986 werkte hij als systeemontwerper bij de stafafdeling Informatie, Systemen en Automatisering (ISA) van de Open Universiteit te Heenen o.a. aan een project over een interactieve beeldplaat.

Sinds 1 juli 1986 is hij verbonden als universitair docent bij de capaciteitsgroep Medische Informatica ten behoeve van de Faculteit Gezondheidswetenschappen van de Rijksuniversiteit Limburg (nu Universiteit Maastricht). Binnen de Faculteit Gezondheidswetenschappen is hij actief (geweest) in diversie commissies ten aanzien van het onderwijs.

Vanaf 1989 is hij lid van de redactie van het Tijdschrift voor Medische Informatica (TMI), nu Informatie \& Zorg (I\&Z), van de VMBI waarvan hij sinds april 1996 hoofdredacteur is. 


\section{Dankwoord}

Ik wil allen, collega's, vrienden en familie, hartelijk danken voor hun bijdrage aan de totstandkoming van dit proefschrift. Het personeel van de afdeling Cardiologie van het azM en het personeel van het CKCHL van het St. Elisabeth ziekenhuis in Tilburg dank ik voor de prettige samenwerking. Speciaal wil ik Henk Goldschmidt bedanken voor de prettige en inspirerende samenwerking bij het totstandkomen van drie van de hoofdstukken van dit proefschrift.

In het bijzonder wil ik mijn promotoren Arie Hasman en Frits van Merode bedanken voor hun adviezen, anekdotes, humor, kritische vragen en inspirerende discussies.

Een bijzonder woord van dank gaat uit naar Antoinette, Kim en Irme voor de gelegenheid die ze me gegeven hebben om thuis "boven aan het werk" te zijn. Dames, ik zal nu vaker beneden zijn. 

